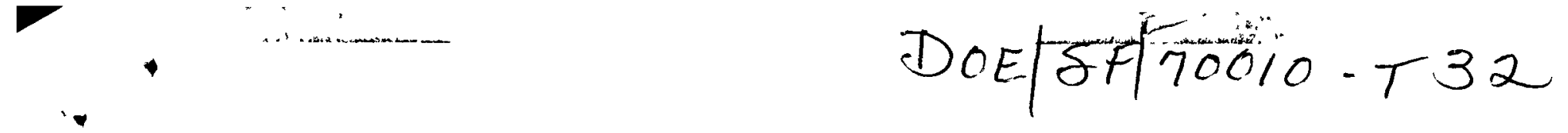

\title{
REVISED EVALUATION OF STEAM GENERATOR \\ TESTING ALTERNATIVES
}

$$
\text { ATO } 3-76.5 F 70010
$$

\section{Table of Contents}

1.0 Introduction

2.0 Summary and Recommendations

3.0 Evaluation of Few-Tube Versus One-Tube Design Support Testing Benefits

4.0 Evaluation of Part Power Versus Full Power Prototype Tests

5.0 - Estimated Test Facility Transient Limitations and Prototype Transient Test Requirements

6.0 Recommended Test Facility Codes and Standards

7.0 EBR-II Steam Generator Test Facility Approach and Recommendations

8.0 SCTI Steam Generator Test Facility Approach and GE Comments

Appendix A - Justifications for Benefit vs Test Model Size Ratings Append $7 x$ B - Summary Draft CRBRP Transients

Appendix C - Agreements and Commitments from December 14-15, 1973, $\mathrm{GE} / \mathrm{W}-\mathrm{ARD} / \mathrm{AEC}$ Meeting Concerning Steam Generator Testing Alternatives

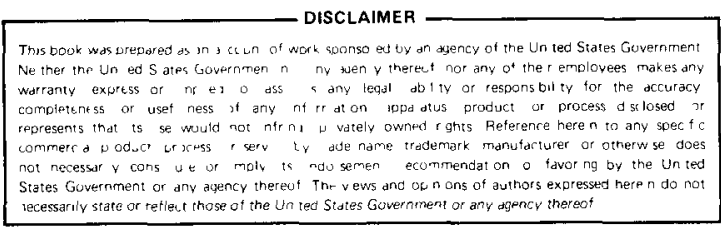




\section{DISCLAIMER}

This report was prepared as an account of work sponsored by an agency of the United States Government. Neither the United States Government nor any agency Thereof, nor any of their employees, makes any warranty, express or implied, or assumes any legal liability or responsibility for the accuracy, completeness, or usefulness of any information, apparatus, product, or process disclosed, or represents that its use would not infringe privately owned rights. Reference herein to any specific commercial product, process, or service by trade name, trademark, manufacturer, or otherwise does not necessarily constitute or imply its endorsement, recommendation, or favoring by the United States Government or any agency thereof. The views and opinions of authors expressed herein do not necessarily state or reflect those of the United States Government or any agency thereof. 


\section{DISCLAIMER}

Portions of this document may be illegible in electronic image products. Images are produced from the best available original document. 


\section{REVISED EVALUATION OF STEAM GENERATOR}

\section{TESTING ALTERNATIVES}

\subsection{INTRODUCTION}

In response to a RRD request, General Electric, working with ANL and LMEC, conducted a scoping evaluation of various facility alternatives for test of LMFBR prototype steam generators and of design-supporting steam generator models. The GE evaluation and recommendations were reviewed at Germantown in a RRD/GE/W-ARD meeting held December 14-15, 1973. The agreements and commitments resulting from this meeting (included as Appendix $C$ ) resulted in agreement to: (1) examine a reduced number of alternatives in somewhat more detai1, (2) revise the Test objectives, (3) quantify the benefits of full-power vs part-power testing and few-tube vs sinqle-tube model testing, (4) establish recommended test facility codes and standards and (5) evaluate the transient limitations of the alternate facility approaches.

Table I is a revised summary of steam generator testing objectives categorized by testing approach. Testing of full size plant prototype units (item-1) has the principal objective of ensuring the integrity of units prior to installation in the plant with second-order objectives as listed. Testing of fractionalsize units (item-2) is intended to be performed on a schedule such that the results obtained could influence the plant prototype units as well as providing endurance experience prior to plant start-up. The remaining test categories are generally addressed to specific data needs for development and confirmation of the designs.

Groundrules assumed for the initial evaluation included: (1) no specific test facility cost target, (2) the prototype test facilities should be ready to accept test units by October, 1976, and (3) no additional 30MW test models will be constructed for candidate plant units. A fourth ground/rule added for this evaluation requires fractional size model initial test results to be available by late $\mathrm{CY}-1975$ in order to influence the prototype configurations. A fifth groundrule added for this evaluation is the assumption that a greater number of evaporator and superheater concepts than actualiy installed in the 
PLANT STEAM GENERATOR

GENERAL TESTING OBJECTIVES AND APPROACHES

1. Plant Prototype Verification Testing

A-• Verify Integrity

- Lack of Infant Mortality Defects and Leaks

- Validate Thermal Transient/Shock Design

B-• Verify Overall Thermal/Hydraulic and Stability Performance

C- Verify Leak Detection System Response

D- Verify Operating Procedures and In-Service Inspectability \& Maintainability

2. Full-Scale, Fractional Size Testing (Few Tube or Model Tests)

A- Long-Term Testing

- Validate Acceptable Tube Spacer and Baffle Wear

- Validate Acceptable Corrosion, Mass Transfer and Fouling

- Confirm High Temperature Design Methods (Fatigue, Creep)

B-• Validate Quality, Fabrication and Assembly Procedures

C-• Confirm Thermal/Hydraulic and Stability Performance Predictions

D-D Evaluate Instrumentation, Leak Detector Drift and Reliability, SteamSide Effects Upon Hydrogen Background

E-• Demonstrate/Develop In-Service Inspection and Maintenace Procedures

3. Single-Tube Testing

A-• Provide DNB Data

B-• Provide Detailed Thermal/Hydraulic and Stability Data

C-0 Evaluate Specific Heat Transfer Tube Design Features (Swirl Generators, Double-Wall Alternatives)

4. Specific Design Development Testing

A-1 Proof-of-Principle (Protector-Tube, Uouble-Wall)

B-• Prove Mechanical Key Features (Tubesheets, Tubesheet Joints, etc.)

C- V Validate Shell-Side Vibration, Flow Distribution (Full Scale Hydraulic Models)

D-0 Qualify Materials and Fabrication Techniques 


\section{TABLE I (Continued)}

5. Materials Testing

A-- Establish Water Chemistry Specifications (Stress Corrosion Testing)

B-- Establish Sodium Chemistry Specifications and Carbon Trap Requirements (Carburization/Decarburization Testing)

C-- Provide Required High Temperature Materials Properties Design Data

D- Develop and Demonstrate Improved NDT Methods and Proof Tests

E- Establish Improved Tubing and Fabrication (Tubesheet) Reliability

6. Sodium/Water Reaction and Leak Detection Testing

A-- Validate Propagation Extent and Containment of Large Sodium-Water Reaction (LLTR)

B- Validate Large-Leak Analysis Methods (LLTR, Analysis Support Tests)

C- Establish Relationship of Small-Leak Rates and Leak Uetector Signal as a function of Operational Parameters, Define Small-Leak Operational Procedures (CCTL)

D- Establish Relationship of Small-Leak Rates and Damage Rates (Leak Behavior and Wastage Tests) 
plant will be carried to the prototype fabrication and test stage. The first groundrule was revised for the updated evaluation in that reductions of cost from the original GE estimates were sought. The second and third groundrules were reconsidered, in addition, in view of the recent extension of the CRBRP schedule; however, no change to the groundrules are indicated since the base program prototype steam generator effort remains oriented to providing prototype evaporators and superheaters on or prior to 0ctober 1976. Thirty-megwatt model preparation would, therefore, still proceed in parallel with the prototype units such that $30 \mathrm{MW}$ model test results could not affect their design.

GE briefly considered FFTF as a potential heat source for steam generator testing, but rejected this approach on the assumption that Reactor and Fuel testing priorities would preclude adequate emphasis upon steam generator integrity tests. GE further recognizes that certain foreign test facilities (e.g, the nominal 50MW Hengelo facility) may be available, but rejects this approach as a groundrule on the basis that U.S. facilities are required consistent with the importance of the steam generator and the national priority placed on the LMFBR effort. This position would be re-evaluated should the testing needs exceed U.S. planned capability. An information gathering trip for review of foreign test facility capabilities would be advisable in the near future.

\subsection{SUMMARY AND RECOMMENDATIONS}

Table II (taken from the original evaluation) is a summary of the prototype test facillty alternatives initially considered. Alternatives $A, C$, and $F$ are those selected for more detailed evaluation. Table III is a summary of scoping cost estimates in somewhat more detail for the selected alternatives as provided by ANL and LMEC, compared to the original GE estimates. ANL did not provide cost estimates for the EBR-II portion of alternative $A$, advising that the cost difference from " $F$ " was within the contingency range. GE estimates the EBR-II part of " $A$ " to be \$6-7M less expensive than " $F$ " on the same contingency basis.

The GE general testing recommendations are summarized in Table IV and discussed following. Problems identified by GE in review of the ANL approach include late 
TABLE $T$

SUMARYY OF gEMO PLANT STEAM GEMERATOR ALTERNATE TEST APPRDACHES

\begin{tabular}{|c|c|c|c|c|c|c|c|c|c|c|c|c|c|}
\hline \multirow[t]{2}{*}{ ALTERAATE } & \multirow{2}{*}{ FACILITY } & \multirow{2}{*}{$\begin{array}{l}\text { I OESIGY } \\
\text { POWER (1) } \\
\text { S H. }\end{array}$} & \multirow{2}{*}{$\begin{array}{l}\text { OESIGA } \\
\text { POAER ( } \\
\text { EVAP. }\end{array}$} & \multirow{2}{*}{$\begin{array}{l}\text { X OESIGN } \\
\text { FLOW (1) } \\
\text { S.H. }\end{array}$} & \multirow{2}{*}{$\begin{array}{l}\text { X OESIGN } \\
\text { FLOW (I) } \\
\text { FVAP. }\end{array}$} & \multicolumn{2}{|c|}{ CAPACITY } & \multirow{2}{*}{$\begin{array}{l}\text { FOSSIL FUEL } \\
\text { REQUIREMENTS } \\
\text { M:LLION } \\
\text { GAL/YEAR(2) }\end{array}$} & \multirow{2}{*}{$\begin{array}{l}\text { SCHEDULE } \\
\text { COMPAIIBLE } \\
\text { WITH OCT. } 76 \\
\text { S.G.OELIVERY }\end{array}$} & \multirow{2}{*}{$\begin{array}{l}\text { DEPENDENCE } \\
\text { ON BOTH } \\
\text { S.H.\& EVAP } \\
\text { AVAILABILITY }\end{array}$} & \multicolumn{3}{|c|}{ ORDER OF MAGNITUDE COSTS } \\
\hline & & & & & & NUCLEAR & Fossits & & & & $\begin{array}{l}\text { FACRIIT } \\
\text { MODIFICAIION } \\
\text { (S MILLION) }\end{array}$ & 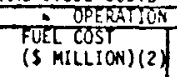 & $\begin{array}{l}\text { CR PERT } \\
\text { OPEVAIING } \\
\text { STAFF }\end{array}$ \\
\hline A & scit & 100 & -- & 100 & -- & $\cdots$ & 35 & 4 & YES & INDEPENOENT & $15(3)$ & 0.8 & $33(4)$ \\
\hline & $E B R=\pi$ & -- & 100 & -- & 100 & 60 & 20 & 3 & $\begin{array}{l}\text { YES } \\
\text { (NEW HEATER) }\end{array}$ & INDEPENDENT & 30 & 0.6 & $15(5)$ \\
\hline 8 & $E B R-I$ & 75 & 75 & 75 & 75 & 60 & 20 & 3 & $\begin{array}{l}\text { YES } \\
\text { (AEE HEATER) }\end{array}$ & DEPENDENT & 35 & 0.6 & $16(5)$ \\
\hline$c$ & SCTI & 65 & $\begin{array}{l}65(85 \text { EYAP. } \\
\text { ONLY) }\end{array}$ & 100 & 100 & & 70 & is & $\begin{array}{l}\text { YES (EXISTING } \\
+ \text { ALT. HEATER) }\end{array}$ & DEPENOENT & $20(3)$ & 2.0 & $33(4)$ \\
\hline 0 & scti & 30 & 30 & 100 & 100 & & 35 & 5 & VES & OEPENOENT & $12(3)$ & 1.0 & $28(4)$ \\
\hline$\varepsilon$ & $\mathrm{SCH}$ & 30 & 30 & 30 & 30 & & 35 & 3 & YES & DEPENDENT & $8(3)$ & 1.0 & $28(4)$ \\
\hline $\mathrm{f}$ & $E B R-$ II & 100 & 100 & 100 & 100 & 60 & 50 & 7 & $\begin{array}{l}\text { RISK OF OELAY } \\
\text { (NEW HEATERS) }\end{array}$ & DEPENDENT & 55 & 1.4 & $20(5)$ \\
\hline G & $\begin{array}{l}\text { NEW } \\
\text { FACILITY }\end{array}$ & 100 & 100 & 100 & 100 & & 110 & 16 & $\begin{array}{l}\text { RISK OF DELAY } \\
\text { (MEM HEATERS) }\end{array}$ & DEPEMDENT & 70 & 3.3 & $40(4)$ \\
\hline
\end{tabular}

SOTES:

$\therefore$ E:SEO ON $3+3$ DEM PLANT S.G. MODULE EONFIGURRTION.

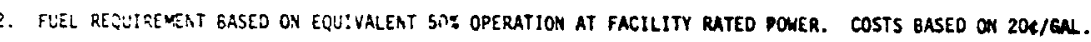

. DUES NOT INCLUDE $34.5 M$ COST OF ALTERMATE 35 MEATER.

4. CPERATIIIG STAFF ONLY, 4 SHIFTS COHTHWUOUS.

5. ADOIIION IO CLRREST OPERATING STAFF ONLY. 
STEAM GENERATOR TEST ALTERNATIVE COST ESTIMATE SUMMARY

(\$MILLION)

\begin{tabular}{|c|c|c|c|c|c|c|c|c|c|}
\hline & \multicolumn{4}{|c|}{ ALTERNATE A } & \multicolumn{3}{|c|}{ ALTERNATE C } & \multicolumn{2}{|c|}{ ALTERNATE $F$} \\
\hline & \multirow{2}{*}{\multicolumn{2}{|c|}{ EBR-I I }} & \multirow{2}{*}{\multicolumn{2}{|c|}{ SCTI }} & \multicolumn{2}{|l|}{ LMEC } & \multirow{3}{*}{$\begin{array}{l}\text { GE } \\
100 \% \\
\text { FLOW }\end{array}$} & \multirow[b]{3}{*}{ ANL } & \multirow[b]{3}{*}{$\mathrm{GE}$} \\
\hline & & & & & $100 \%$ & $65 \%$ & & & \\
\hline & $\operatorname{ANL}(6)$ & GE & LMEC & $\mathrm{GE}$ & FLOW & FLOW & & & \\
\hline ENGINEERING \& INSPECTION & 6.7 & 5.0 & 1.4 & 3.0 & 3.0 & 2.8 & 4.0 & 7.2 & 10.0 \\
\hline Na HEAT TRANSFER SYSTEM & 10.1 & 8.0 & $2.2^{(1)}$ & 4.2 & $4.9^{(1)}$ & $2.8^{(1)}$ & $6.0^{(2)}$ & 13.2 & 14.0 \\
\hline $\begin{array}{l}\text { STEAM \& FEEDWATER } \\
\text { SYSTEM }\end{array}$ & $(2.0)(.5)$ & $2.5^{(3)}$ & 1.2 & 2.2 & 1.2 & 1.2 & 2.5 & 1.0 & $5.0^{(5)}$ \\
\hline $\begin{array}{l}\text { CONTROL \& DATA ACQUI- } \\
\text { SITION ELECTRICAL }\end{array}$ & 2.0 & $1.8^{(4)}$ & .5 & .8 & 1.4 & 1.4 & 1.0 & 2.5 & 3.0 \\
\hline $\begin{array}{l}\text { OTHER COMPONENTS \& } \\
\text { SYSTEM }\end{array}$ & 4.4 & 5.3 & .6 & 1.0 & 1.2 & 1.2 & 1.5 & 5.8 & 11.0 \\
\hline CONTINGENCY & $10.0(40 \%)$ & $6.7(30 \%)$ & $1.5(20 \%)$ & $3.4(30 \%)$ & $3.1(20 \%)$ & $2.5(20 \%)$ & $4.7(30 \%)$ & 11.51 & $12.0(30 \%)$ \\
\hline TOTAL & $(34.2)(5)$ & 29.3 & 7.4 & 14.6 & 14.8 & 11.9 & 19.7 & 41.2 & 55.0 \\
\hline
\end{tabular}

NOTES:

(1) Does not include $\$ 4.5 \mathrm{M}$ cost of alternate heater or $\$ 2.4 \mathrm{M}$ heater installation in primary sodium loop.

(2) Included piping required to connect alternate heater to primary loop.

(3) Includes water-side blowdown system.

(4) Fossil fired heater concept

(5) Not utilizing existing EBR-II main condenser.

(6) GE modified ANL cost information for Evaporator Only testina. 
TABLE IV

SUMMARY OF GE RECOMMENDATIUNS

LMFBR STEAM GENERATOR TESTING APPROACHES

1. PROTOTYPE TESTING

GE recommends that AEC provide Approval-In-Principle to initiate work at ANL for the preliminary design of modifications to EBR-II which would lead to a 110 MW testing capability for prototype LMFBR evaporators and superheaters (Alternative F) and to initiate work at LMEC for the preliminary design of modifications to SCTI which would lead to a $70 \mathrm{MW}(2 / 3$ sodium flow) testing capability for prototype LMFBR evaporators and superheaters (Alternate C). After receipt of AEC Approval-In-Principle, GE will establish the extent of any additional resources required. After $A E C$ authorization GE would prepare and transmit Test Requests to ANL and LMEC. ANL and LMEC will then submit conceptual design and proposals for the complete effort, GE at that time would recommend for AEC approval either that two facilities be constructed or that one approacin be selected. It is estimated that the test requests can be available 1-month after AEC authorizations and the proposals, 6-weeks subsequent to the test requests. GE would assume technical management responsibility for this effort through the conceptual design phase.

\section{FEW TUBE TESTING}

GE recommends that AEC provide Approval-In-Principle for the test of a few-tube model of the $\underline{W}$ duplex tube evaporator design in GPL-1 and for the test of few-tube models of the AI single-wall superheater and FW protector-tube evaporator designs in the SGTR. These tests would be constrained to provide initial test results prior to the late CY-75 CRBRP hardware approach selection date. Due to the need for immediate initiation of these efforts in order to provide timely results, it is suggested that AEC authorize the resources required for this project consistent with the GE midyear review recommendations for 893-10.

\section{SINGLE-TUBE TESTING}

It is recommended that AEC provide Approval-In-Principle for GE to initiate planning and definition of a single-tube thermal cycle and screening test program for alternate double-containment steam generator approaches. Alternate double-containment concepts would be established by GE and solicited from the steam genrator vendors, and the available SCTI intermediate loop would be considered as a test site. GE could submit a plan for this effort within 3-months of AEC authorization.

GE currently envisions DNB tests for several configurations followed by long-term testing to explore tube degredation for operation with DNB in the ANL single-tube facility. 
facility availability and (based upon previous EBR-II transient experience) a 1 imitation in transient capability as compared to tentative desired prototype steam generator transient tests. GE also believes the proposed electrical heaters require further design definition to assure feasibility. Overal1, however, the ANL approach and costs are very attractive for full-power test capability. The brief assessment of the benefits of full-power testing summarized subsequently confirm its desirability; however, facility transient limitations weaken the benefits.

The LMEC approach to option "C" (2/3 sodium flow case) results in an attractive schedule and appears to be quite feasible. The use of the existing heater in parallel with the alternate heater results in facility transient limitations, but considerably less severe than the EBR-II approach. With respect to the SCTI part of alternative "A", GE considers the steam compressor to be partially developmental in nature and believes further definition of this item is required to establish schedule feasibility and costs. It should be pointed out that the $\$ 6.9 \mathrm{M}$ procurement and installation cost of the alternate heater should be added to SCTI option " $C$ " to place it on a comparable cost to the government basis with EBR-II option $\mathrm{F}$.

GE observes that both options "C" and "F" remain attractive at this time, and further observes that either option is capable of providing for test of evaporator alone, as well as of both evaporator and superheater. Thus, either facility could test either evaporator alone or evaporator with superheater if one facility were delayed or if the prototype superheater were delayed. It is worthwhile, therefore, to investigate the complexities and costs which would be introduced in both options to allow testing of superheater only. Even if this is not practical for options "F" and/or "C", GE believes the advantages of option "A" which does dllow superheater only testing to be marginal, since if either facility were delayed under the "A" option, testing of evaporator or superheater would be also delayed. GE further considers that construction of both facilities to be justifiable considering the criticality and development nature of LMFBR steam generators in view of the national priority addressed to the Breeder effort. It is currently assumed that a number of prototype evaporators and superheaters will 
be fabricated for test. There will be a need, in addition, for fractional size model testing in support of longer-range commercial plant units of larger size than currently projected for the CRBRP. GE feels, therefore, that both options "C" and "F" should proceed through an initial design phase, with a decision to select one approach or to continue both being made after more detailed information is established.

With respect to few-tube and single-tube design oriented testing, the benefits evaluation discussed subsequently leads GE to reconfirm its recommendation that few tube tests in support of the CRBRP design concepts be authorized immediately. Small-leak wastage and behavior data being obtained under the base program do not allay GE's concern regarding leak propagation in the single-wall design. Programs to assess the liklihood of small leaks, to improve reliability and to mitigate and expedite recovery from small leaks have been initiated or planned, but the results cannot be guaranteed favorable. The protector tube and/or duplex tube concepts, therefore, should be made ready for use in the CRBRP. The extrapolation from proof-of-principle testing to prototypes is great, and few tube tests would contribute much to reduce this risk. Further single-tube testing (endurance) would be beneficial, but the design benefits of multiple-tube testing are considerably greater.

The same small-leak damage concerns that suggest increased emphasis on the protector tube and duplex-tube designs lead GE to suggest a broader effort on the doub1e-wa11 approach in general. There are double-containment approaches in addition to the duplex-tube; such as co-extruded, and explosively bonded tubing, double walls with large spacing filled with liquid metal, single tubesheet approaches, etc., which are not now being considered as part of the base program. A principal problem with many double-containment approaches lies in the interferenece between the two boundaries due to thermal expansion and transients. These effects can be scoped experimentally through transient shock and endurance testing of few or singletubes. GE recommends that an effort of design studies and experimental screening of double-containment alternatives be initiated, with the first step being submittal of a proposed program. The currently available intermediate loop of SCTI would be evaluated for the tests. 


\subsection{EVALUATION OF FEW-TUBE VERSUS ONE-TUBE DESIGN SUPPORT TESTING BENEFITS}

Quantization of the benefits of few-tube testing over single-tube testing in support of concept design development and confirmation was attempted by establishing a more detailed list of test objectives, and judging the extent to which these objectives can be satisfied as a function of test model size. Table $V$ presents these more detailed objectives along with the judgemental ratings for several size test models (including one and few-tube) up to full size. Figure 1 is a plot of the summed ratings as well as estimated costs plotted as a function of model size. Justifications of the individual ratings are presented in Appendix $A$ of this document.

Also tabulated on Table III are the Table I general objectives which correspond to the more detailed 1ist. A second appraoch to quantization was made by summing the Table III ratings according to the general objectives weighted as follows:

\begin{tabular}{cc}
$\begin{array}{c}\text { Table I } \\
\text { Objective }\end{array}$ & $\begin{array}{c}\text { Weighting } \\
\text { Factor }\end{array}$ \\
\cline { 3 - 3 } $2 A$ & 3 \\
$2 B$ & 2 \\
$2 C$ & 2 \\
$2 D$ & 1 \\
$2 E$ & 1
\end{tabular}

The result obtained by this second method resulted in a rating of 20 for the single tube tests and 54 for the few-tube tests.

These quantitative ratings support the value of few-tube over single-tube testing, but remain judgemental in detail. Some principal general observations are as follows:

1) Relative thermal expansion galling and fatique between tubes and among tubes and spacers cannot be assessed via a single-tube test. 
Test Modei Size

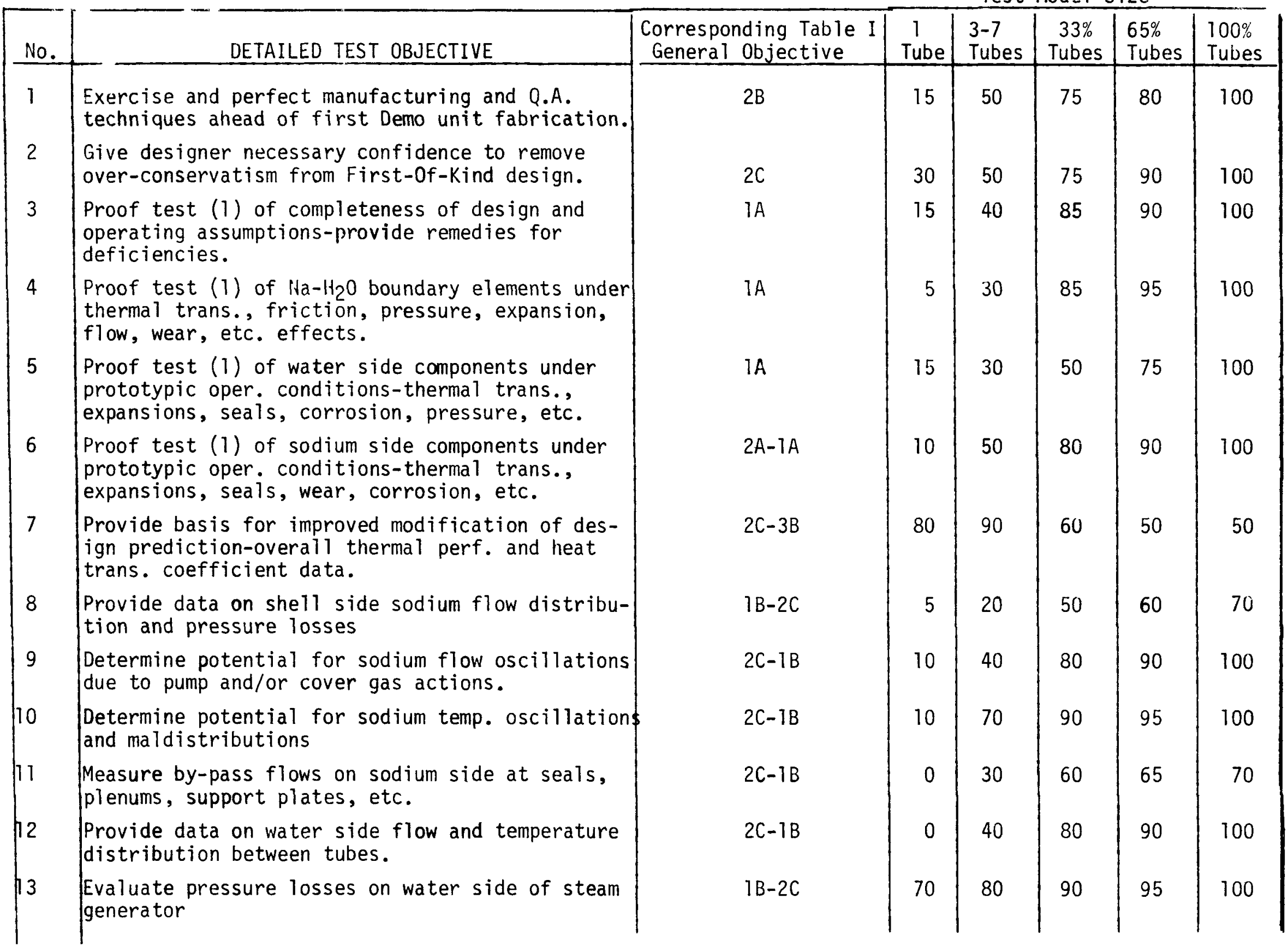




\begin{tabular}{|c|c|c|c|c|c|c|c|}
\hline No. & DETAILED TEST OBJECTIVE & $\begin{array}{l}\text { Corresponding Table I } \\
\text { General 0bjective }\end{array}$ & $\begin{array}{l}1 \\
\text { Tube } \\
\end{array}$ & $\begin{array}{c}\text { 3-7 } \\
\text { Tubes }\end{array}$ & $\begin{array}{l}33 \% \\
\text { Tubes } \\
\end{array}$ & $\begin{array}{l}65 \% \\
\text { Tubes } \\
\end{array}$ & $\begin{array}{l}100 \% \\
\text { Tubes }\end{array}$ \\
\hline 14 & $\begin{array}{l}\text { Evaluate the recirc. system characteristics } \\
\text { (flow, } \Delta \mathrm{P} \text { and power req.) including steam sep- } \\
\text { arator-dryer eff. }\end{array}$ & $1 B-2 C$ & 20 & 50 & 80 & 90 & 100 \\
\hline 15 & $\begin{array}{l}\text { Determine operating limits with respect to DNB } \\
\text { and consequences of operating with DNB. }\end{array}$ & $3 A$ & 70 & 60 & 50 & 45 & 40 \\
\hline 16 & $\begin{array}{l}\text { Determine operating limits with respect to } \\
\text { hydraulic stability. }\end{array}$ & $3 B-2 C$ & 50 & 95 & 100 & 100 & 100 \\
\hline 17 & Measure heat losses through vessel insulation. & $2 C-1 B$ & 5 & 20 & 50 & 75 & 100 \\
\hline 18 & Exercise and evaluate leak detection techniques & $2 D-1 C$ & 50 & 60 & 80 & 90 & 100 \\
\hline 19 & $\begin{array}{l}\text { Practice leak location, tube plugging, and } \\
\text { in-service surveillance of tubing integrity. }\end{array}$ & $2 E-10$ & 30 & 80 & 90 & 95 & 100 \\
\hline 20 & $\begin{array}{l}\text { Measure effect of plugged tubes on thermal } \\
\text { hydraulic \& mechanical performance of unit. }\end{array}$ & $2 E-1 D$ & 0 & 60 & 90 & 95 & 100 \\
\hline 21 & $\begin{array}{l}\text { Obtain operating experience - Na fill, startup, } \\
\text { shutdown power maneuvers, power split (EV-SH), } \\
\text { instrumentation, etc. }\end{array}$ & $1 D-2 E$ & 20 & 70 & 90 & 95 & 100 \\
\hline 22 & $\begin{array}{l}\text { Coupon tests in } \mathrm{Na} \& \mathrm{H}_{2} \mathrm{O} \text { sides-evaluate alter- } \\
\text { nate mtls., corrosion, mass transport, water } \\
\text { treatment methods, etc. }\end{array}$ & $2 A$ & 20 & 60 & 90 & 95 & 100 \\
\hline 23 & $\begin{array}{l}\text { Practice and perfect maintenance techniques } \\
\text { including unit cleaning and disassembly. }\end{array}$ & $2 E-1 D$ & 10 & 70 & 90 & 95 & 100 \\
\hline 24 & $\begin{array}{l}\text { Perform post-test destructive exam - evaluate } \\
\text { effects of stresses, corrosion, erosion, wear, } \\
\text { decarb., etc. }\end{array}$ & $2 A-1 A$ & 20 & 60 & 90 & 95 & 100 \\
\hline \multirow[t]{3}{*}{25} & $\begin{array}{l}\text { Confirm high temperature stress criteria in } \\
\text { critical components. }\end{array}$ & $2 A-1 A$ & 0 & 30 & 60 & 70 & 90 \\
\hline & & AVERAGE RATINGS - & 22 & 53 & 77 & 84 & 93 \\
\hline & $\begin{array}{l}\text { (1) Deviations from prototypic operating condi- } \\
\text { tions include less than full term endurance } \\
\text { time but full term equivalent thermal trans } \\
\text { ient history. }\end{array}$ & & & & & & \\
\hline
\end{tabular}


Figure 1 RELATIVE BENIFITS AND COSTS OF STEAM GENERATOR

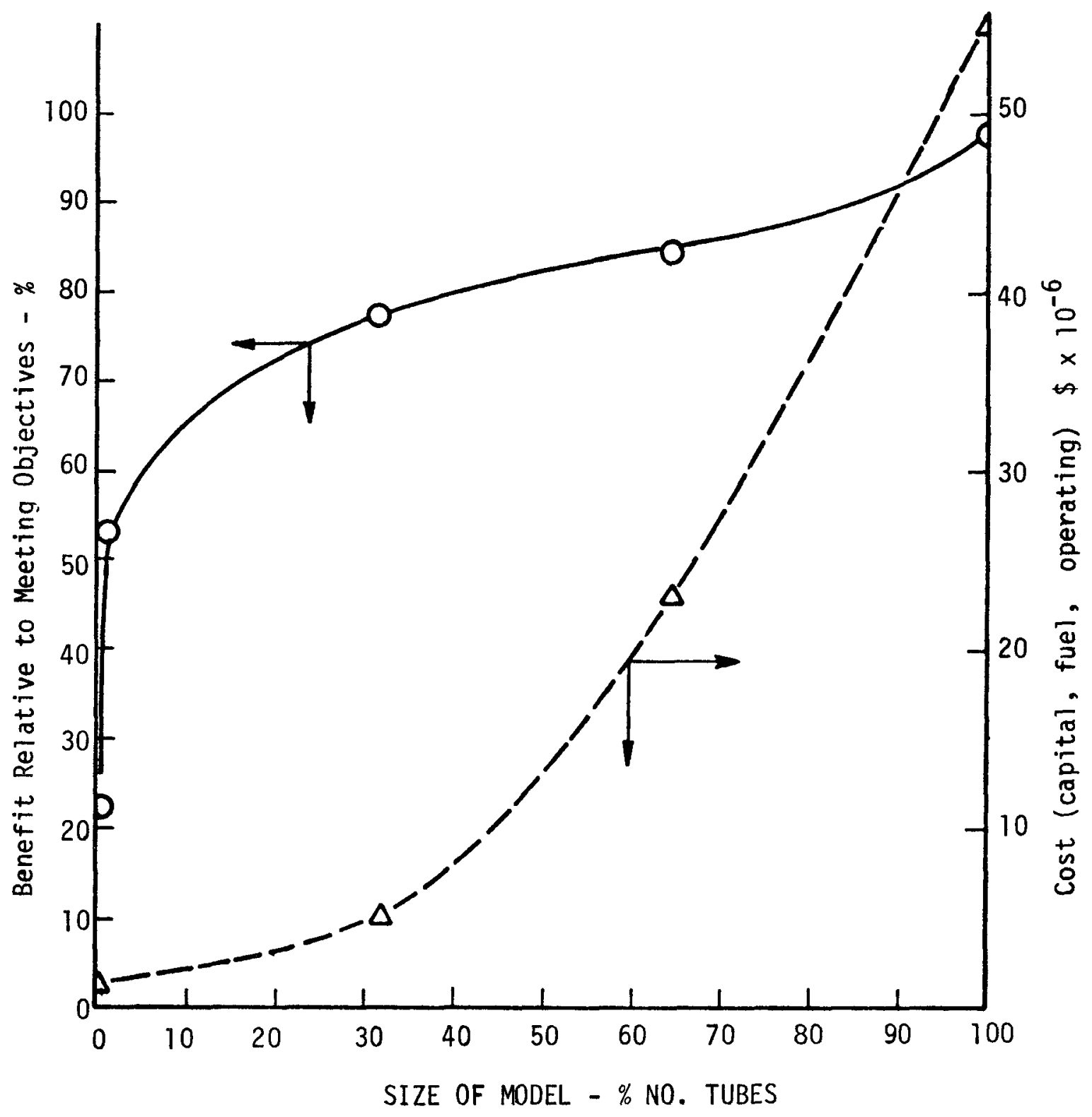

COST TO BENEFITS RATIOS

1-tube (ANL)

Few Tube (GE-SGTR/W-GPL

LMEC SCTI (unmodified)

LIIEC SCTI (expanded to 65\%)

100\% CAPACITY (al ternate A)
$=.075$

$=.033$

$=.0625$

$=.262$

$=.580$ 
2) The thermal and mechanical effects of a plugged tube cannot be assessed via a single-tube test, nor can maintenance procedures be demonstrated.

3) Inter-tube she11-side and tube-side flow maldistribution effects cannot be assessed via a single-tube test.

\subsection{EVALUATION OF PART POWER VERSUS FULL POWER PROTOTYPE TESTS}

The Figure-1 assessment includes the full powen versus part power comparison. A comparison based upon summing by the more general Table 1 objectives was also conducted for this case based upon the following weighting factors:

\begin{tabular}{cc}
$\begin{array}{c}\text { Table I } \\
\text { Objective }\end{array}$ & $\begin{array}{c}\text { Weighting } \\
\text { Factor }\end{array}$ \\
\cline { 1 - 1 } IA & 4 \\
IB & 1 \\
IC & 1 \\
ID & 1
\end{tabular}

The results obtained are a rating of 76 for $33 \%$ tubes, 87 for $65 \%$ tubes and 98 for $100 \%$ of full size tubes.

These ratings are misleading for full power versus part power benefits, since they were prepared on the basis of fractional power, fractional size models (full power for reduced size). Fractional size models run at full power corresponding to their size can provide fairly good transient simulations since full temperature differences can be achieved at both extremes of the unit with scaled flowrates. Full size units operated at part power on the other hand, cannot achieve prototypical temperature differences throughout and, therefore, cannot simulate full transients. At.tempts can be made in part power tests to achieve representative transients 10cally through the use of stress analysis methods and special test conditions, however, such attempts partially defeat the purpose of a proof test through reliance on analysis and full simulation cannot be achieved in any case. It must be pointed out that even full power transient tests must rely somewhat on analysis, since transients are system phenomena and no test facility will respond identically to the CRBRP. The net effect of these additional problems leads to estimated ratings of 60,75 , and 98 for $33 \%$ power, $65 \%$ power and 100\% power for the test of full size units. 


\subsection{ESTIMATED TEST FACILITY TRANSIENT LIMITATIONS AND PROTOTYPE TRANSIENT TEST REQUIREMENTS}

Analysis of the CRBRP system transients is not complete at this time. Representative worst case transients for the current AI/AI evaporator/superheater configuration as well as the normal scram transient are presented, however, in Appendix B in preliminary form. There is reason to believe the magnitude of certain of these transients may reduce as system analysis proceeds.

The transient testing approach currently under consideration envisions tests employing a large number of "normal" transients and a smaller number of "severe" transients. A good validation of high temperature design would be obtained by testing to the point where some damage/deformation would be predicted by analysis, and comparing the damage vs prediction. A less severe but still useful test would include validation for the design values of number and severity of representative transients. It is generally accepted that the system transients are best simulated in the test rig by performing the hypothetical upset or emergency condition, e.g., stop pumps, blowdown steam, etc., even though it is recognized test rig response will not be identical to plant response.

Two transients based upon Appendix $B$ have been selected for the purpose of facility limitation assessment as follows:

Case 1: Norma 1 Scram - 500 cycles of $3.5^{\circ} \mathrm{F} / \mathrm{sec}$ drop in temperature at evaporator sodium out let for 10 seconds; $1.5^{\circ} \mathrm{F} / \mathrm{sec}$ drop at superheater inlet for less than 100 seconds.

Case 2: Emergency or Inadvertent Steam Blowdown - $30 \mathrm{cycles}$ of $25^{\circ} \mathrm{F} / \mathrm{sec}$ rise in temperature at evaporator sodium outlet for less than 10 seconds; $5^{\circ} \mathrm{F} / \mathrm{sec}$ drop at superheater inlet for 10 seconds.

EBR-II: A representative scram transient in EBR-II provided in section 7.0 exhibits an approximate $3^{\circ} \mathrm{F} / \mathrm{sec}$ drop in temperature at the superneater outlet. This transient rate would be insufficient to meet all test objectives thus the GE recommendations include a study by ANL to define transient mitigation equipment such that more severe transients could be supplied to test steam generators. 
SCTI: The SCTI approach using the alternate heater could accommodate a $+25^{\circ} \mathrm{F} / \mathrm{sec}$ transient at the evaporator outlet by mitigation of this transient in the large expansion tank to $5^{\circ} \mathrm{F} / \mathrm{sec}$ which the heater is designed to except. The existing heater is cause for concern, however, and it is believed the current approach using the two heaters in parallel might limit the transient rates to about $15 \mathrm{~F} / \mathrm{sec}$. The GE recommendations include a study by LMEC to define the permissable transient rates and to determine the equipment necessary to meet test objectives. 


\subsection{RECOMMENDED TEST FACILITY CODES AND STANDARDS}

GE recommended codes and standards approach for the steam generator test alternatives are provided below. ANL comments are included in Section 7.0 and LMEC comments are included in Section 8.

\section{RECOMMENDED CODES AIND STANDARDS APPROACH}

The steam generator test alternatives under consideration involve modifications and additions to existing facilities utilizing, where applicable, available components to provide a suitable test bed for prototype steam generator units. Design and construction of the facility modifications to the highest level of present day nuclear standards is neither consistent with the utilization of existing facilities which were designed and constructed to the level of standards existing at the time of their construction or necessary to assure an appropriate level of quality to meet the requirements of a test facility for tine intended application.

GE recommends that the design, fabrication and test of the facility modifications, and additions be based on the codes and standards to which the facility or component was originally designed and built, (i.e., ASME Boiler and Pressure Vessel Code and ANSI B31.1 Power Piping Code)upgraded where applicable by additional material requirements, inspection procedures, welding requirements, cleaning and handling requirements, etc. based on applicable RDT standards.

Requalification of existing components would be based on the edition of the code to which the unit was originally constructed. However, use of a new component built to a lower level of codes and standards than the system to which it would be added will not be permitted.

Specific codes and standards to be applied to individual components and system modifications will be identified in the preliminary SDD prepared during the conceptual design. 
Recommended general guidelines for codes and standards for facility modifications are as follows:

1. All new components for sodium systems shall meet the requirements of the latest addition and addendi of Section VIII Division 1 - ASINE$B \& P V C$. In addition, when considered appropriate, design analysis methods in accordance with NB-3000 of Section III ASHE-BQPVC will be employed. For high temperature conditions this analysis shall be performed using the oplicable design rules and stress limits of ASliE B\&PVC Case 1331-8.

2. All sodium system material shall meet the requirements of Section II ASME B\&PVC and where applicable, shall be upgraded by additional quality assurance requirements based on the appropriate RDT material standard.

3. All new sodium piping shall meet the requirements of the latest addition of ANSI B31.1 Power Piping Code. In addicion, where applicable, requirements of ASME B\&PVC Section III, ClasS 2 piping subassemblies shall be applied.

4. All steam system piping and components shall weet the requirements of AllSI B31.1 Power Piping Code or Section VIII - Division 1 ASME $B \& P V C$.

5. Requalification of existing components shall meet the requirements of the code edition to which the component was originally designed and constructed. Any component which was originally built to a lower level of codes and standards than that applied to the system in which it is to be used will be upgraded.

6. SDD's will be prepared in accordance with RDT Standard FT-2T.

7. All quality assurance requirements for design shall be based on the provisions of RDT Standard F2-2. 


\subsection{EBR-II STEAM GENERATOR TEST FACILITY APPROACH AND GE COMMENTS}

7.1 Argonne National Laboratory Information

7.2 Overlay on ANL Scoping Information

7.3 Work Areas to be Emphasized During the Conceptual Design at ANL/EBR-II 


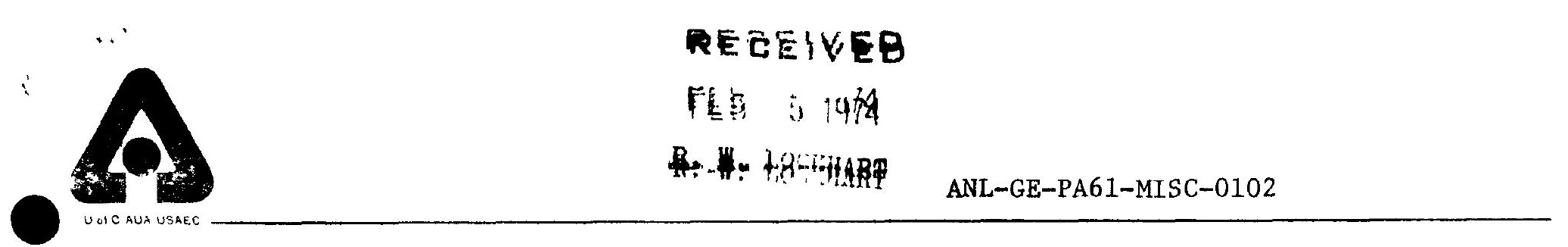

ARGONNE NATIONAL LABORATORY

7.1 AND $\cdots, \because \because$

January 31,1974

Mr. R. Lockhart

General Electric Company

310 DeGuigne Drive

Sunnyvale, California 94086

Dear Mr. Lockhart:

Your telecopy of December 18, 1973, requested information concerning the possible testing of a demonstration-plant steam generator module at EBR-II. The attached material is our response and confirms the discussion with you on January $25,1974$.

Mr. Lottes stated in his letter to you of December 27, 1973 the Laboratory's strong support for the proposed use of EBR-II. I wish to reaffirm the Laboratory's support for this proposal. We believe that a conceptual study should be undertaken immediately to develop the proposal in greater detail and to weigh carefully the merits of the approach. We are prepared to move rapidly once we obtain agreement to do so with you and RRD.

Should you have any questions concerning the enclosed material or should you need our support for the proposal, please feel free to request our assistance.

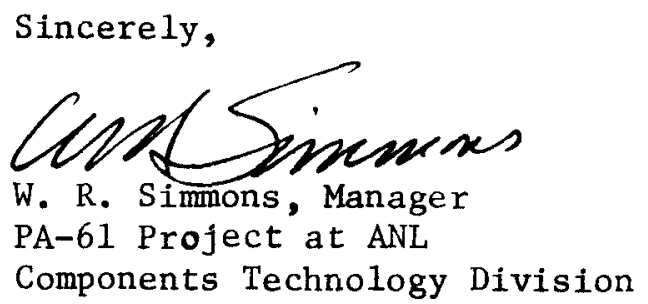

WRS $/ \mathrm{n}$

Enclosure 


\section{INFORMATION CONCERNING THE POSSIBLE USE}

OF EBR-II TO TEST A DEMONSTRATION-PLANT

PROTOTYPE STEAM GENERATOR

The information that is provided here is in response to an inquiry from R. W. Lockhart on December 18, 1973. During the intervening period, the Laboratory has examined the feasibility of testing a demonstrationplant prototype steam generator as an integral part of the operation of EBR-II. The results of this brief study indicate that such a test is feastble.

The use of EBR-II as a test facility for the testing of steam generators and other LMFBR components has a number of important advantages. These are:

-Avallability of experienced $R \& D$, engineering and operating personnel -Availability of a test system that directly provides sodium-cooled, fast-reactor, power plant operating characteristics

-Minimal new equipment requirements; thereby reflecting cost and schedule advantages

- Improved usage of commission facilities and resources - Low operating costs

- Improved capability for obtaining in-service experience with other components such as large valves, large rupture discs, parallel operation of EM pumps, sodium mixing tees, etc.

-Possible alternate heat dump for EBR-II

On tine other side of the ledger are the possible effects such a test program might have on EBR-II's role as a fuels test facility. Clearly, some 
facility down time will be required during the tie-in of the new test loop with the other systems of the plant, and some aspects of the steam generator test program could reflect adversely on the fuels test program, e.8., recovery from the failure of a steam generator, unless the design inciudes adequate provisions for such situations. Appropriate consideration of these matters will be undertaken during the design of the new test facility with emphasis on the requirement that the fuels testing program at EBR-II shall not be unduly affected.

General Description of New Test Loop

The new test loop will have the capability of testing a $110 \mathrm{MWt}$ superheat/evaporator module or an $80 \mathrm{MWt}$ evaporator module only at rated conditions $^{1}$ for the demonstration plant. The test loop will tie into the secondary sodium inlet and outlet lines- to the EBR-II intermediate heat exchanger (IHX), and the steam, feedwater, and blowdown lines between the Power Plant and Sodium-Boiler Plant. The new test loop and the current secondary sodium system will be essentially independent--each capable of operating if the other is inoperative.

The test loop will include two electric, resistance-heated, sodium hesters having a total capacity of $\sim 50 \mathrm{MW}$. One heater will be in parallel with the IHX and the other will be in series. Conceptually, the design of these heaters is based on an extension of the technology that was used to design and fabricate the $250 \mathrm{kw}$ heater in the present secondary system surge tank. Some considerations leading to the selection of electric heat are given in Appendix A.

Rated conditions provided by R. W. Lockhart's communication of December 18, 1973. 
A relief system will be provided for handling the effects of a sodiumwater reaction in the test steam generator module. The system will include appropriate rupture discs, reaction product separators, and gas relief systems. See Appendix B for further details.

Two EM pumps will be used in parallel. One pump is available. A second pump plus power supplies and controls for both will be required. The design of the test loop will follow the design approach used for the present secondary system. System operation will be made as compatible as possible with the present system in order to maximize use of available technology and proven operating procedures and practices.

The steam, feedwater, condensate, blowdown, and related systems will remaln essentially unchanged and will operate normally. Water purity control will be provided by the present water conditioning system-demineralization plus morphaline and hydrazine additions. No additional cooling tower capacity is required.

A major fraction of the steam from the test superheater (1450 psig, $\left.900^{\circ} \mathrm{F}\right)$ will be conditioned $\left(1250 \mathrm{psig}, 840^{\circ} \mathrm{F}\right)$ for use in the main turbinegenerator. The remainder of the steam will be condensed in a separate steam condensing system to be provided; one approach is to utilize a hIgh-pressure steam-to-air condenser (see Appendix C for additional information). For an evaporator-only test two possibilities exist. The steam could go to the air-cooled steam condenser only or the steam flow be split between the air-cooled condenser and the main vacuum condenser (by-passing the turbine). The former requires a larger air-cooled condenser than the latter; $80 \mathrm{MWt}$ vs. $45 \mathrm{MWt}$. The latter is chosen for now but further study is required to determine feasibility. 
The test loop w111 be located in a new bullding. Two bullding locations are possible; one immediately south of the west end of the Sodium-Boiler Building (Drawing No. G0041-0004-DE-00) and the other due north of the Sodium Boller Building (Drawing No. G0041-0005-DE-00).

- Drawing No. G0041-0008-DX-00 is an isometric layout showing a possible arrangement of the major items of equipment.

Power for the electric sodium heaters will be provided from the $13.8 \mathrm{kV}$ output from the EBR-II main generator and from the NRTS site $138 \mathrm{KV}$ system. A total of about 30-40 MW will be required from the $138 \mathrm{KV}$ system, about $20 \mathrm{KW}$ for evaporator only testing.

Process Diagram

Preliminary process diagrams, Drawing No. G0041-0006-DX-00, EBR-II

Steam Generator Facility--Superheater and Evaporator Test, and Drawing No. G0041-0007-DX-00, Evaporator Test only,., are enclosed.

Evaporator and Superheat Test (Drawing No. G0041-0006-DX-00)

Sodium System

Sodium at $650^{\circ} \mathrm{F}$ is taken from the surge tank by two, electromagnetic pumps operating in parallel. The pumps discharges are first combined and then split; one stream to the IHX via yard piping and 1solation valves, the other to sodium heater no. 1. The sodium streams (at $860^{\circ} \mathrm{F}$ ) from the IHX and heater no. 1 are combined in a mixing tee and routed to the sodium heater no. 2 where the sodium temperature is raised to $936^{\circ} \mathrm{F}$. The total heat gain of $108.4 \mathrm{MWt}$ is provided as follows: $48.4 \mathrm{MWt}$ electrically ( 14 MW from the main EBR-II generator and $~ 235 \mathrm{MW}$ from the NRTS $138 \mathrm{KV}$ grid) and the remainder from the reactor. Sodium at $936^{\circ} \mathrm{F}$ flows to the superheater, exits at $859^{\circ} \mathrm{F}$, and enters the evaporator. Sodium leaves the evaporator at $650^{\circ} \mathrm{F}$ 
and returns to the surge tank; completing the sodium circuit. Liquid level 18 maintained in the surge tank by continuously recirculating sodium from the sodium storage tank to the surge tank and overflowing the excess to the storage tank. The recirculating system includes a sodium purification system (not shown on the drawing). A Na- $\mathrm{H}_{2} \mathrm{O}$ relief system is provided. The system includes a reaction-products separator tank, large diameter rupture-disc assemblies to isolate the IHX form deleterious pressure surges, and related plping, vents, drain tanks, etc.

\section{Steam System}

Feedwater from the present EBR-II feedwater system and from the new air-cooled condenser system supplies the steam drum; the latter via a new feedwater pump rated at about $450^{\circ} \mathrm{F}$ and $160,000 \mathrm{lb} / \mathrm{hr}$. Saturated steam at 1600 psia enters the superheater and exits at 1500 psia and $904^{\circ} \mathrm{F}$. The flow is split; one stream supplies the main turbine-generator via a pressure-reducing/desuperheating station, the remainder goes to the air-cooled condenser via a pressure reducing station (1500 psia to 450 psia). The air-cooled condenser dissipates $45.8 \mathrm{MW}$ of heat to the atmosphere. Water conditioning is provided via the current $20,000 \mathrm{lb} / \mathrm{hr}$ blowdown and demineralization system. Condensate levels and makeup are provided by. the present systems.

Evaporator-0nly Test (Drawing No. G0041-0007-DX-00)

\section{Sodium System}

The sodium system is configured the same as described above except that ro heat is added by sodium heater no. 2 and there is no superheater. The $80 \mathrm{MW}$ of heat is provided as follows: $62.5 \mathrm{MW}$ by the reactor, the remainder electrically--a11 from the NRTS $138 \mathrm{KV}$ grid. 


\section{Steam System}

Saturated steam at 1600 psia flows from the steam drum. Part of the steam $(\sim 250,000 \mathrm{lb} / \mathrm{hr})$ is processed in the pressure reducing/desuperheating station to conditions acceptable for direct by-pass around the turbine to the condenser. ${ }^{2}$ The remainder of the steam flows to the air-cooled condenser via a pressure reducing valve. All other systems operate as described above except that the heat loads on the various feedwater heaters change as a consequence of the turbine being off-stream. The heat dissipation load is split as follows: 254 MWt to the existing vacuum condenser and cooling water system and 226 MWt to the air-cooled condenser.

\section{Heat Balance}

An example set of system conditions for testing the steam generator modules are shown on the process diagrams. The increased secondary sodium temperatures at the IHX will be obtained by increasing the secondary sodium flowrate through the IHX and raising the temperature of the primary system a few degrees; approximately $7^{\circ} \mathrm{F}$. Both of these requirements appear feasible.

Interface and Safety Considerations

The effect on the IHX of a sodium-water-reaction in the steam generator Is the principal consideration. A requirement of the design of the test loop w1ll be to preclude a sodium-water reaction from effecting deleteriously those portions of the facility that are required for fuels testing. This appears to be a feasible requirement, however, this matter will require a thorough investigation during the conceptual design stage.

The feasibility of this approach requires further study. An alte mative is to increase the capacity of the alr-cooled stean-condensing system to take the entire heat dissipation load. 


\section{Transient Conditions}

Appendix D provides selected data from Run $67 \mathrm{~b}$ of the EBR-II which describe transient conditions in the secondary and steam/feedwater systems for a typical startup and scram-from-power. In the event of a scram-frompower the maximum temperature transient in the secondary sodium occurs at the outlet from the superheater (also inlet to the evaporator). This transient condition is highly system and equipment dependent and should be used with caution if applied to different conditions.

The temperature difference that exists normally between the sodium from the EBR-II evaporator and the inlet recirc. water is usually very small (less than $5^{\circ} \mathrm{F}$ ). As a consequence, the principal sodium transient at this point in the EBR-II system during, a scram-from-power derives from the transient experienced by the water in the steam drum which, in turn, causes a reduced water temperature at the inlet to the evaporator. If a greater temperature difference exists between fluids at the inlet to the evaporator, such as obtained in the test unit, then the transient at this point in the system will be more severe. However, the surge tank provides attenuation of the temperature transient and will reduce the transient that obtains at the secondary sodium inlet to the IHX.

\section{Ayallable Equipment}

A list of equipment or systems that are available, or which must be provided, is given in Appendix E. 
Schedule

The proposed schedule of three (3) years from initiation of conceptual design to the start of test operation is overly optimistic. A period of about four (4) years from the start of preliminary design to the start of test operation appears more realistic. To meet an early test date the Laboratory must (1) be free to proceed aggressively at all times without undue influence from or interface with Others, (2) experience no delays from lack of funds, (3) initiate early procurement of long lead items, (4) be free to specify the applicable codes and standards using as an acceptable base the codes and standards to wh1ch the EBR-II was originally constructed, and (5) have a firm set of test requirements for the test module for facility design purposes by the start of preliminary design.

The four (4) year schedule assumes the use of the two EM pumps of which one is currently available. A second pump may be available from SEFOR. The pumps would differ in capacity and performance characteristics. Should a SEFOR pump not be available or should an early study of the parallel operation of these pumps indicate control difficulties, a second, new, duplicate pump would be procured--probably within the desired schedule. Should the fabrication of a new pump of different design be required-for reasons not presently envisaged--it will probably be the pacing item and extend the schedule.

Other long-lead items are (a) large, electrically-heated sodium heaters, (b) high-temperature/pressure steam condensing apparatus and felated equipment, (c) $138 / 13.8 \mathrm{kV}$ transformers and related appurtenances, and (d) instrumentation panels and special 1tems such as large EM sodium flowmeters, and (e) sodium valves, fittings and piping. 
$\underline{\text { Cost }}$

The total cost is roughly estimated to be about \$41M. A breakdown is given below.

The additional operating cost of the facility beyond that required to operate EBR-II now consists primarily of (1) the additional operating staff needed for the tests, (2) energy charges of about $\$ 2 \mathrm{M}$ per year, and, (3) such other services as may be required in connection with the tests.

\section{Cost Breakdown}

\section{Item}

$\underline{\$(000)}$

Equipment

- Sodium Heaters

1,500

- Surge and Storage Tanks

1,250

- EM Pump, Power Supplies, Panels, etc.

1,000

-Sodium Valves

3,500

- Na Purification System

450

- Na Piping System and EM Flowmeters

3,900

-Sodium and Na Loading System

100

- $\mathrm{Na}-\mathrm{H}_{2} \mathrm{O}$ Relief System

1,500

-H1gh-pressure Steam Condenser System

650

-Steam Drum, Recirculation Pumps, etc.

400

-Instrumentation and Control and Data Acquisition System

2,500

\section{Equipment Subtotal}

16,750

Building and Utilities

$$
2,250
$$

Equipment Erection and Installation (excludes piping) e 20\%

2,550

Electric Power Substation

1,000

Subtotal

22,550

Engineering @ 33 1/3\%

Contingency @ 40\%

Subtotal

$\frac{7,200}{29,750}$

Tota1

11,500 
Codes and Standards

The codes and standards to be used for EBR-II modifications is currently a subject of discussion between ANL and RRD. The outcome of these conversations will provide the basis for our selection of codes and standards for the proposed test loop. In the meantime one response to the draft statement received from R. W. Lockhart on January 25, 1974, Is contained in Appendix F. 


$$
\text { A-1 }
$$

APPENDIX 7-A

Sodium Heater Selection

\section{Requirements}

Two separate heater units

-Parallel - $1.1 \times 10^{6} \mathrm{lb} / \mathrm{hr} 650^{\circ}$ inlet, $860^{\circ} \mathrm{F}$ outlet, $20 \mathrm{MW}$

. Series - $4.2 \times 10^{6} \mathrm{lb} / \mathrm{hr} \quad 860^{\circ}$ inlet, $936^{\circ} \mathrm{F}$ outlet, $230 \mathrm{MW}$

II. Selection

Electrical resistance-type heaters selected after consideration of relative pros and cons of oil-fired and electrical sodium heaters. Major considerations:

-Simplicity in design, installation, and operation

-Avallability of on-site (EBR-II) and off-site (utility) power

-Utilizes existing technology

- Transient characteristics more like other parts of secondary sodium system - Low cost

\section{Design}

Vertical cylindrical tank, with single-ended

immersion heaters

Immersion heaters, $1^{\prime \prime}$ OD $\times 10^{\prime}$ long, each with $3, Y$-connected, 10-KW elements 
Electric Sodiun Heater: Fros \& Cons

Pro

-Simple

- Compact size

- Low Sodium Inventory

-Ease of control

. Low thermal mass

- Low design and fabrication cost

-high heat density

-modular construction

-available heater technology

-simple configuration

- Low energy cost ( $7 \mathrm{mills} / \mathrm{kw}-\mathrm{hr}$ )

- Large fraction of heat source is nuclear

.Off-site power available

- No fuel inventory or procurement problems

- Rollability

-redundancy of calrods readily provided

-Operation like present system; less

additional operator training

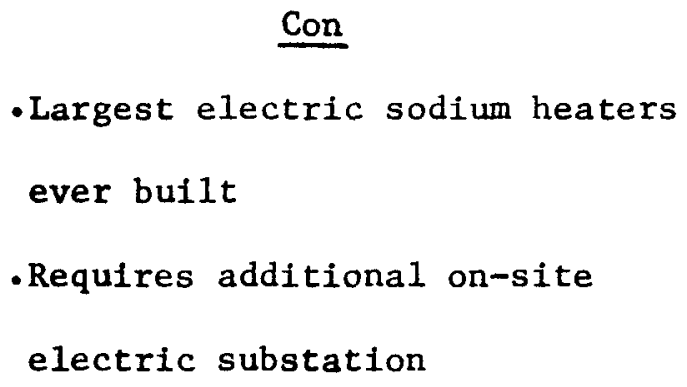

$\underline{\text { Con }}$

- Largest electric sodium heaters ever built

- Requires additional on-site

electric substation 


\section{A-3}

011-Fired Sodium Heater: Pros \& Cons

$\underline{\text { Pro }}$

$\underline{\text { Con }}$

- Adequate fuel availability

- Fuel storage and handling

- High cost

- Increased number of operating personnel

- Large, complex facility

- High initial first costs

-complex geometry

-complex stress analysis

-complex controls

- Tube failure shuts down unit

- Combustion products; air pollution

.High fuel cost (17c/gal-- $10 \mathrm{mlll} / \mathrm{kw}-\mathrm{hr}$

(c) 50\% energy conversion efficiency)

-Operation unlike present system;

increased operator training 


\author{
A-4 \\ Availability of Electric Energy
}

Requirements:

$\cdot 30-40 \mathrm{MW}$

-Starting early 1977

$.50-60 \%$ of each year

Avallability:

- Initial contact with utility (Utah Power and Light Company) ind1cates requirements can be met

$.138 \mathrm{KV}$ NRTS power loop to EBR-II site has 96 MVA capability

- Ma1n NRTS Substation $161 \mathrm{kV} / 138 \mathrm{kV}$ require addition of forced air or oil cooling

Energy Cost (Current):

o $7 \mathrm{mill} / \mathrm{kw}-\mathrm{hr}$ ( $\sim 1 / 2$ is demand charge)

-Some increase expected because NRTS site demand will double 


$$
\begin{gathered}
\text { B-1 } \\
\text { APPENDIX 7-B } \\
\text { Na- }{ }_{2} 0 \text { Relief System }
\end{gathered}
$$

\section{Requirements}

- Protect the IHX--No Effect on Reactor Safety

- Mitigate Effects on Other Systems--Plant Safety

- Contain the Sodium

-Provide Safe Release of Gaseous Reaction Products

\section{Design Features}

- Rupture Discs (at appropriate locations)

- Reaction Products Separator Vessel

- Liquid Retention Tank

- Gas Release System

- Inert Gas Blanket 


$$
\mathrm{C}-1
$$

APPENDIX $7 \multimap C$

High Pressure Steam Condenser

I. Requirements

- Capacity 40-45 MW (for SH + EV testing; $80 \mathrm{MW}$ for EV only if main vacuum condenser is unavailable)

II. Alternatives Considered

- Turbine, condenser, cooling tower

-Water-cooled condenser, cooling tower

- Alr-cooled condenser

\section{Selection}

The air-cooled condenser selected for preliminary investigation

based on the following reasons:

- Simplicity of configuration, operation and control

- Compactness

- Cost (design and fabrication)

IV. Design

Three sections: desuperheating, condensing, subcooling

Air-cooled once-through

Counter-cross flow

60,000 linear ft. ( $I^{\prime \prime}$ OD $\times .083$ wall, smooth tubes)

$21 / 2 \%$ chrome, $1 \%$ molybdenum stee 1

6 blowers, 100,000 CFM, 75 hp each

Tube bundle size: $20^{\prime} \times 20^{\prime} \times 5^{\prime}$ high (approximately) 


\author{
APPENDIX 7-D \\ Selected Transient Data from EBR-II \\ Run 67B
}

18:00 November 30, 1973 to 18:00 December 1, 1973

\title{
Included:
}

1. Power vs. Time

2. Secondary Sodium IHX Inlet Temperature

3. Secondary Sodium IHX Outlet Temperature

4. Secondary Sodium Superheater Inlet Temperature

5. Secondary Sodium Superheater $\$$ \#10 Outlet Temperature

6. Steam From Evaporator \#706 Outlet Temperature

7. Steam Drum Temperature

8. Steam From Superheater Outlet Temperature

9. Secondary Sodium Flow

10. Secondary Sodium Flow Decay after Scram 
INITIRL RISE TO POWER. RUN 678

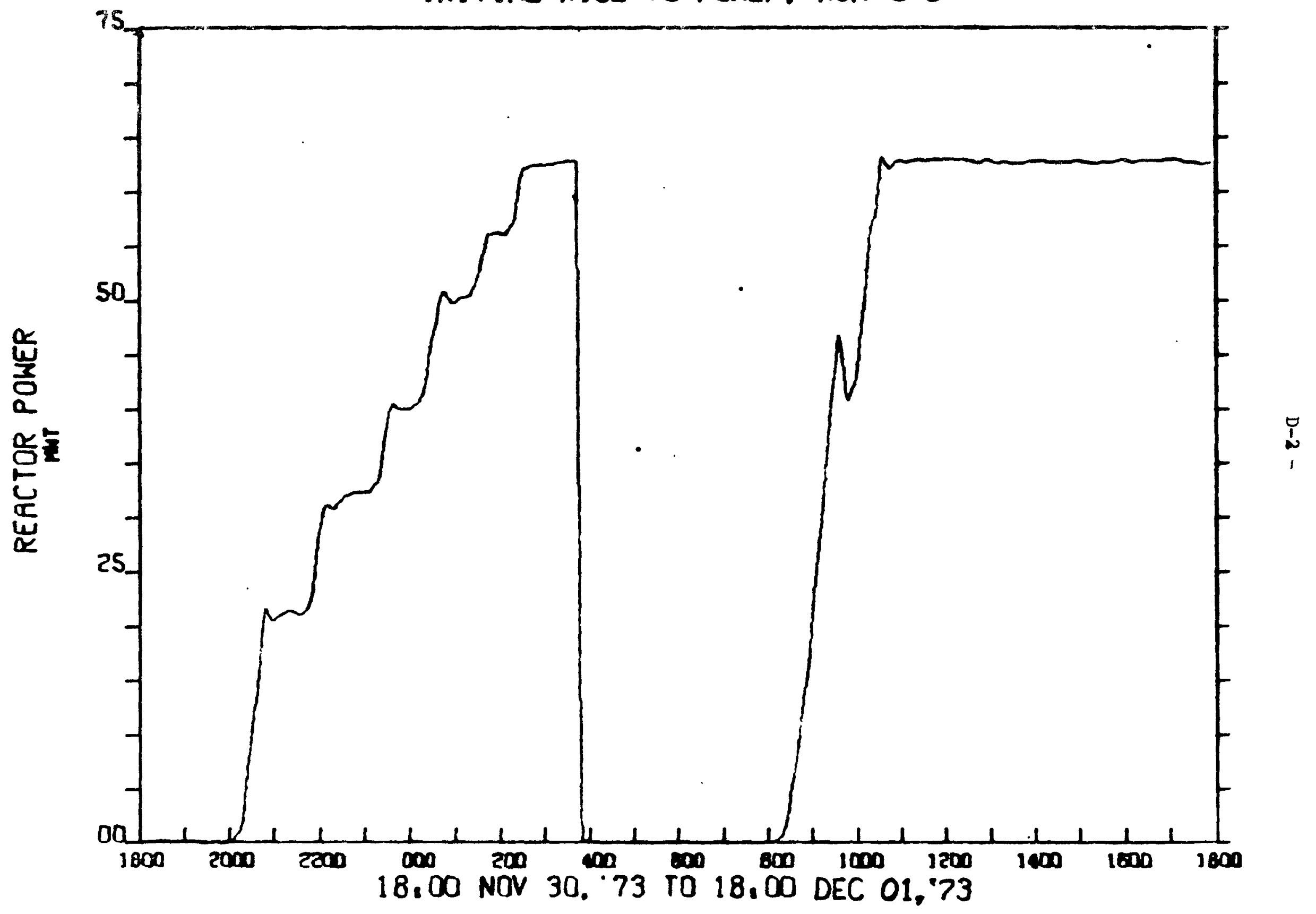




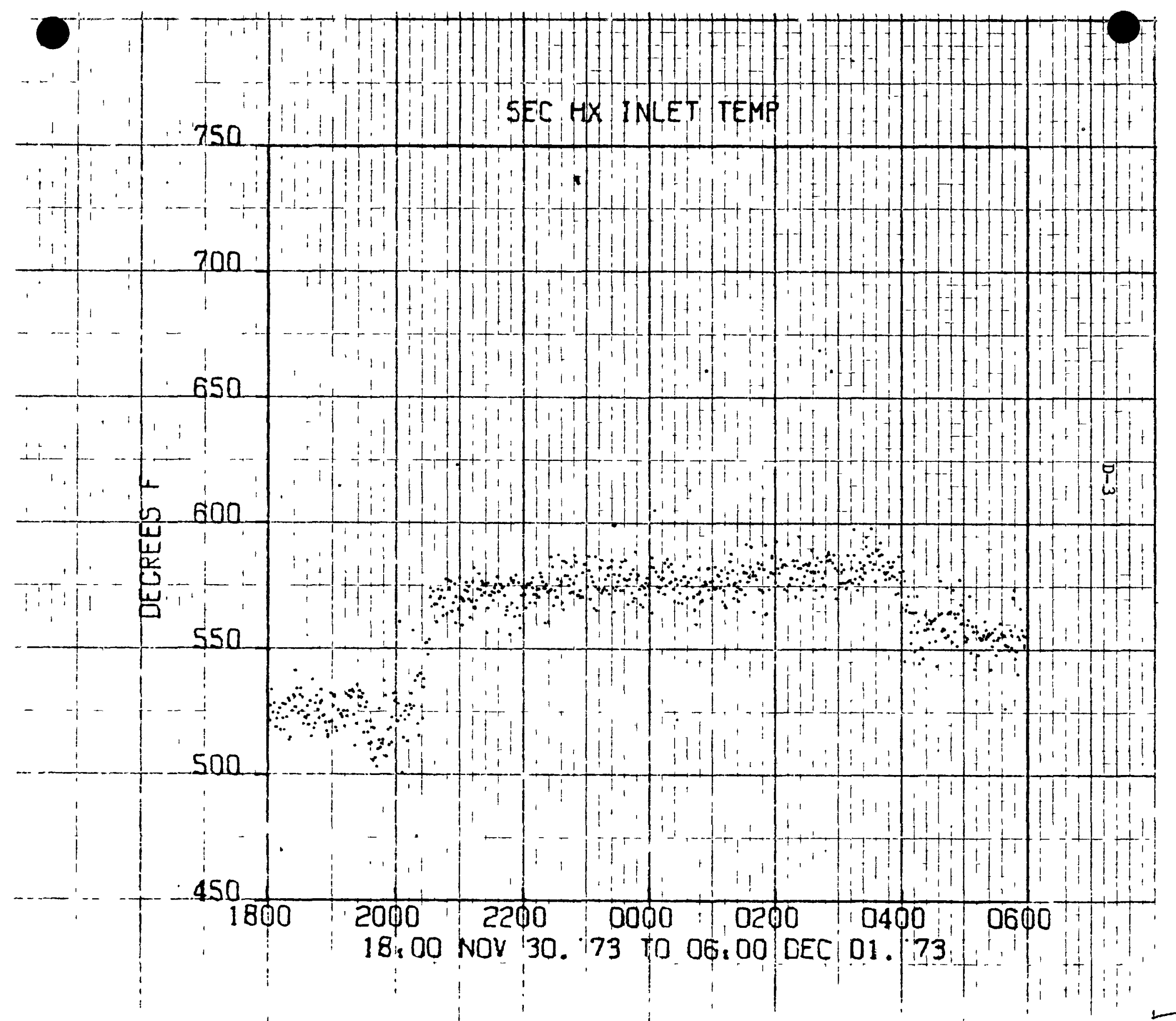




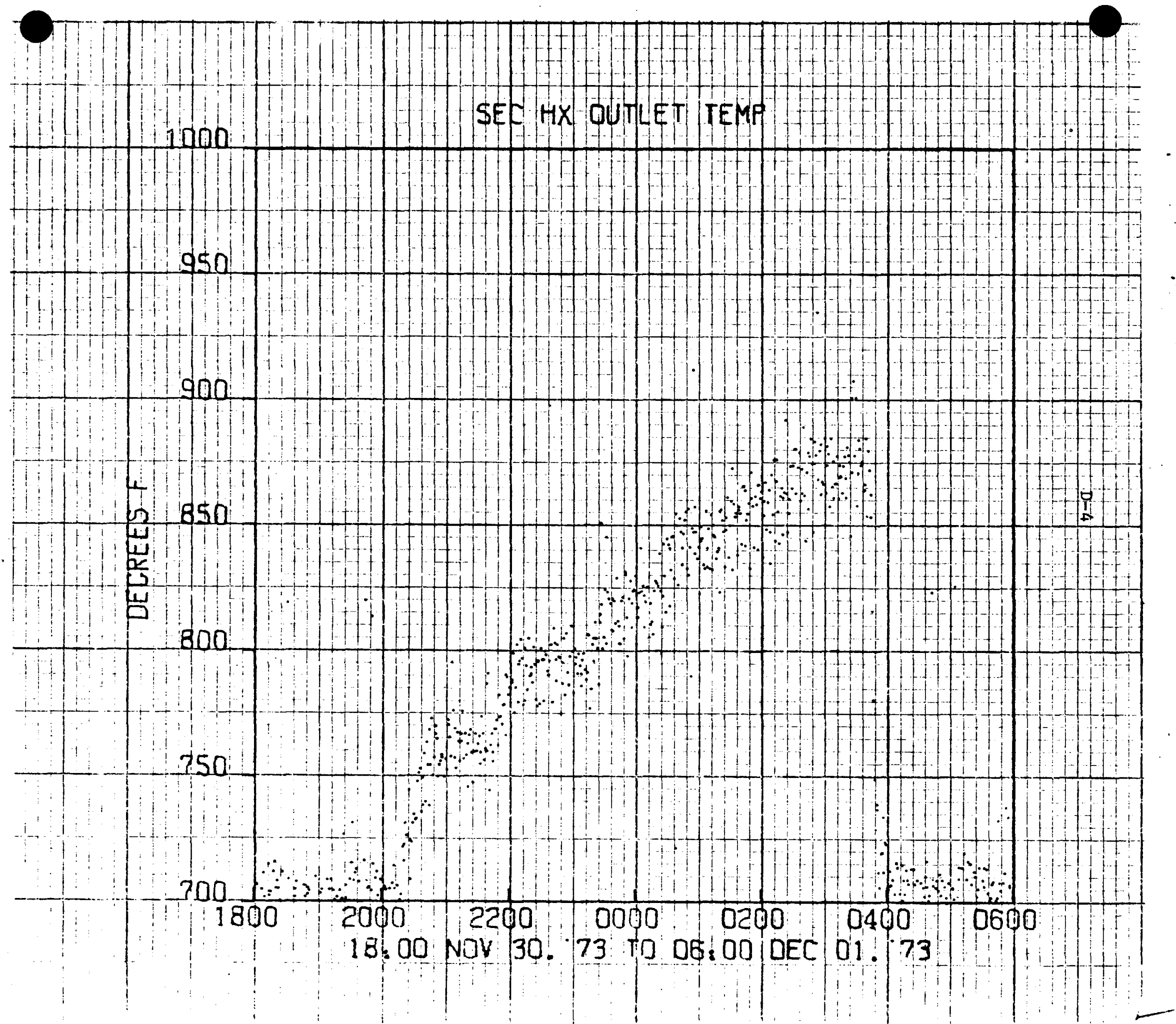




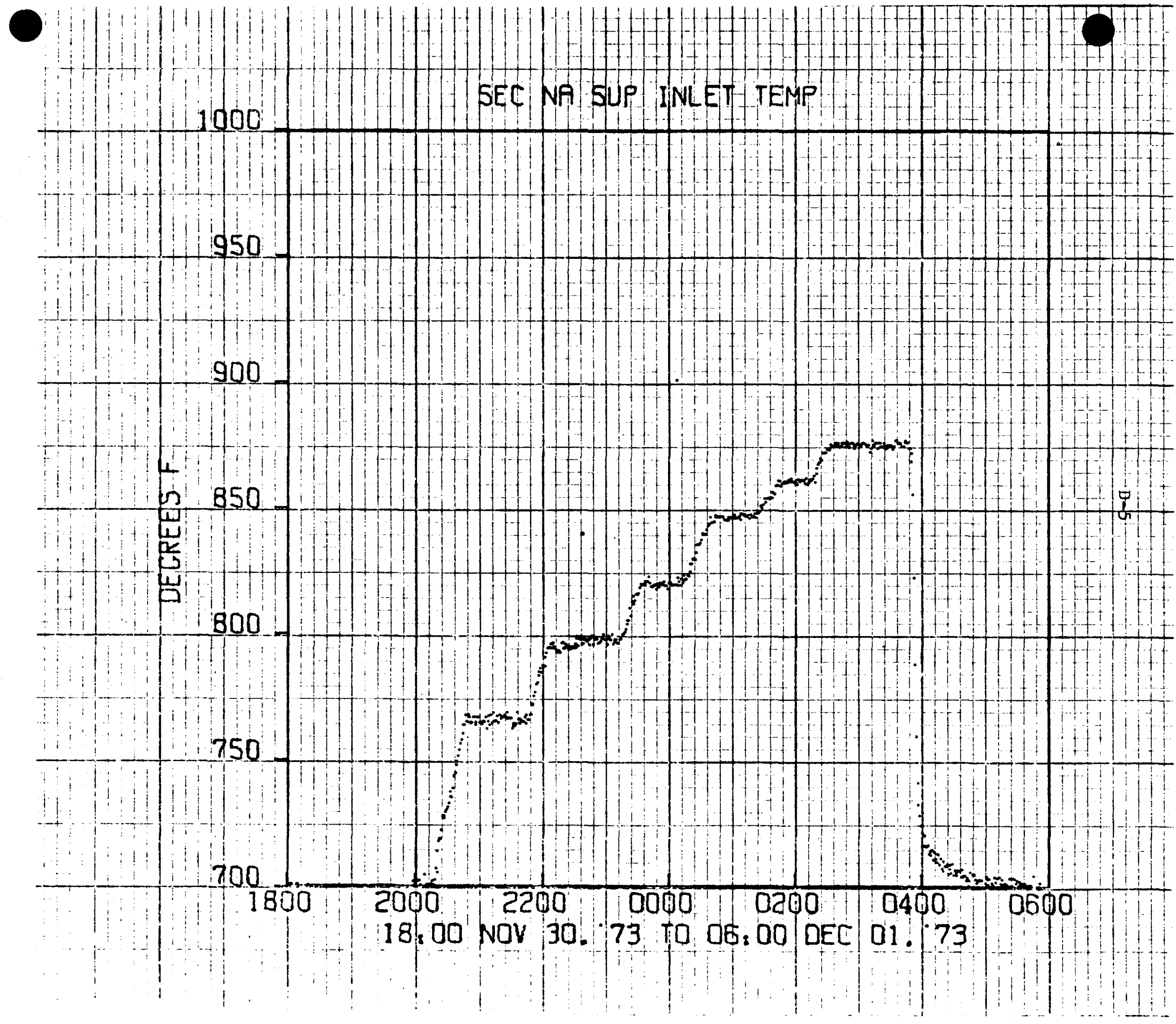




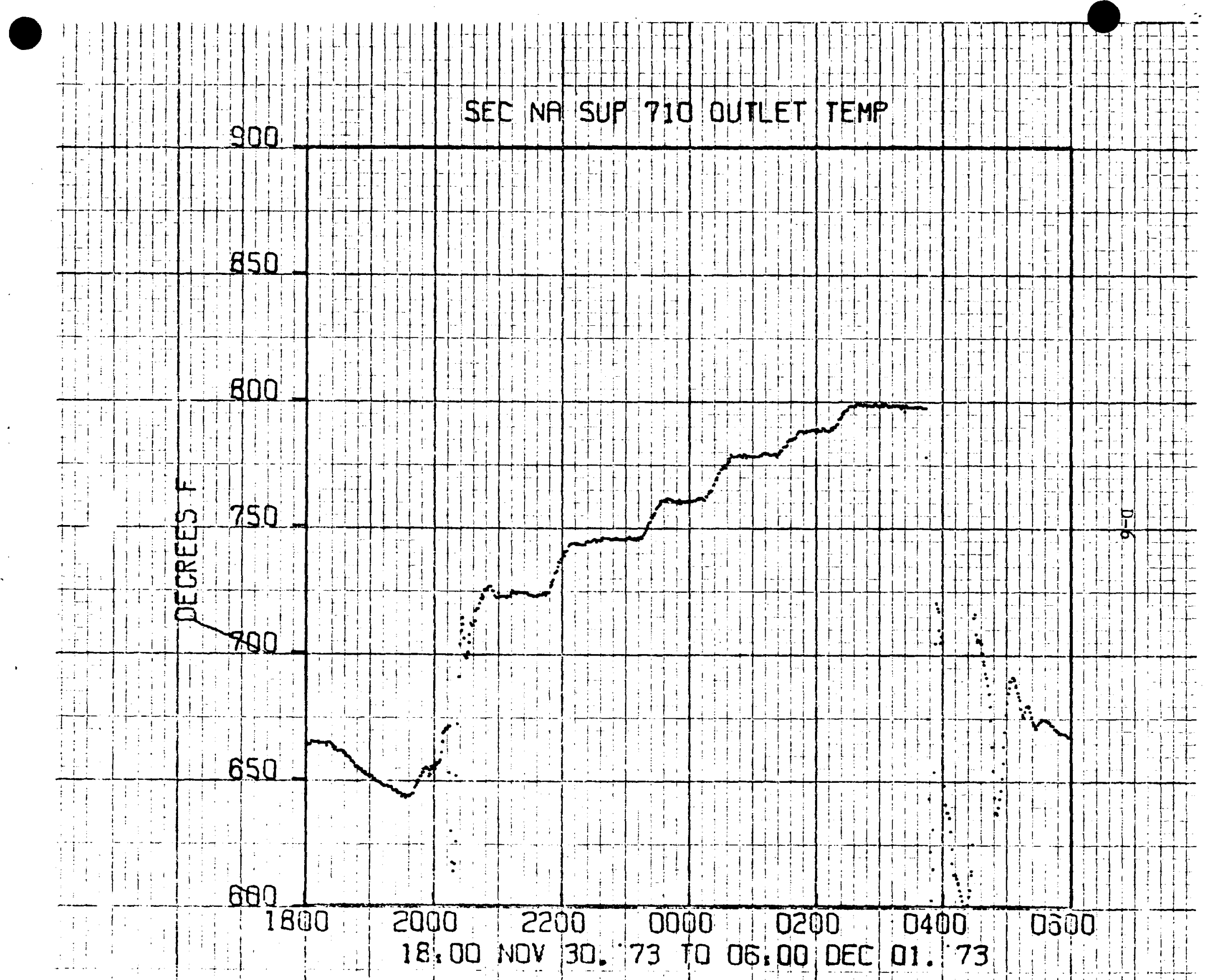




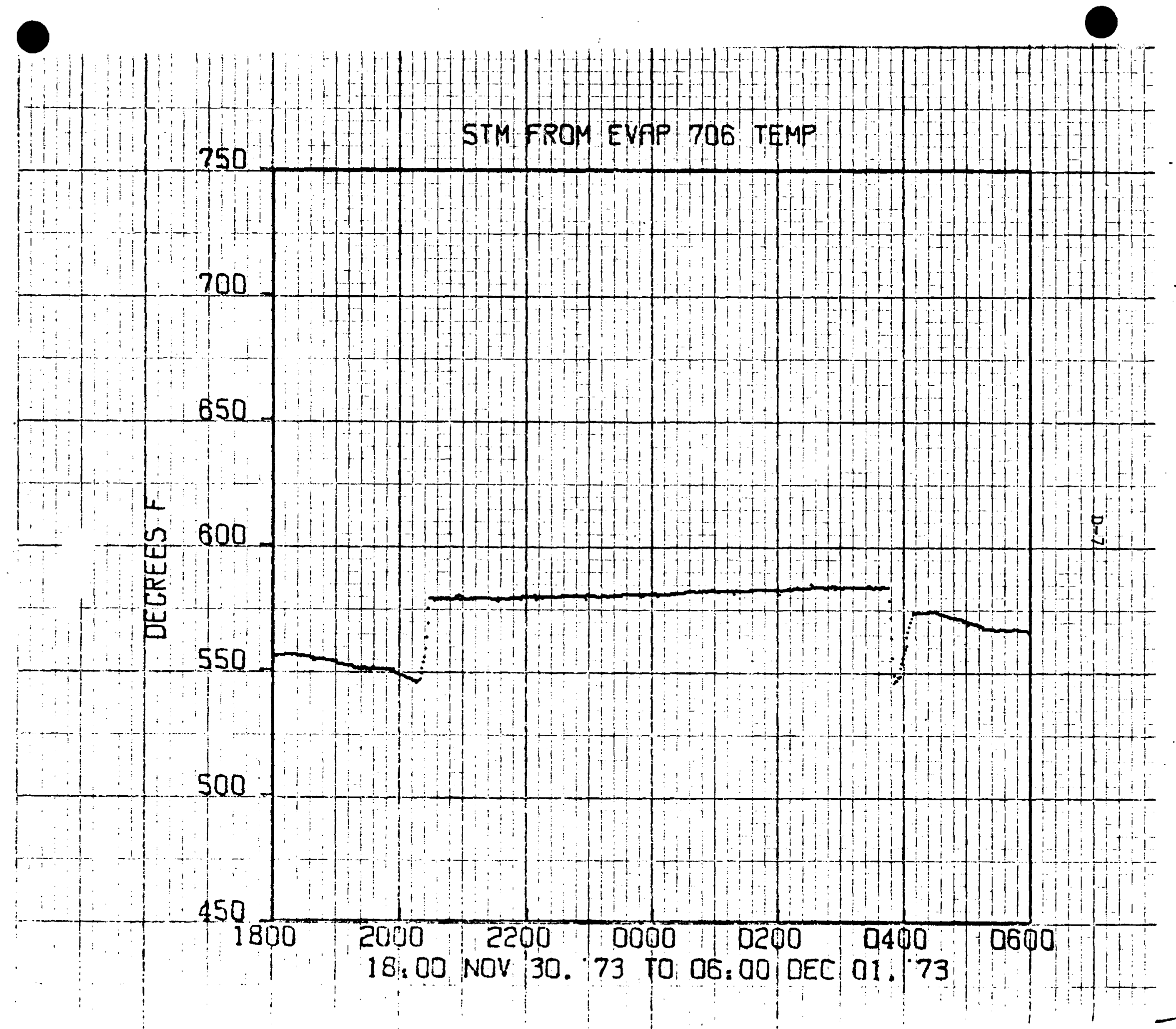




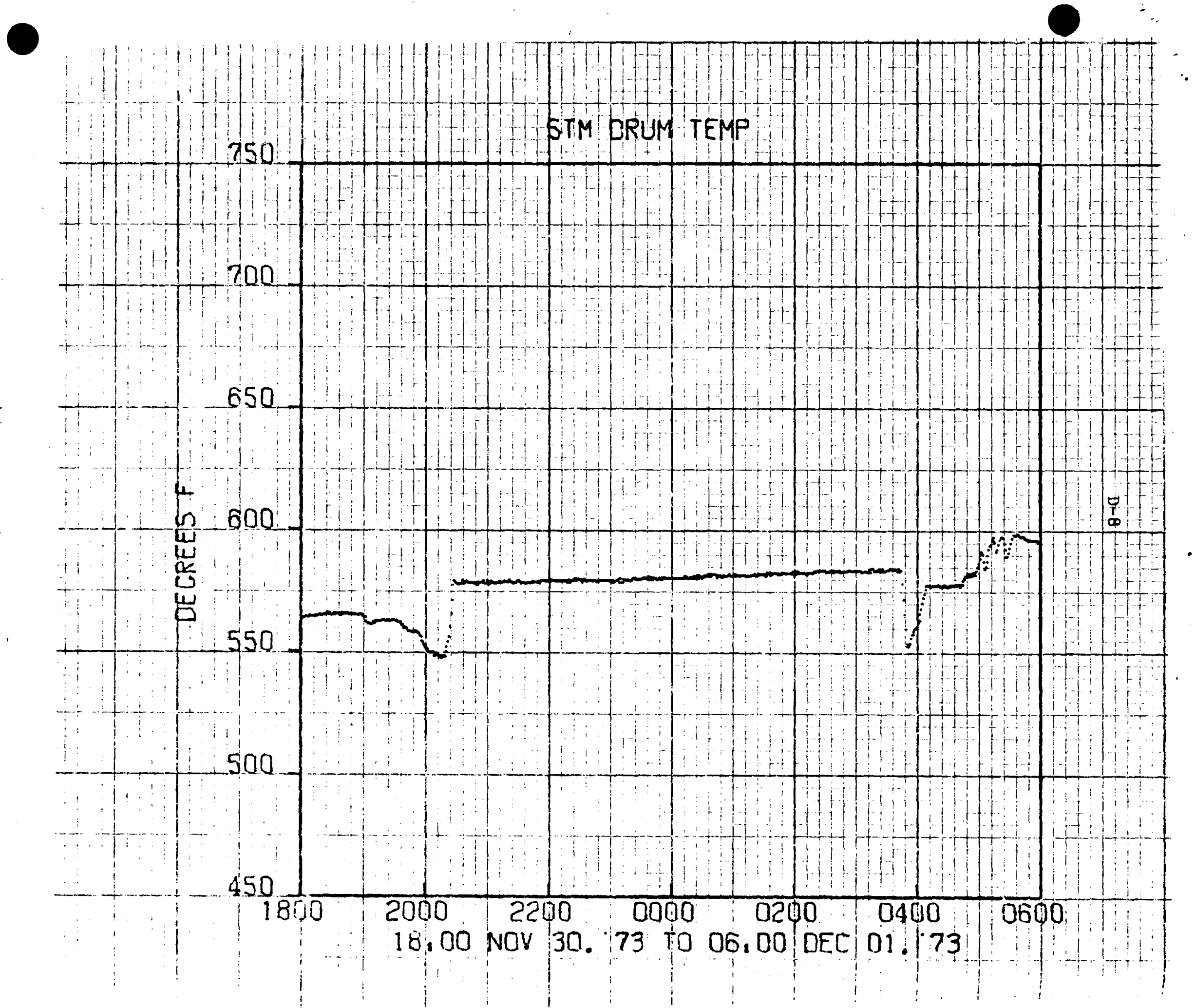




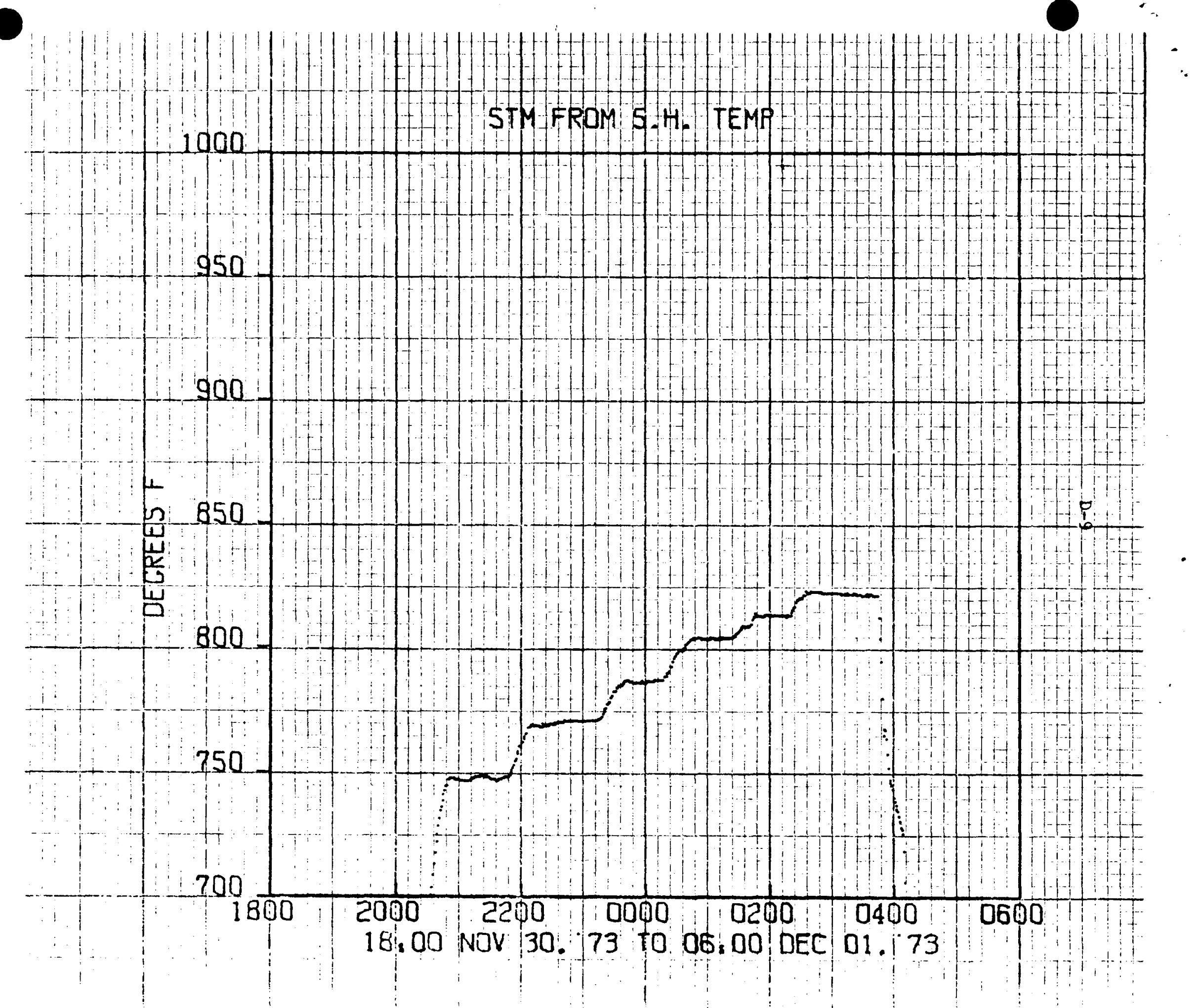




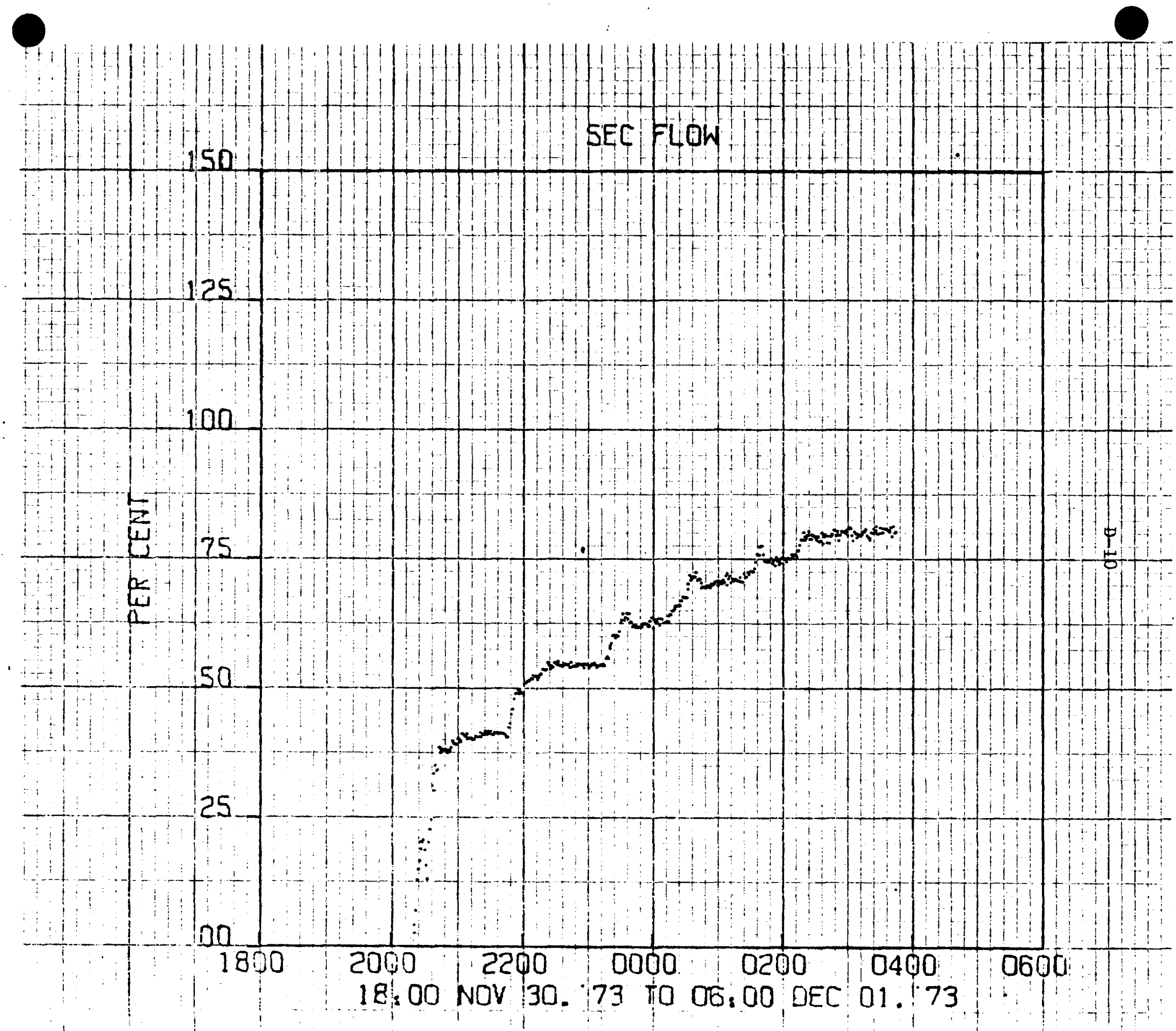




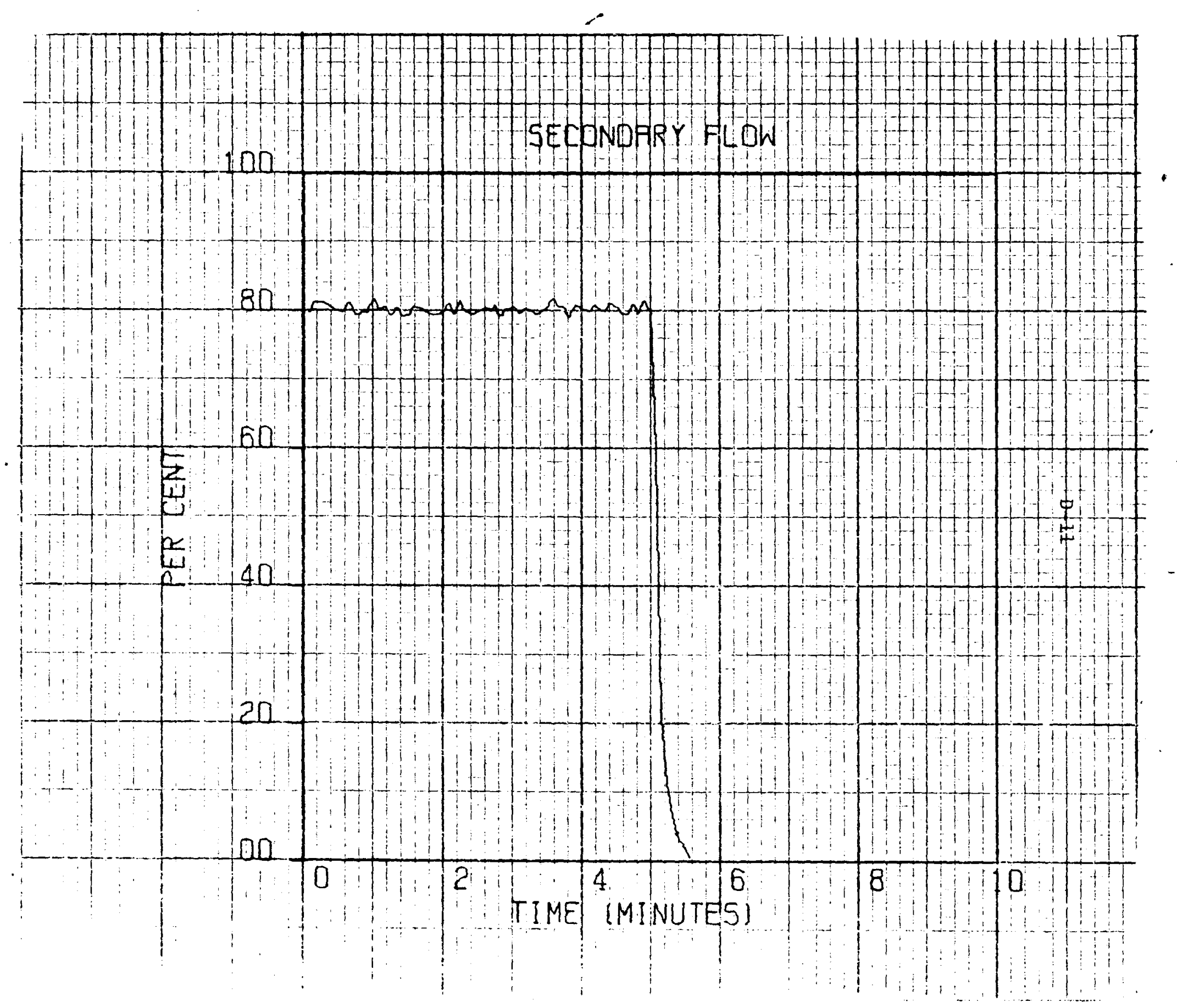




\author{
$D-12$ \\ Selected Scram Transient Data from EBR-II \\ 17:00 February 4, 1973 to 14:26 February 7, 1.973
}

Included

1. Normal Scram

a. Superheater Outlet Sodium Temperature vs Time

b. Superheater Inlet Sodium Temperature vs Time

c. Evaporator Outlet Sodium Temperature vs Time

2. Scram Initiated by Feedpump Shut-off

a. Superheater Sodium Outlet Temperature vs Time 


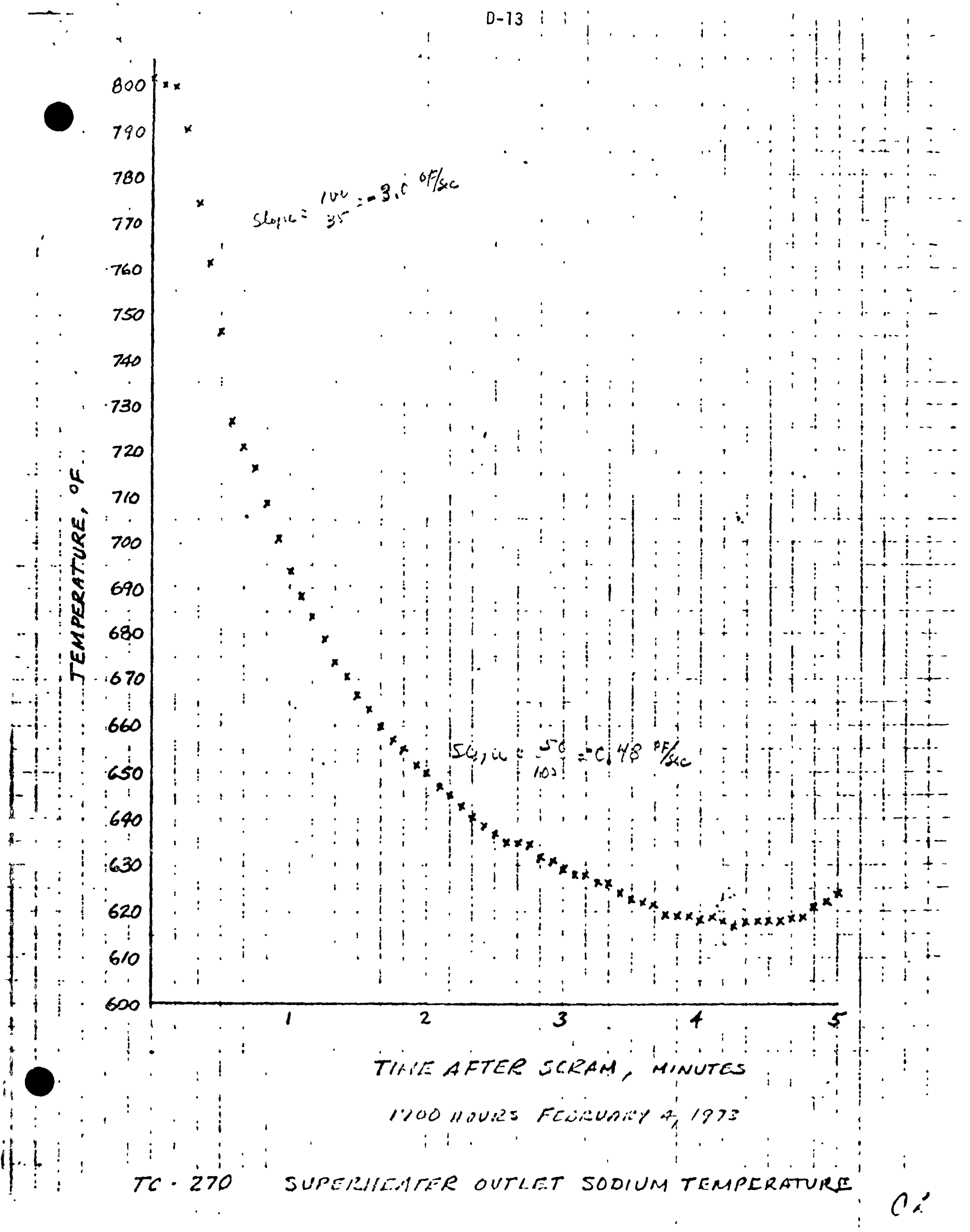




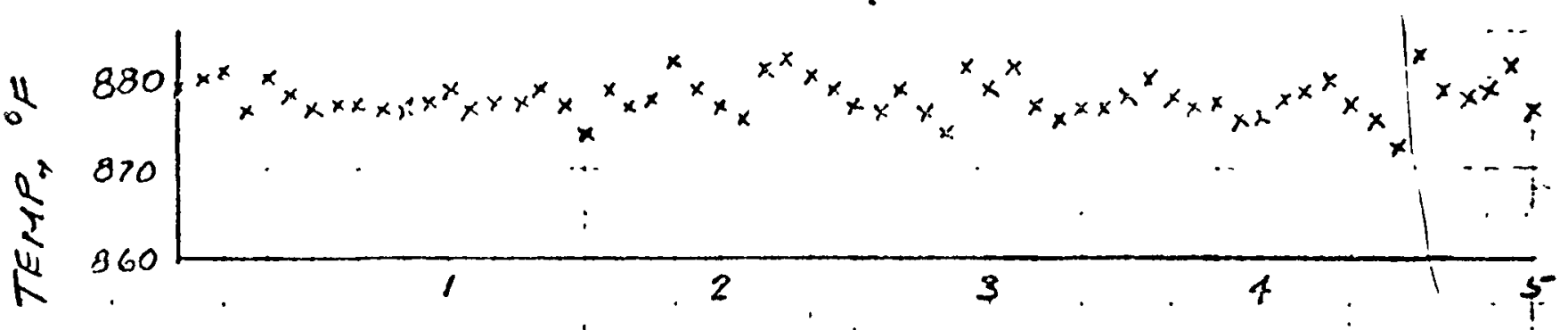

TIME AFTER SCRAM, MINUTES

1700 HOVES FESRUARY 4,1973

TC - 269 SUPERHEATER INLET SODIUM TEMPERATURE

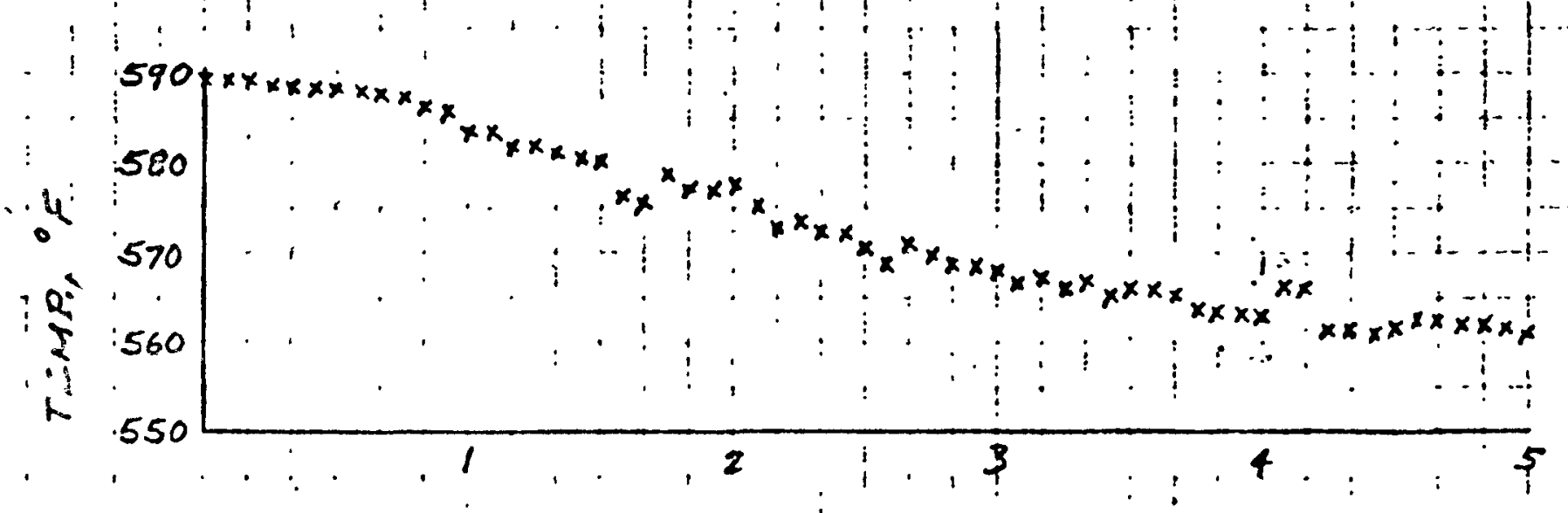

TIME AFTER SCRAM, MINUTES

1700 HOUEE FEERUARY 4, 1973

TC-268 EVAPORATOR OUTLET SODIUM TEMPERATURE 


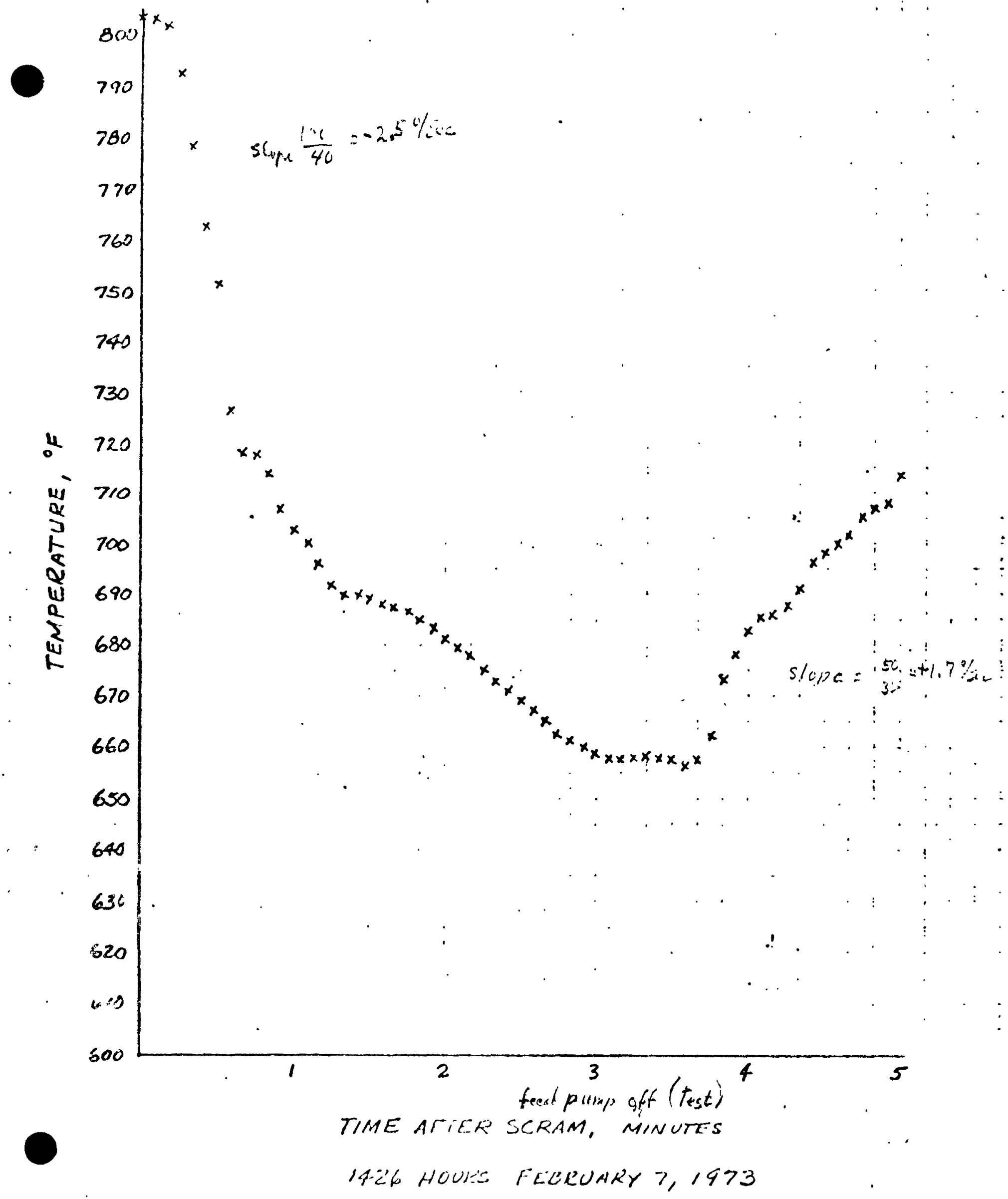


APPENDIX 7-F

RECOMMENDED CODES AIN STANDARDS

The design, construction and successful operation of the EBR-II has verifled its engineering adequacy; therefore, design criteria for modifications to the existing facility should not be less stringent than those used In the original design. The advances made in both design technology and fabrication technique including quality control should be considered. Also to be weighed is the fact that the modiffcations being considered, do not directly involve a nuclear radiation hazard nor are they expected to operate over a thirty year life. Application of the highest level of present day nuclear standards are necessary for long-lived facilities where radiation hazards are possible; these requirements do not apply to these modifications. Therefore it is recommended that the design criteria be no less than and In most instances somewhat more restrictive than those applied to the original design, specifically in the area of fabrication and for those components which are first-of-a-kind designs.

Specific codes and standards to be applied to individual components and system modifications will be identified in the preliminary SDD prepared during the conceptual design and a preliminary Q/A plan prepared during this design phase.

Recomended general guidelines for codes and standards for facility modifications are as follows:

1. All first-of-a-kind components for sodium systems sha11 meet the IEquirements of Section III, Class 2 (Section VIII, Division 1 for design) and appropriate code cases of the ASME Boiler and Pressure Vessel Code. 


$$
\text { F-2 }
$$

2. All new sodium piping shall meet the basic requirements of Section III, Class 2 and the appropriate cases of the ASME Boller and Pressure Vessel Code.

3. Inert gas piping and components shall meet the requirements of Section III, Class 3 and appropriate code case of the ASME Boller and Pressure Vessel Code.

4. All steam system piping and components shall meet the requirements of ANSI B31.1 Power Piping Code or Section VIII, Division 1 - ASME Boiler and Pressure Vessel Code, as appropriate.

5. SDD's will be prepared in accordance with the guidelines in RDT Standard F1-2T.

6. All quality assurance requirements for design shall be based on the guidelines and provisions of RDT Standard F2-2. 


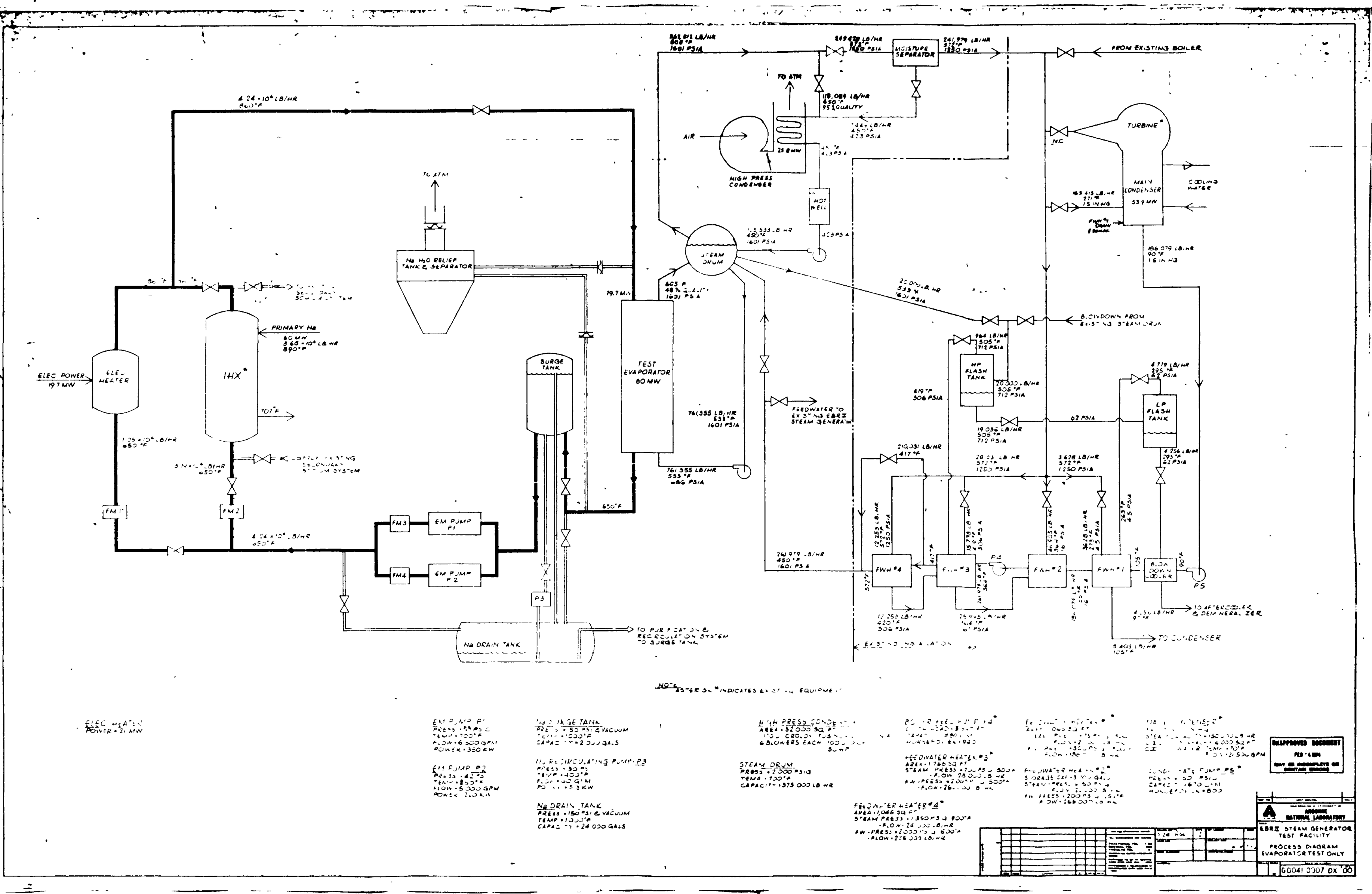





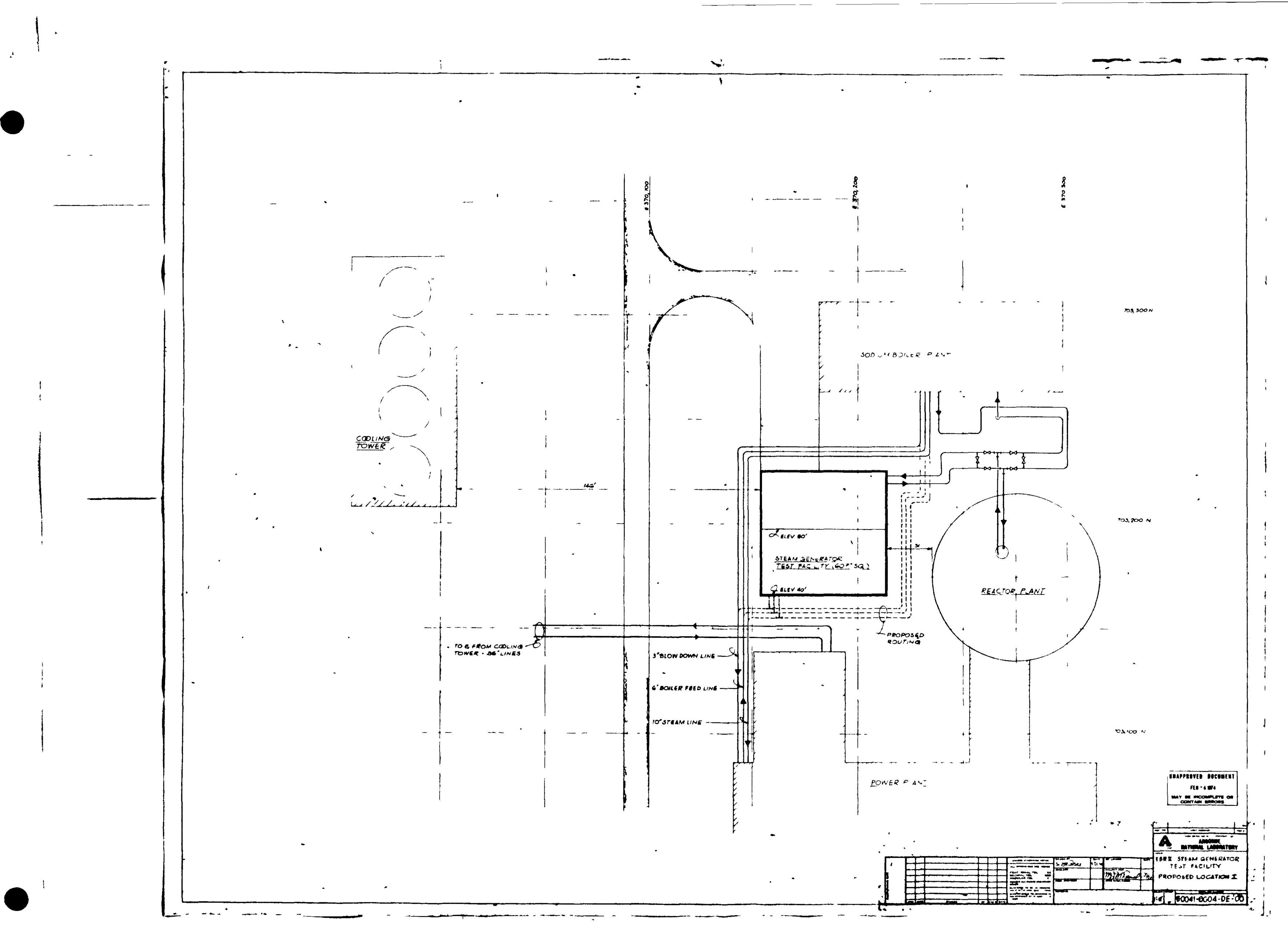




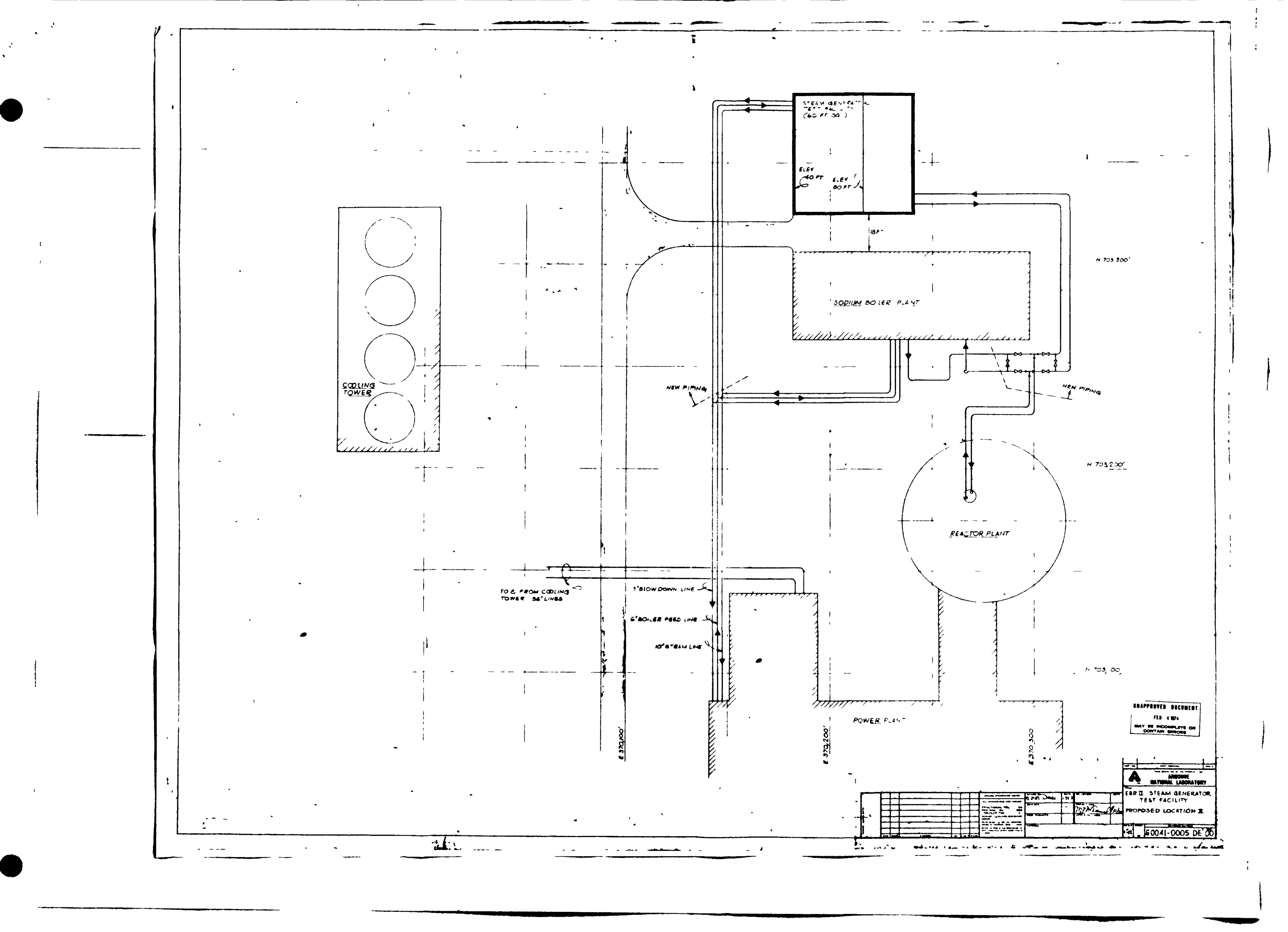




\subsection{Overlay on ANL Scoping Information Report}

GE found the ANL management, component and engineering groups receptive, enthusiastic, inventive and practical in supplying their responses to the numerous questions that GE asked regarding large-scale steam generator testing at the EBR-II site in the National Reactor Testing Site in Idaho. GE wants to thank W. R. Simmons, R. S. Zeno, and Ken Kuczen and their groups for preparing the information provided in the attached report.

Originally, ANL, as requested, provided scoping information for testing a $4+4$ per loop capacity evaporator ( $60 \mathrm{MWt}$ ). This facility utilized the full output of the EBR-II intermediate heat exchanger (IHX). Fortunately, the existing EBR-II sodium temperature and flow conditions were acceptable. The existing steam dump and feedwater system also appeared to be adequate. In general, the steam generator test facility was to provide a second steam generation system in parallel with the existing EBR-II system. During prototype testing, the existing system was to be maintained such that in a few days time, if necessary, the sodium and steam/water could be rerouted such that the reactor heat could be dissipated through the existing system. Thus, the prototype test generator will become a backup for the existing single loop system and vice versa.

Since early December the $\underline{C}$ inch $\underline{\text { River }}$ Breeder Reactor $\underline{\mathrm{P}}$ lant designers have been studying the desirability of using fewer steam generator modules per plant loop. All the work presented in the present report, as requested, is based on a $3+3$ per loop capacity ( $280 \mathrm{MWt}$ for the evaporator and $~$ $30 \mathrm{MWt}$ for the superheater). The choice of "typical" steam generation components for illustration was arbitrarily chosen to be an AI hockey stick superheater and a Foster wheeler protected bayonet tube evaporator. The test facility is to be capable of testing any of the present three $S G$ concepts. 
At the RRD/GE/WARD meeting on December 14-15, 1973 it was requested that more definitive EBR-II site information be provided for (1) an evaporator only facility with about 80 MWt capacity, and (2) a full steam generator module $(S H+E V)$ of about 110 MWt capacity.

The ensuing study, as requested, indicates full power $(110 \mathrm{MW})$ prototype testing capability at EBR-II utilizing the full thermal output of the EBR-II reactor plus the addition of 50 MW of electrical heat. Most of the EBR-II steam dump and feedwater system would be utilized; and, where necessary, additional capacity would be added. Additional condensing capacity is proposed to be provided by a high pressure ( 500 psia) air cooled unit.

The purpose of the EBR-II facility is to provide a fast reactor fuel test bed. During the recent few years, the reactor has been operated at full power over $50 \%$ of the time and shut down monthly for fuel tests and refueling. During the month, there are typically two reactor scrams that shut the plant down for several hours. The existing steam generator has operated for the life of the plant (10 years) and appeared to be in good condition during the inspection in 1973. The operating crew has demonstrated their competence in operating and maintaining the power plant.

The following comments are provided to amplify indicated portions of the material provided:

1. The advantages of building and operating the prototype steam generator test facility at EBR-II are listed on the first page of the ANL information. In addition to the list of sodium components that will accumulate in-service experience, most of the components in the steam generator and steam systems will also receive in-service experience. They are expected to be identical or similar to the equipment to be used in the CRBRP. 
2. A system that should be added to the test facility during the conceptual design work is a steam/water isolation and dump system. In the plant this system limits the amount of potential damage to the steam generation components, should a water to sodium leak occur, by removing water from the affected component. Intentional operation of this system will be part of the transient temperature operation of the facility. The function of the system is to produce realistic operation of the isolation and dump equipment and thermal conditions in the test equipment.

3. Sodium pumps to provide the required $4.25 \cdot 10^{6} \mathrm{lb} / \mathrm{hr}$ sodium flow appear to be available, but the power supplies will have to be replaced or modified. The spare secondary 1 inear EM pump at the EBR-II site is one of the candidates, and either recovery of a second "spare" EBR-II type pump, use of spare "Seawolf" pumps or transfer of the SEFOR main pumps and power supplies are believed to be available.

Linear EM pumps of this design and capacity have demonstrated their reliability and flexibility for programed test condition changes. They also have been used, as in the existing secondary EBR-II pump, for flow resistance (brake) to minimize natural convection flow or inertia when rapidly decreasing flow.

Some used centrifugal pumps are potentially available from Fermi or. Hallam but were not considered during this scoping study due to the availability and desirability of using pumps similar to the one in use at EBR-II. The power supply for these pumps control the 3 phase, 480 volt electric power required to operate these units. 
4. Two alternate schemes were presented by ANL to condense the steam generated by the combined SH + EV test or for the evaporator only test. Additional assessment of the capacity of the continuous turbine bypass steam dump to the main EBR-II condenser will have to be made and/or tested. When this capability is obtained, the remainder of steam will be desuperheated and condensed in an aircooled (high pressure) condenser. This type of condenser has been used on smaller capacity units. It is proposed that the unit be fabricated without extended surface on the air side to simplify fabrication and inspection and save capital cost. Upstream of the condenser would be suitable pressure reduction equipment such that the resultant hot well temperature would be the same as the feedwater temperature. The existing feed and purification system would be used to maintain water level and purity in the steam/water system.

5. The cost "guesstimate" provided on Page 9 of the ANL information package lists the estimated costs for the combined superheater plus evaporator test facility. The cost for the facility if it was only designed and built for the evaporator test would be only slightly less. Cost savings on the $30 \mathrm{MW}$ heater, sodium piping, rel ief systems, and storage tank capability are offset by potentially twice the size high pressure condenser if the site vacuum condenser (turbine bypass line) cannot be utilized. If the vacuum condenser can be used, the high pressure condenser requirements will be about half of the combined test requirements. GE based on the ANL information estimates that the evaporator only facility would be from $\$ 6$ to $\$ 7$ million less expensive than the combined evaporator and superheater facility. 
6. Operating expenses of the test facility at EBR-II appear to be low as stated assuming no EBR-II use charges due to the items described by ANL. The additional operating, site engineering, and inspection costs for following and maintaining the test facility are estimated to be about 20 man years for the combined test facility and 15 man years for the evaporator only test facility; the yearly power costs are estimated to be $\$ 2$ million and $\$ 1$ million, respectively. 
7.3 Work Areas to be Emphasized During the Conceptual Design at ANL/EBR-II Based on the existing scoping information work, emphasis should be directed during the conceptual design toward the following three areas: thermal transient test improvement and facility mitigation, electric sodium heater design and means to reduce the four year design, procurement, and installation schedule.

\section{Thermal Transients}

Steam generator testing consists of steady-state and transient temperature and flow operation. Thus, during the conceptual design, the new parts of the facility should be designed to provide realistic up and down temperature transients to the test steam generators and, where necessary, mitigate by mixing tanks or bypass sodium the transients imposed on the existing parts of the facility. Present transient information is described in Section 5.0 and more detailed requirements will be provided soon after the conceptual design effort is initiated. The transient work should include a description of realistic transients that the facility is capable of withstanding without significant upset to the fuel test program or primary system capability.

In the plant system, normal load changes are accompanied by flow changes so the temperature of the SG system varies very little, up temperature transients in the steam generator are caused by inadvertant or SWR trip/operation of the steam/water isolation and dump system so the evaporator boils dry.. Down transients are caused by continuation of sodium flow after a decrease in heat generation or reactor scram. Many transients are being considered by the plant design and analysis groups. SG test transients based on an "umbrella" concept will be provided and updated for each stage of the facility design. 
Since the proposed SG test facility provides about half of the heat source and heat sink, appropriate control of these components and the sodium pumps should provide adequate test conditions without jeopardizing the existing facility or fuel test program. Transient mitigation equipment such as the in-line, down stream of the evaporator surge tank will continue to provide less severe transients to the EBR-II IHX and primary sodium system.

\section{Electric Sodium Heater Design}

Although sodium systems are frequently (trace) heated with electric heat, the proposed sodium heaters are vital to the success of the SG test program. Usual heat exchanger design problems such as flow distribution, vibration, thermal shock and baffles to minimize bypass flow will have to be considered as well as the troublesome problem of the design of the electrical leads in and near the head or flange of the heater vessel. The conceptual design of these components should develop the design criteria, design of critical components, and describe potential solutions to marginal design areas. Conceptual diagrams of the attendant electrical distribution, safety, and control systems are to be provided.

\section{Reducing the Schedule}

It is important that the steam generator testing of prototype units start immediately after the test units are made available. Such items as the following should be considered to reduce the time to initiate testing.

o Simplify factlity design; el iminate some sodium valves

o Utilize specialized additional design and procurement help

- Plan and execute all phases on a tight schedule

- Utilize acceptable existing components

- Obtain agreements with the customer on who is responsible for each phase of the work, what codes and standards are to be applied, what is required to be submitted for each approval and how disputes are resolved. 
Additional Scoping Work

The scoping study should be continued during this period to include other possible modes of steam generator testing such as part-1oad, prototype superheater only testing utilizing steam from the existing EBR-II evaporator drum (or a separate steam generator) and a $2+2$ capacity ( $120 \mathrm{MW}$ ) evaporator only testing. 


\subsection{SCTI STEAM GENERATOR TEST FACILITY APPROACH AND RECOMMENDATIONS}

The following summarizes additional information provided by LMEC regarding utilization of the SCTI for prototype steam generator testing included in the attached trip report and developed during a GE/LMEC meetina he1d 1/18/74 to review the LMEC input.

GE found the LMEC management and engineering personnel to be receptive, enthusiastic, inventive, and practical in their response to the numerous questions posed by GE regarding large scale steam generator testing at the SCTI site. GE wishes to express its thanks to LMEC for the information supplied in the attached trip report.

\section{SCHEDULE}

Testing could start January or February 1977 if test articles are available July 1976.

\section{LMEC COST ESTIMATE SUMMARY}

Full power S.H. test ( $35 \mathrm{MW}$ ) (Alternate A)

$65 \%$ power and sodium flow S.H. \& evap. (70 MW)

$65 \%$ power $100 \%$ sodium flow S.H. \& evap. (70 MW) (Alternate C)

$30 \%$ power and flow S.H. \& evap. (35 MW) (A7ternate E)
$\$$ Millions*

7.4

12.0

$14.9 * \star$

2.7

* These estimates do not include the $\$ 4.5 \mathrm{M}$ cost of the alternate heater or an estimated $\$ 2.4 \mathrm{M}$ cost for installation in the SCTI primary sodium system. The cost estimates are based on use of ASME class 1 transient analysis and RDT material and process standards for the sodium containment boundary and applicable commercial standards for the remainder of the facility. LMEC/GE believe that the codes and standards approach recommended Section 6.0. would reduce the cost of the sodium system by between $15-25 \%$ and have a significant schedule advantage for long lead time procurement items. LMEC recommended approach for use of RDT items from LMEC stores would be to use these items only where there is a definite schedule advantage due to their availability.

** LMEC estimate for Alternate $C$ is based on using an FFTF sodium pump design instead of the available HALLAM pumps to meet the increased pressure drop requirements for $100 \%$ sodium flow conditions. 
RECOMMENDED STEAM SYSTEM FOR ALTERNATE A

Non-condensing using steam compressor.

ENERGY SOURCES FOR LMEC NATURAL GAS

Capability - 200MNT

Firm supply for next 5 years-3.5 MWT

Remaining energy interruptible with the following days per year curtailment projected for 1976

\begin{tabular}{|c|c|}
\hline Winter Season & Days/Year \\
\hline Average & 30 \\
\hline Cold & 120 \\
\hline
\end{tabular}

ALTERNATE ENERGY SOURCE

Sodium heaters are capable of operation with \#2 fuel oil. 0il storage available at LMEC by modification of existing government facility.

RELIABILITY OF EXISTING H-1 35 MW HEATER WHEN OPERATED IN PARALLEL WITH ALTERNATE HEATER

The reliability of the $\mathrm{H}-1$ heater is currently being investigated in connection with DHX test planning. The heater experienced a tube failure in 1966. Following repair the heater has operated reliably and free of failures. The heater has operated 6700 hours with the main burners at temperatures up to $1300^{\circ} \mathrm{F}$ and an additional 5100 hours with the pilot burners between $350^{\circ} \mathrm{F}$ and $850^{\circ} \mathrm{F}$. LMEC anticipates that trouble free performance of the $\mathrm{H}-1$ heater will continue in the future. Planned inspections and analysis currently underway are designed to verify and quantify this expectation.

LMEC preliminary assessment indicates that the $\mathrm{H}-\mathrm{l}$ heater and alternate heater could be operated in parallel at steady state conditions without significant additional development effort. Parallel operatiolı for transient tests would require development of a new control system. Such a mode of operation is problematical because of possible limitations in the transient capability of the existing $\mathrm{H}-1$ heater.

ASSESSMENT OF CONDITION OF HALLAM PUMPS FOR USE IN THE SCTI

Two HALLAM pumps are stored disassembled in LMEC warehouses. All parts are believed to be in satisfactory condition. LMEC recommends the following inspections for qualifying these pumps for use in the SCTI.

1. NDT examination of welded areas.

2. Surface examination of wearing areas.

3. Dimensional checks of alignment fits.

4. Electrical checkout of drive speed control system and preheaters. 
CODES AND STANDARDS

LMEC comments on GE's draft codes and standards approach have been incorporated in the GE recommendation included in Attachment IV. LMEC agrees with this approach for SCTI modifications.

CAPABILITY OF SCTI TO PRODUCE S.G. DESIGN BASIS TRANSIENTS

The $35 \mathrm{MW}$ alternate is designed to generate and accept representative steam generator transients without the need of protective bypass loops. LMEC experience during transient testing of the MSG is that the preferred method of imposing transients is by performing the system operation which causes the transient in the actual system as opposed to elaborate temperature control system provided for programming transient tests as provided in the present SCTI to protect the sodium heater. From this standpoint, parallel operation of the alternate heater with the existing $\mathrm{H}-1$ heater will either limit the transient capability of the system or require development of a new control system which will protect the existing heater.

LMEC COMMENTS ON IMPACT OF TESTING AT LESS THAN FULL POWER CONDITIONS

a. Hydraulic and heat transfer data could be adequately extrapolated to full power from data up to $65 \%$ power.

b. Stability data obtained would be satisfactory since this data is normally obtained with reduced power conditions.

c. Leak detection is less sensitive at reduced flow conditions, therefore there would be no sacrifice of this data by reduced power operation.

d. There would be some reduction in vibration effects if full flow tests were not run. However, water tests are considered preferable for vibration testing due to severe instrumentation limitations in obtaining vibration data in an elevated temperature sodium environmenty

e. Identical thermal transients could not be produced with less than full power tests. However, full power tests will not result in transients identical to the plant transients because of differences between the test and plant system, which would result in somewhat different transient rates. Testing at reduced flow rates in proportion to the power might compensate for this difference to some degree. The reduction of $\log$ mean $\Delta T$ would be less than power reduction due to reduction of overall heat transfer coefficient $(U)$ for reduced power and flow conditions. 
CONCLUSIONS

a. GE concurs with LMEC that SCTI modifications for superheater testing only (Alternate A) should be based on the non-condensing steam system approach. However the steam compressor required for this approach is considered a development item which may adversely impact the proposed schedule. This alternate has the further disadvantage that it would eliminate evaporator test capability from the SCTI without major facility modification.

b. GE considers the $2 / 3$ power $2 / 3$ flow ( $70 \mathrm{MW}$ ) arrangement for testing combined superheaters and evaporators the optimum utilization of the SCTI for prototype steam generator testing recognizing that special transient migration equipment may be required to protect the existing $\mathrm{H}-\mathrm{l}$ heater during SG design transient testing. This arrangement will also allow evaporator tests up to $70 \mathrm{MW}$ if a superheater was unavailable.

c. GE considers the $1 / 3$ power superheater evaporator test arrangement an economically attractive approach with the highest assurance for the earliest start of testing of prototype SG units. Further this arrangement would provide a test bed for models of future steam generator designs.

\section{RECOMMENDATION}

GE recommends that $A E C$ provide approval-in-principle to initiate preliminary design by LMEC of SCTI modifications required for the $2 / 3$ power $2 / 3$ flow (70 MW) alternative. Initial engineering should include an evaluation of the requirements for protecting the existing $\mathrm{H}-1$ heater during $S G$ test transient conditions. 
BREEDER REACTOR OPERATION

Sunnyvale, California

January 24, 1974

\author{
cc: F. E. Tippets \\ J. M. Case \\ H. Matthiesen \\ R. Meyer \\ J. J. Regimbal \\ L. R. Boyd \\ R. Lockhart
}

T0: J. R. Peterson

FROM: J. C. AnIos $\Rightarrow$

SUBJECT: $\quad$ Trip Report - LMEC/GE Meeting on S.G. Test Alternatives, January 18, 1974

1. Principal LIIC participant in this meeting was Bernie Deitz. K. L. Alder participated in the discussion on the impact of full vs partial pover tests and the results of the meeting were reviewed with R. Ginera.

2. GE provided LMEC with Attachment I. to summarize the status of the GE study and provide the basis of items to be discussed.

3. LIMEC provided CE. with Attachment II in response to specific questions from GE. LIMEC advised that the first 11 pages of this information had been given to the RRD Facility Branch by Mr. J. C. Cochran. GE noted that the Alternate $C$ (70MW) P\&I and cost estimate was based on 65\% sodium flow to motch the $65 \%$ power, instead of $100 \%$ flow as used for this alternate in the GE study. LMEC agreed to provide a $\$ /$ of the Alternate C estimate to GE by January 24, 1974. (See Attachment III).

4. LIMEC indicated that the steam drum and recirculation pump were included in the estimate, but they strongly recommended that these items be procured by GE as test articles rather than by $L I I[C$ as faci]ity items to assure maximum prototypicality.

5. LMEC reviewed the GE draft codes and standards approach (Attachrent IV) and agreed with this approach in principal, and made several suggestions which are noted on the attachment.

6. Preliminary umbrella transients as described in GE letter, GE-AI-PAGIK0.0-0712, were discussed. GE indicated that they would develop the design basis transients for the test facility design criteria from tnis umbre!la as additional analysis code data becomes available. LMEC indicated the SCTI modifications could probably produce transients similar to those selected for the S.G. design. They also pointed out that they were successful during MSG testing in imposing transicnts by performing the systen optration which causes the transient in the actual system (i.e., loss of sodium flow snut off facility sodium pump), as opposed to use of the elaborate temperature control systen provided for nrnaramming transient tests 
7. A discussion of the impact of less than full power testing resulted in the following LIIEC comments, based on a reduced power level of $65 \%$ of full power, as proposed for Alternate C:

a. Hydraulic and heat transfer data could be adequately extrapolated to full power from data up to $65 \%$ power.

b. Stability data obtained would be satisfactory since this data is normally obtained with reduced power conditions.

c. Leak detection is less sensitive at reduced flow conditions, therefore, there would be no sacrifice of this data by reduced power operation.

d. There would be some reduction in vibration effects if full flow tests were not run. However, water tests are considered preferable for vibration testing due to severe instrumentation limitations in obtaining vibration data in an elevated teluperature sodium environinent.

e. Identical thermal transients could not be produced with less than full power tests. However, full power tests will not result in transienis identical to the plant transients because of differcices between the test and plant system, which would result in somewhat different transient rates. Testing at reduced flow rates in proportion to the power might compensate for this difference to some degree. The reduction of log mean $\Delta T$ would be less than power reduction due to reduction of overall heat transfer coefficient (U) for reduced power and flow conditions.

8. LMEC reaffirmed their offer to support GE's presentation to RRD of the SCTI alternatives and reemphasized the need for an agreement of principle witi AEC to allow LMEC to initiate engineering at the earliest possible date to meet the nrojected scherule for start of test oderation. 


\section{Attachment I}

GE/LMEC MEETING

JANUARY 18,1974

on

PROTOTYPE STEAM GENERATOR TEST ALTERNATIVES

I. SUMMARY STATUS OF GE-S.G. TEST ALTERNATIVES STUDY REQUESTED FROM GE BY RRD

a. GE MET WITH RRD/W ON DECEMBER 14, 15, 1973 AND PRESENTED THE RESULTS OF THEIR EVALUATION BASED ON THE GROUND RULES PROVIDED BY RRD.

b. GE RECOMMENDED FULL POWER S.H. TESTING AT SCTI AND FULL POWER EVAPORATOR TESTING AT EBR-II. GE RECOMMENDED NEAR TERM IMPLEMENTATION TO INCLUDE PREPARATION OF CONCEPTUAL DESIGN AND COST ESTIMATES BY ANL AND LMEC FOR FACILITIES FOR THE RECOMMENDED ALTERNATE.

c. RRD REQUESTED ADDITIONAL DETAIL FROM GE ON THREE ALTERNATES A, C, AND F TO INCLUDE THE FOLLOWING BY FEBRUARY 1, 1974

7) DESIGN BASIS CODES AIID STANDARDS

2) DESIGN BASIS TRANSIENTS

3) IMPACT OF LESS THAN FULL POWER TESTS

4) UPDATED COST DATA

5) LIST OF AVAILABLE EQUIPMENT

d. GE REQUESTED ADDITIONAL INFORMATION FROM ANL AND LMEC PRINCIPALLY IN THE AREA OF 4) \& 5) TO AID IN THIS STUDY.

II. PURPOSE OF THIS MEETING

a. OBTAIN AND REVIEW LMEC RESPONSE TO GE QUESTIONS.

b. DISCUSS CODES AND STANDARDS BASIS FOR FACILITY MODIFICATION.

c. DISCUSS TRANSIENT CONSIDERATIONS

d. OBTAIN ANY COMMENTS LMEC MAY HAVE ON IMPACT OF FULL POWER VS. PART POWER TESTS.

e. RESOLVE PROCEDURES TO BE FOLLOWED FOR IMPLEMENTING ADDITIONAL ENGINEERING EFFORT BY LMEC TO PROVIDE COIICEPTUAL DESIGIN AND COST ESTIMATES FOR SELECTED FACILITY MODIFICATIOIS. 
TABLE 1

SUMARYY OF DEMO PLANT STEAM GEMERATOR NTERRATE TEST APPROACHES

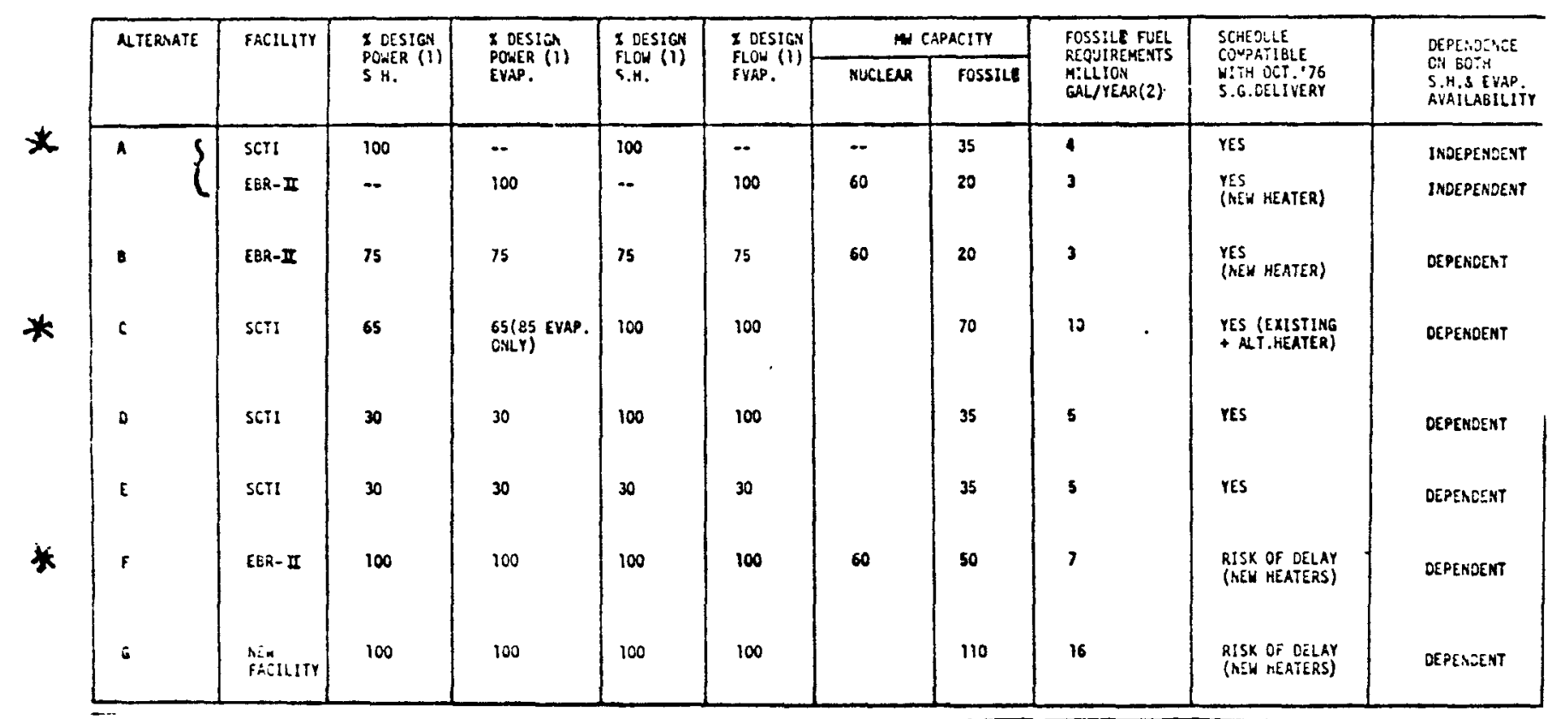

i.oTES:

1. SASED ON 3 + 3 DENO PLANT S.G. MEJLLE GONFICURATION. 
SCHEDULE FO. ACILITY MODIFICATION

FOR DEMO PLANT S.G. TESTING

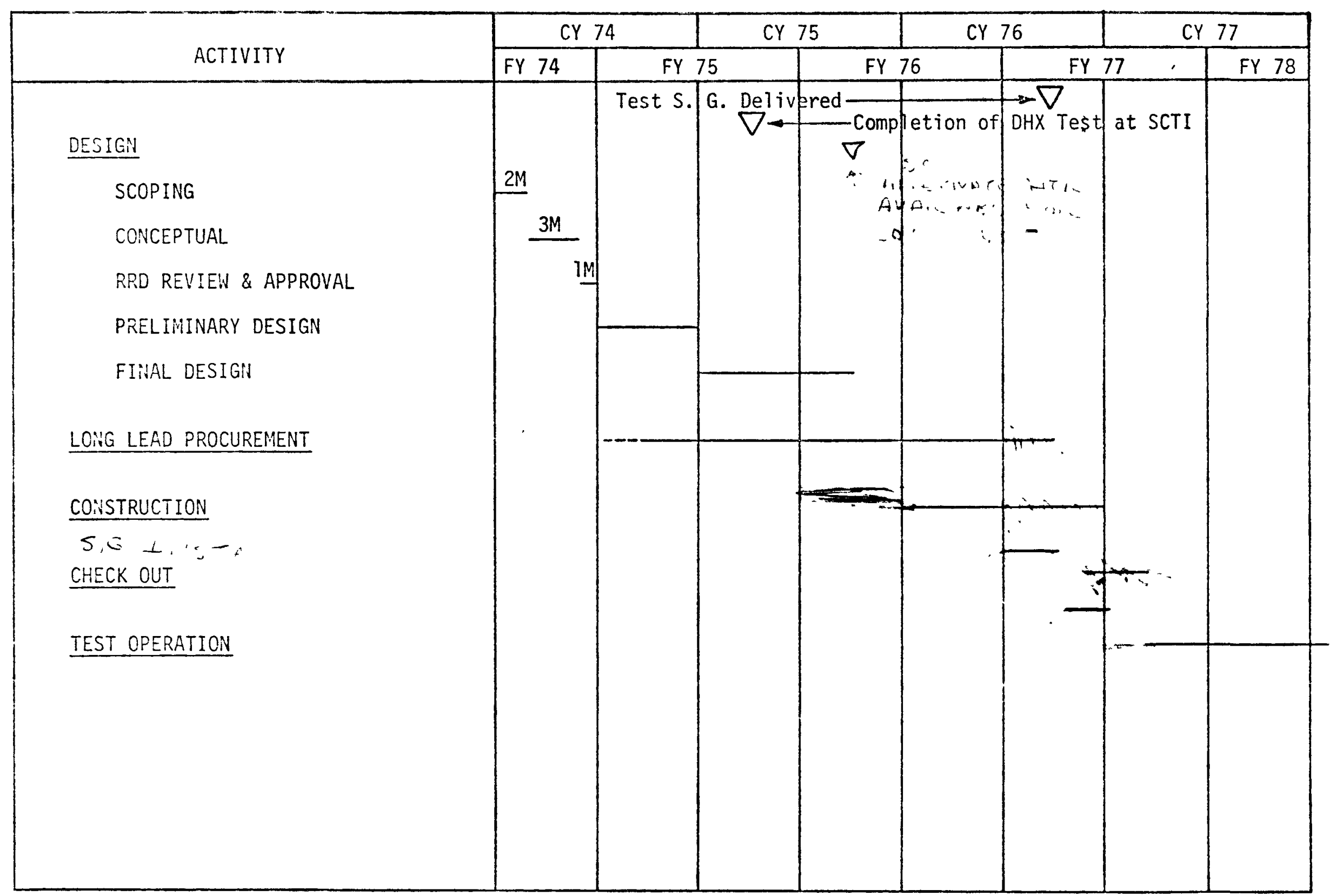


AI Stem Goneritor

$3: 3$

0
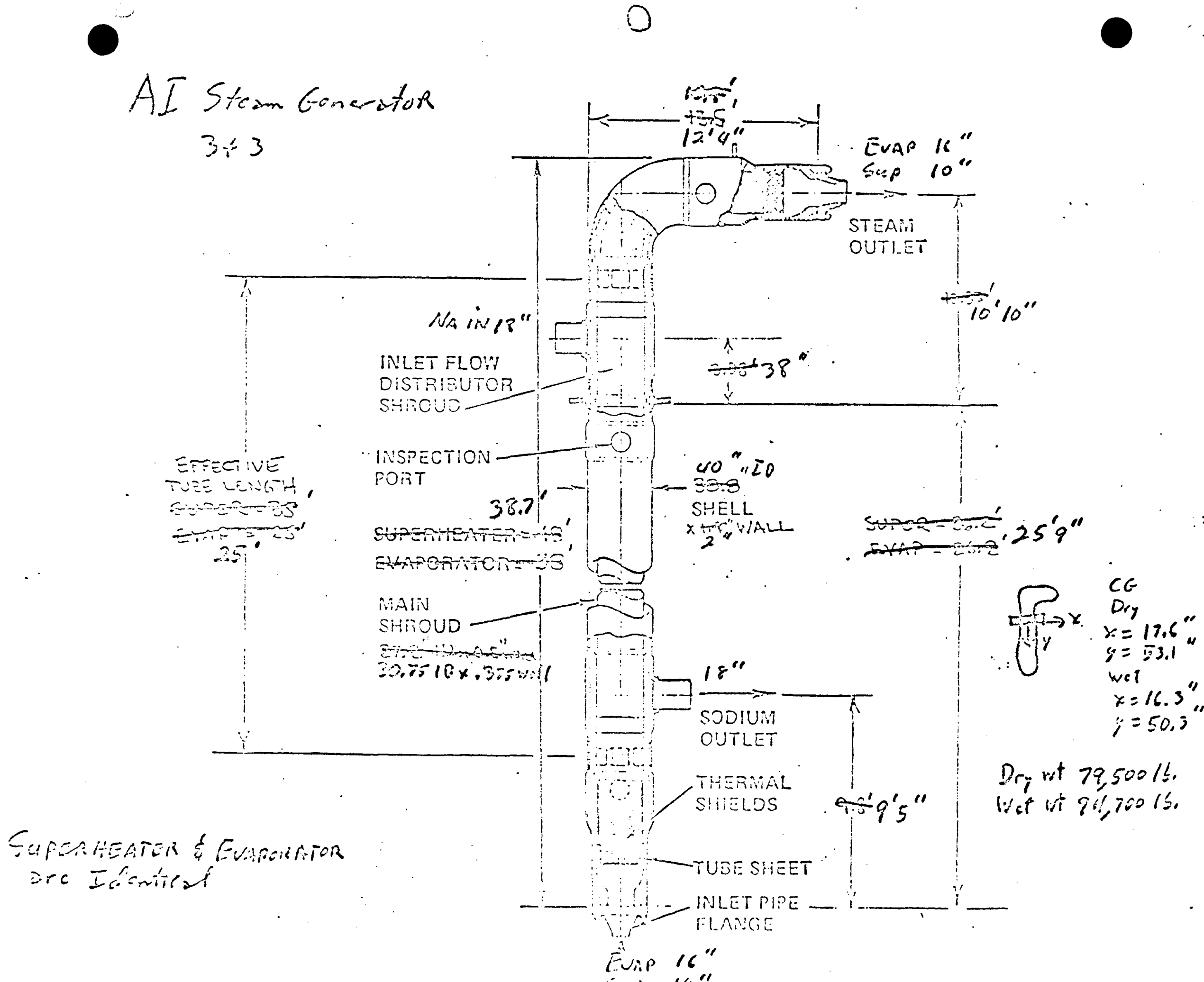


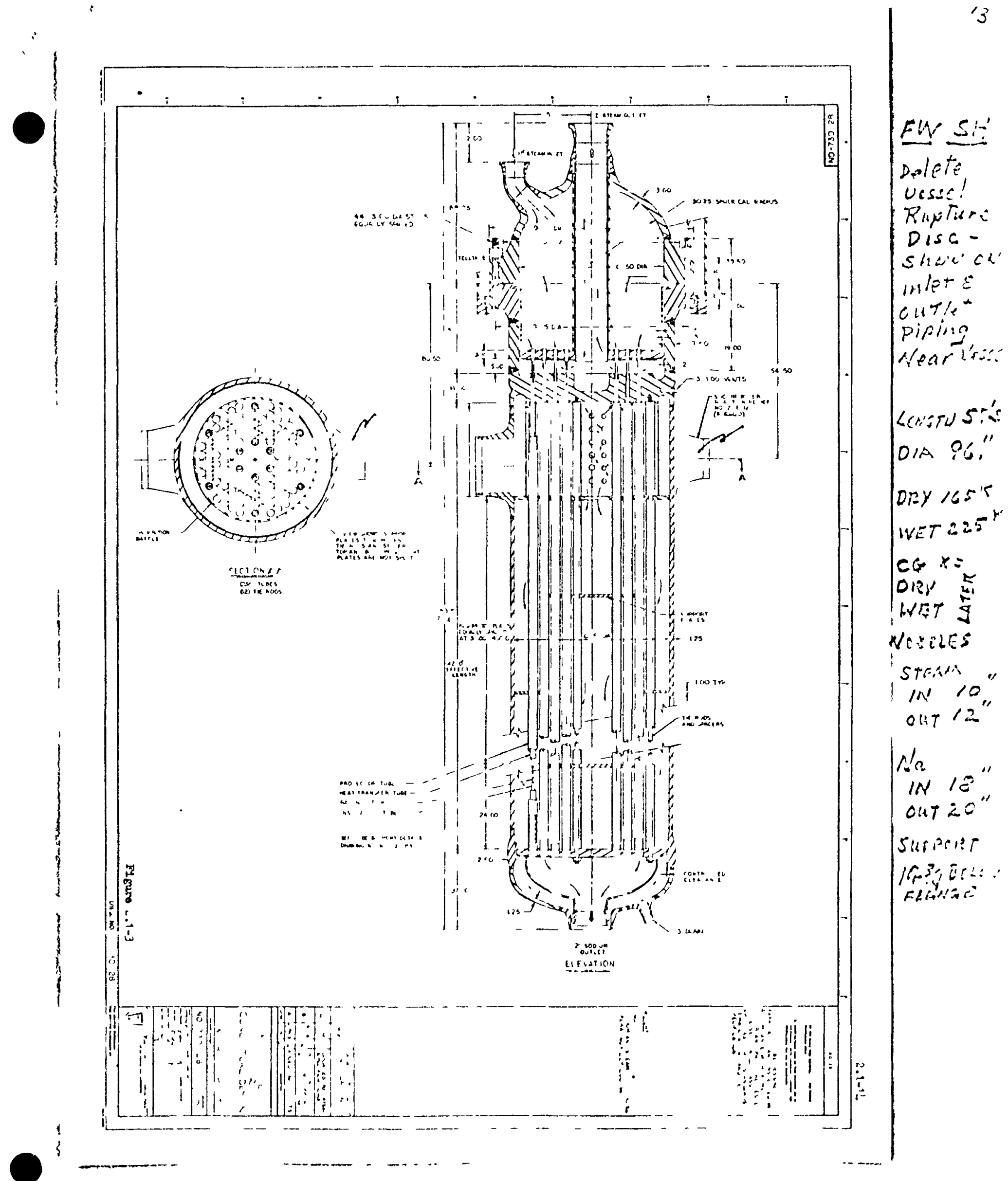




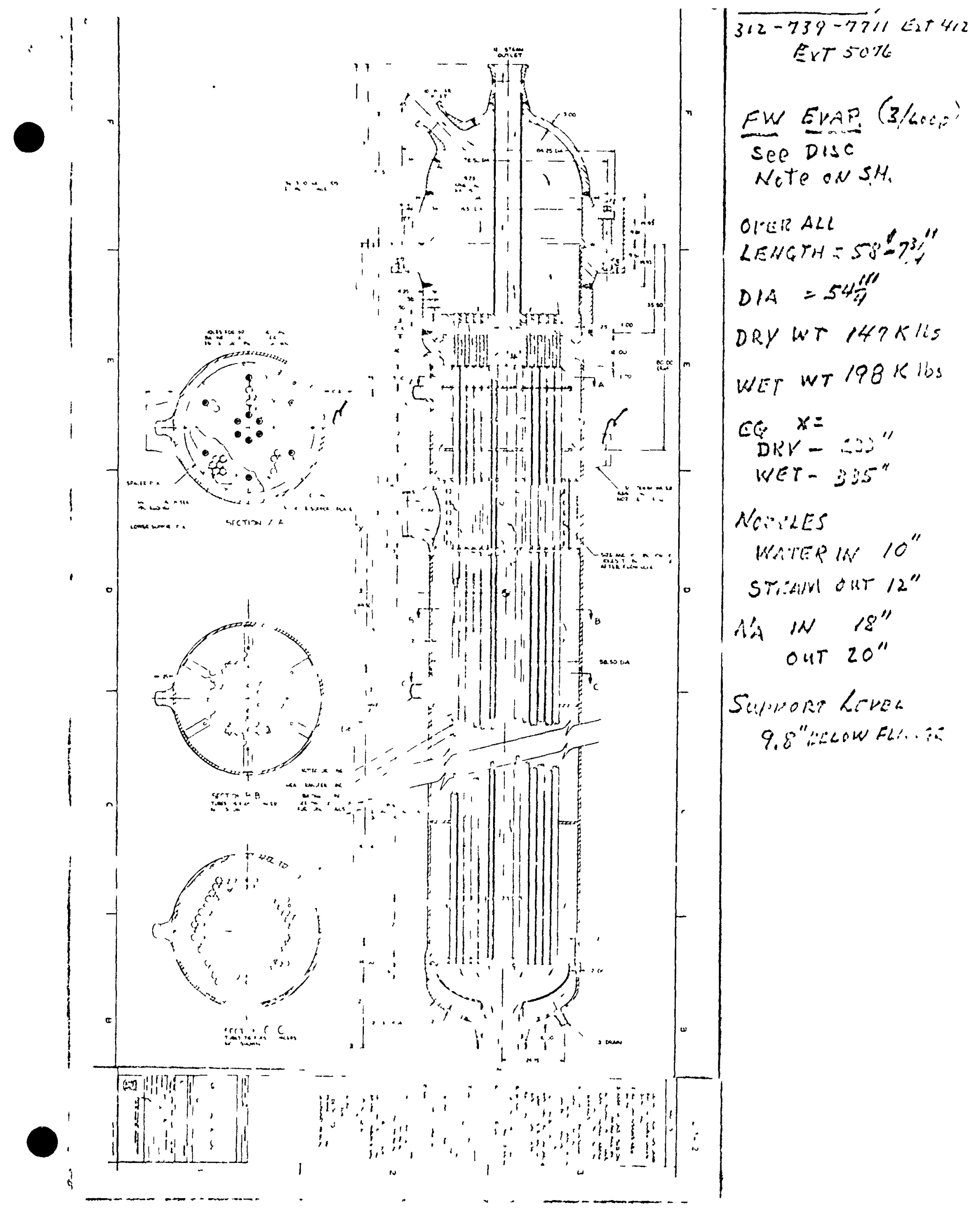




\section{HTTI7CHMI ENT II January 11, 1974}

DEMO PLANT STEAM GENERATOR TESTING AT LMEC

The primary purpose of the SCTI is to perform liquid metal heat exchanger testing. The primary fuel used at LMEC for large scale testing is natural gas supplied through a $6 "$ high pressure main directly to the SCTI site. The main is capable of delivering $>200$ MWT of gas of which 3.5 MWT is fixed and the remainder is interruptible. The Southern Calif. Gas Co. projects that in 1976 gas usage may be interrupted for 30 days during the year. LMEC has a plan to provide fuel oil to avoid interruptions to testing.

The projected modifications schedule for demo plant steam generator testing does not conflict with any presently scheduled testing. Present SCTI improvements in progress such as the steam/feedwater system upgrade provides the potential for stcam/feedwater system power expansion to 70 MWT. The addition of an alternate sodium heater increases the potential plant power to $70 \mathrm{iNT}$. Other components are existing at the LMEC which could be used to support $70 \mathrm{ITT}$ test capability. For example, two $7200 \mathrm{gpm}$ pumps, three 10,000 gal. fill and drain tanks and numerous other conponents are available from inventory for use in accomplishing necessary facility mods for steam generator testing.

Three alternates are shown in the following pages.

a) Superheater only test (non-condensing cycle)

b) Evaporator and superheater test $35 \mathrm{Mr}$

c) Evaporator and superineater test 70 MHT

of the three alternates, the most significant test would be that of an exaporator and superheater at $70 \mathrm{MTT}$. Nio other facility in the U.S. could be made ready for tinis test at a lower cost than the sCTI and wichin the expected delivery date for the stean senerator $(\sim 6 / 76)$. LMEC recomends that a conceptual desizn be initiated irmediately to assure test facility readings for the demo plant prototype unit.

Note: All estimates assume that the alternate heater installed and conacted to the SCTI sodium system.<smiles>C1C2CC1C2</smiles><smiles>[Li][Mg]</smiles>
i. غuent.

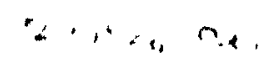

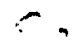

io $2 \vec{\mu}, \ldots ;-, 1$ a. $\because ; \cdots$ 


\section{SCTI Modifications Required}

Increased flow capability in sodium system, new non-condensing steam system.

Components Available

Sodium pumps (two Hallam pumps), fill and drain tank (Hallam tank)

\section{Major Components To Be Purchased}

Steam compressor with motor, dry cooling tower, blower, motor, economizer (steam-to-steam heat exchanger), preheat boiler system, sodium expansion tank, sodium-water reaction relief system, sodium piping system, steam piping system

Schedule
Required project start date
April 1974
Comence L.L. procurement
Nov. 1974
Start construction
Aug. 1975
Test article (superheater) available
May 1976
Construction complete
Oct. 1976
Commence test prozram
Jan. 1977

\section{Cost Estiriate}

$\begin{array}{lrr}\text { Engineering, Design, and Inspection } & \$ 1,383,000 \\ \text { Construction } & 4,436,000 \\ \text { Na heat transfer system } & \$ 2,200,000 & \\ \text { Steam system } & 1,200,000 & \\ \text { Plant control system } & 460,000 & \\ \text { Other components and systems } & 576,000 & 1,544,000 \\ \text { Contingency @ 20\% and fee @ 5.5\% } & \$ 7,363,000\end{array}$



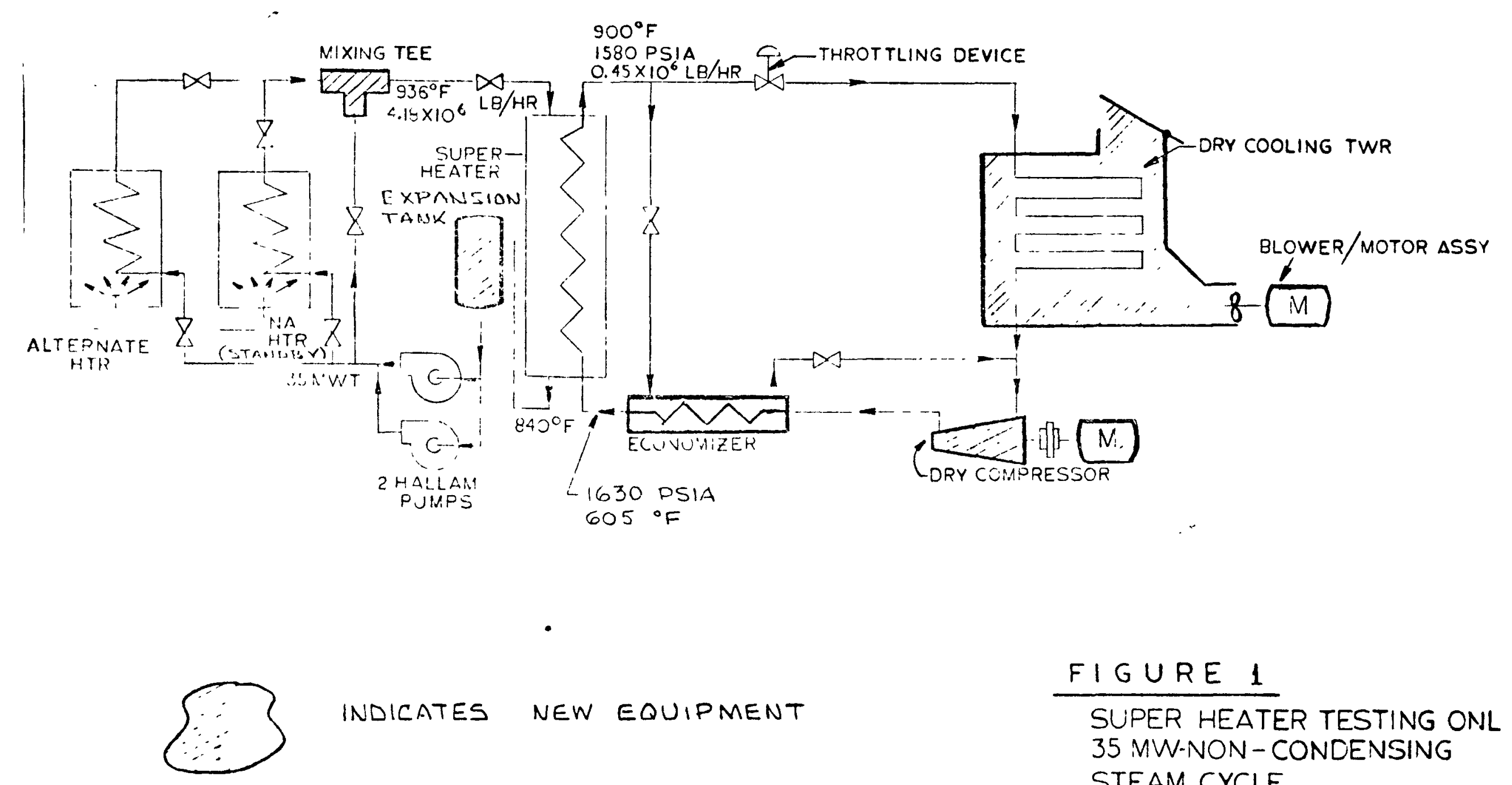
FIGURE 1
SUPER HEATER TESTING ONL 35 MW-NON-CONDENSING STEAM CYCLE


SCTI Modifications Required

Water Recirculation System - Not facility items, test article related.

Major Components to be Purchased

Steam Drum

Recirculating Pump

Blowdown Tank

Sodium-Water Reaction Relief System

Water Recirculation Piping System

Not facility items, test article related.

Schedule

Required Project Start Date - . - . . - . - December 1974

Commence L. L. Procurcment - - - . - . - May 1975

Start Construction - - . . - . - . . - January 1976

Test Article Available _ . . . . . . . . . . . July 1976

Construction Complete - . - . - . . . - November 1976

Commence Test Program _............. January 1977

Cost Estimate

Engineering, Design, and Inspection

Construction

$\mathrm{Na}$ Heat Transfer System Modification $\$ 560,000$

Steam \& Feedwater. System Modification

Plant Control System Modification

Other Components and Systems

Contingency@20\% and Fee 5.5\%

TOTAL PROJECT ESTIMATE
$\$ 554,000$

$1,564,000$

246,000

372,000

386,000

564,000

$\$ 2,682,000$ 

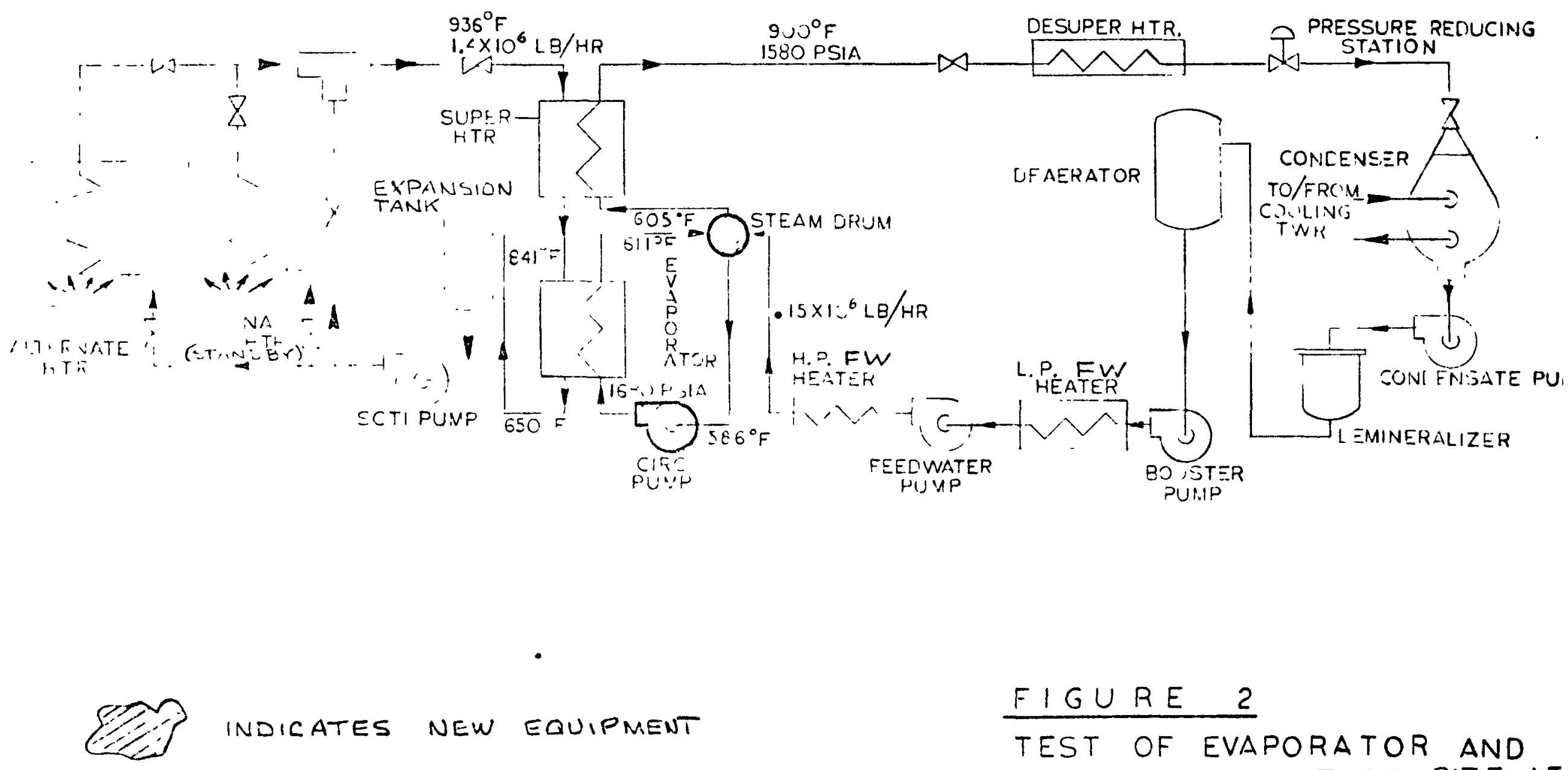

INDICATES NEW EQUIPMENT

$$
\begin{aligned}
& \text { FIGURE } 2 \\
& \text { TEST OF EVAPORATOR AND } \\
& \text { SUPERHEATER-FULL SIZE AT } \\
& 1 / 3 \text { POWER (35 MW) AND FL }
\end{aligned}
$$




\title{
EVAPORATOR AND SUPERHEATER TESTING AT SCTI (70 MUT - 2/3 POWER)
}

\section{SCTI Modifications Reouired}

Increased Flow Capability in Sodium System, Increased Flow Capability in

Steam and Feedwater System, Water Recirculation System

Components Available

Sodium Pumps (Two Hallam Pumps), Fill and Drain Tank (Hallam Tank),

Feedwater Heaters, Condenser, Condensate Pump, Condensate Booster Pump

Major Components To Be Purchased

Sodium-hater Reaction Relief System, Steam Drum, Recirculation Pump,

Blowdown Tank, Water Recirculation Piping system - Test Article Related

Desuperheater, Deaerator Heater, Demineralizer, Boiler Fecd Pump,

Sodium Expansion Tank, Sodiun Piping System, Steam and Feedwater Piping System

Schedule

Required Project Start Date

Commence L.I. Procurement

Start Construction

Test Article Available

Construction Complete

Commence Test Program

\section{Cost Estirate}

Engineering, Design, and Inspection

Construction

Na Heat Transfer System

Steam and Feedwater System

Plant Control Syster

Other Components \& Systems

Contingency $20 \%$ and Fee $25.5 \%$

Total Project Estinate

.
April 1974

November 1974

October 1975

July 1976

November 1976

February 1977

$\$ 2,766,000$

$\$ 6,658,000$

$\$ 2,823,000$

$\$ 1,237,000$

$\$ 1,390,000$

$\$ 1,208,000$

\author{
Total Project Estinate
}

$\frac{\$ 2,501,000}{\$ 11,925,000}$




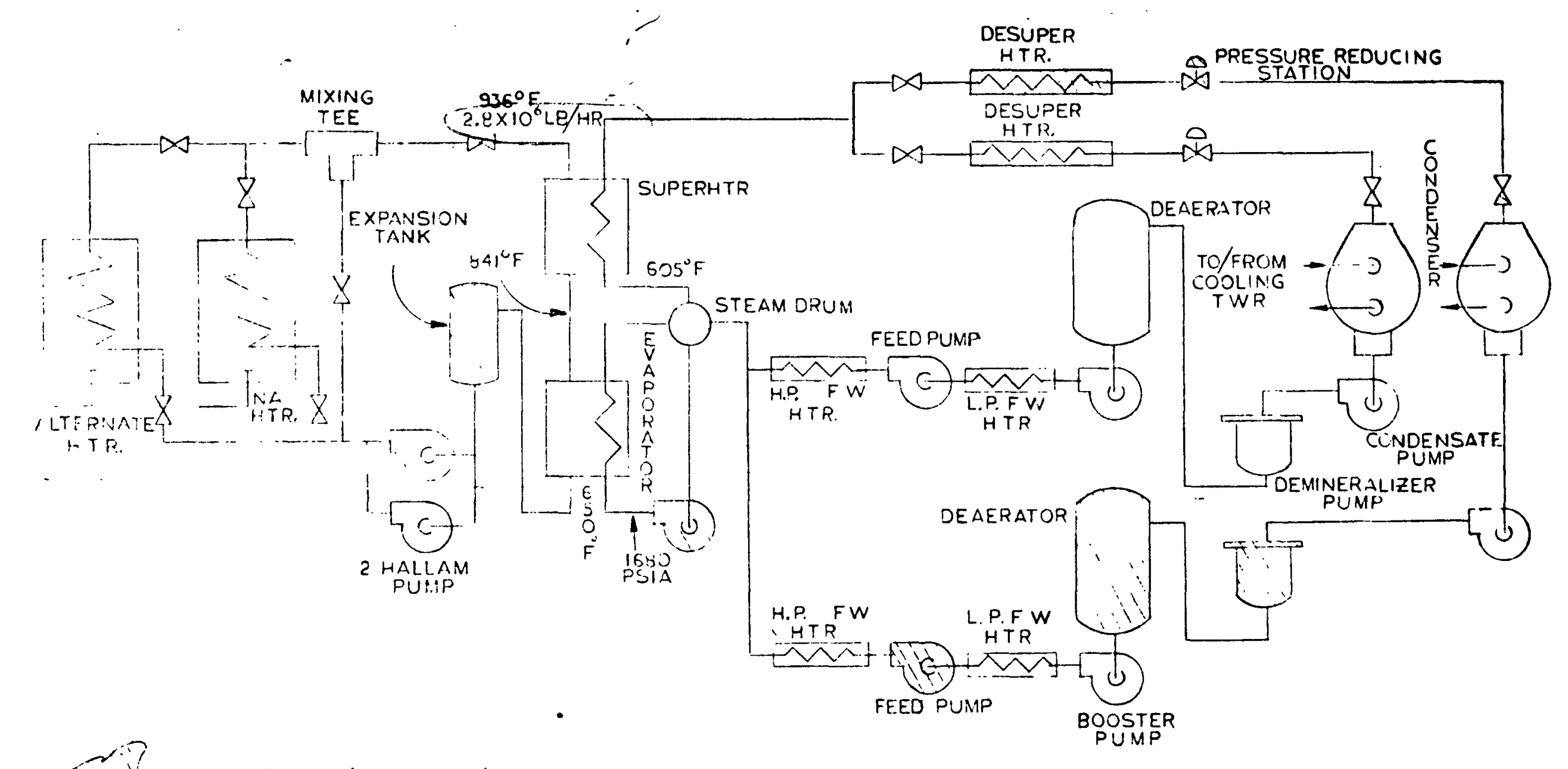

INOIGATES NEIV EQUIPMENT

\section{FIGURE 3}

TEST OF EVAPORATOR AND SUPERHEATER FULL SIZE AT 2/3, P:WWER ( $70 \mathrm{MW}$ ) AND FLOW 


\section{ALTERNATES CONSIDERED AND REJECTED}

\section{Alternate}

Evaporator and Superheater Testing Full scale, full power - $105 \mathrm{mw}$

Evaporator and Superheater Testing $1 / 3$ scale model units at

$1 / 3$ full power - $35 \mathrm{mw}$

Evaporator and Superheater Testing $2 / 3$ porver; full scale with 46 mwt turbo-generator

\footnotetext{
Superheater Testing Only Condensing steam cycle; full power - $35 \mathrm{mw}$
}

Evaporator Testing Only - $35 \mathrm{mw}$ Evaporator Testing only - $70 \mathrm{mw}$

\section{Remarks}

Rejected because of highest cost; longest lead time

Rejected by G.E. Extended lead time for full scale units unless some risks are taken by concurrent fabrication of full scale units.

Rejected: Cost of T.G. unit not offset by reduced net work required, and smaller condenser load; 2nd condenser still needed.

Power generated not significant nor useful.

Rejected because only about one-half of superheater available eneray can be recovered to cvaporate fesduater; 35 mwt fossil-iired boiler nefded alonf with 2nd condcnser and cooling tower.

Rejected because it docs not provide for any superheater testing; also, only $1 / 2$ poner level.

Although full porer evaporator testing is possible, this concept is rejected because it does not provide for superheater tests at any power level. 


\section{ENFRCY SOURCES AT LMEC FOR STEAM GENERATOR TESTING}

NATURAL GAS.-(SO. CALIFORNIA (GAS CO.)

CAPABILLTY - 6-INCH, 200 PSI MAN CAPABLE OF PROVIDING ENERGY FOR 200 MWT TEST FACILITY

AVAILABILITY - 3.5 MNT FIRM SUPPLY FOR NEXT 5 YEARS

RILLINING ENERGY AVAILABLE AS INTERRUPTIBLE SUPPLY WITH THE FOLLONING DAYS PER

CUSTOMILK CLRTALLMENT PRIORITY PROJECTEI) FOR 1976:

\begin{tabular}{c|c} 
WINIER SEASON & DAYS/YEAR \\
\hline AVERAGE & 30 \\
COLD & 120
\end{tabular}

ALTERNATE ENERCY SOIRCE

SODIUY HEATERS CAN BE CAPABLE OF DUAL FUEL OPERATION - NATURAL GAS AND/OR \#2 FUEL OIL

\#2 FLA: OIL STORACE CAPABILITY AT LMEC BY MODIFICATION TO AN EXISTING GOVERNMENT-OWNED FACILITY

ALTERNATE ENERGY SOURCE ( $\$ 2$ FUFL OIL) WOULD BE USED DURING WINTER ENERGY CURTAILMENT 
DEMO PLANT STEAM GENERATOR TEST CONDITIONS

\section{SODIUM SIDE}

SUPERHEATER INLET $\left({ }^{\circ} \mathrm{F}\right)$

SUPERHEATER OUTLET/EVAPORATOR INLET $\left({ }^{\circ} \mathrm{F}\right)$

840

SUPERIEATER OUTLET $\left({ }^{\circ} \mathrm{F}\right)$

SODIUM FLOW (LB/HR)

SUPERHEATER $\triangle \mathrm{P}$ (PSI)

EVAPORATOR $\triangle P(P S I)$

650

$4.18 \times 10^{6}$

$\sim 20$

$\sim 12$

\section{STEAM SIDE}

SUPERHEATER OU'TLET'/INLET $\left({ }^{\circ} \mathrm{F}\right)$

$900 / 605$

EVAPORATOR OUTLET/INLET $\left({ }^{\circ} \mathrm{F}\right)$

$611 / 586$

EVAPORATOR INLET PRESSURE (PSIA)

1680

EVAFORATOR $\triangle P(P S T)$

50

SUPERIEATER $\triangle \mathrm{P}$ (PSI)

50

SLIPIEHEATER OUTLET PRESSURE (PSIA)

1580

STEAM FLOW @ SUPERHEATER OUTLET (LB/HR)

$0.45 \times 10^{6}$

\section{POWER LEVHL}

SULERIEATER INT

$30-40$

EVAPORATOR MWT

$70-80$

TOTAL 


\section{SUPERHEATER TESTING ONLY - 35 MWT}

The non-condensing steam system for this testing is preferred over the condensing system for reasons of cost and energy utilization. The sodium system is identical for each configuration (condensing and non-condensing), however, the cost of the steam and feedwater system and other associated equipment and system requirements for the condensing cycle is considerably more than for the non-condensing cycle. The SCTI modification for the noncondensing system for superheater testing is estimated to cost $\$ 7,400,000$ compared to $\$ 9,500,000$ for the condensing type system. Primary causes for the additional cost of the condensing type system are the requirement for the following major components and systems:

1) an additional new $35 \mathrm{MWT}$ cooling tower and water system

2) a 35 MWT fossil fueled steam generator

3) new feedwater components for a system with approximately 3 times the flow capacity of the current SCTI system (condenser, feedwater heaters, pumps, deaerator, etc.)

The condensing type system also requires 70 MWT for full power operation versus $47 \mathrm{MWT}$ for the non-condensing system.

The non-condensing system requires three components not used in the condensing system, but which cost considerably less. These are 1) an air dump desuperheater, 2) a steam turbine drive compressor, and 3) a 12 MWT fossil fueled package boiler. This system uses approximately $10 \%$ of the main steam flow $(45,000 \mathrm{lb} / \mathrm{hr}$ at $100 \%$ power $)$ to drive the compressor turbine. This auxiliary steam flow is then passed through the existing SCTI condenser and feedwater system to a 12 MWT package boiler where it is evaporated and returns to the main steam loop at the inlet to the test superheater. 
Reliability of Existing H-1 Heater When Operated

in Parallel with the Alternate Heater

The reliability of the $\mathrm{H}-1$ Heater is currently being investigated in connection with DHX test planning. Transient heater and tube temperature data during scrams from several power levels have been obtained. An inspection plan has been formulated and a program of structural analysis and capability evaluation has been outlined. The $\mathrm{H}-1$ Heater was not designed to provide temperature transients other than normal load-following on a test article; the SCTI primary system was designed to achieve upset and emergency-type test article transients by using an array of bypass loops which protect the heater and pump from severe transients.

The Alternate Heater is being designed to generate and accept test transients without the need of protective bypass loops. The control system for the Alternate Heater is being designed for operation of that heater by itself, not in parallel with the $\mathrm{H}-\mathrm{I}$ Heater.

Preliminary assessment, without in-depth analysis, indicates that the two heaters could be operated in parallel at steady state without significant additional development effort. Parallel operation for transient tests would, as a minimum, require development of a new control system. Achievability of such a mode of operation is problematical because of possible limitations in the transient capability of the existing $\mathrm{H}-1$ Heater.

The H-1 Heater experienced a tube failure in 1966 when a leak occurred at the weld between a tube and the upper header stub on the outlet header. The cause of the failure was overstress due to restrained differential thermal expansion. Cracked sections of tube were replaced with new material and the monolithic poured refractory was replaced with separated blocks. Since that time, the heater has operated reliably and free of failures throughout the Alco/ BLH and AI-MSG test programs. It is anticipated that such trouble-frec performance of the $\mathrm{H}-\mathrm{l}$ Heater will continue in the future. The planned inspections and analyses described in the lead paragraph above are designed to verify and quantify this expectaiion. 


\section{MEMORANDUM}

\section{Date: January 17, 1974}

To:

$$
\text { H. B. Dietz }
$$

720-203 T038
From: R. W. Atz

720-203 T486

Phone: 6445

Subject: Use of Hallam Secondary Sodium Pumps in SCTI

Reference: TĆR, J. Amos' GË' (Sunnyvale) to R. J. Gimera, LMEC, 12/19/73, "Steam Generator Testing in SCTI."

The third item of information requested by GE (reference) was the present condition of the Hallam secondary sodium pumps, with recommendations for inspection and tests to requalify them for operation in SCTI.

A trief summary of the status of the equipment and preliminary recommendations follow.

The se pumps were built in 1960-1961 by the Byron Jackson Pump Company (Serial Numbers 366605,366606 and 366607). They accumulated approximately 20,000 operating hours each prior to shutdown of the HNPF. They were designed to deliver 7200 GPM of $1000 \mathrm{~F}$ sodium against a head rise of 160 feet. The three pumps, their drives, speed control systems and preheater were delivered to LMEC as AEC surplus equipment.

One of the pumps (Serial Number 306607) was converted to a bearing test fixture. This conversion included modifying the pump tank, inner barrel and shaft. The drive was not used.

The remaining two pumps and all three drives are stored disassembled at repositories at LMEC and Los Angeles Division warehouses.

All parts are believed to be in satisfactory condition, being stored in dessicant-charged storage boxes. The motors and speed controls have been kept protected with'tarpaulins.

As a preliminary recommendation for assessing usability of these pumps for $\bigcup_{t<}$ SCTI, the following is recommended:

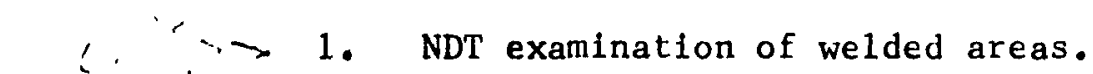

$\begin{array}{lll}3 & 20 & 2\end{array}$

, 4 .

3. Dimensional checks of alignment fits.

4. Electrical checkout of drive, speed control system and preheater. 
Memo to H. B. Diets

$-2-$

$74-203-07-27$

A copy of Byron Jackson Test Curve T-24142-1, a typical water performance test for these pumps, is attached for your information.

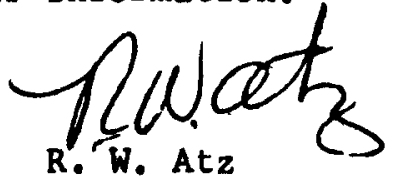

R. W. At

Mechanical Components

dc: J. F.'Horning $5:$....

C. C. Conner

J. 0. Bates

R. J. Gimera

R. J. Beeley, AI

J. $\mathrm{Ha} 11$

K. L. Adler 


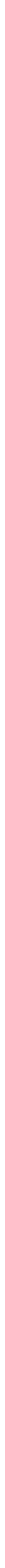




$\begin{array}{ll}\text { FROM: } & \text { Jack Amos } \\ \text { COMPANY: } & \text { GE } \\ \text { DEPT: } & \\ \text { AODRESS: } & \begin{array}{l}\text { Sunnyvale, California } \\ \text { PHONE: }\end{array} \\ & (408) 297-3000, \text { EXt. } 533\end{array}$

To: H. B. Dietz $\mathrm{BO}$,

COMPANY: LMEC

DEPT: $\quad$ 720-203

ADDRESS: Canoga Park, California PHONE: (213) 341-1000, Ext. 6387

DATE OF CALL $1 / 22 / 74$

TIME OF CALL 3:00 PM

SUBJECT:

Additional Cost Details for 70 MWT Steam Generator Thermal Testing at SCTI

SUMMARY, HIGHLITES, KEY POINTS, AGREEMENT, COMMITMENTS:

Mr. Amos requested a cost estimate for modifications to the SCTI for evaporator and superheater testing at $70 \mathrm{MWT}$ thermal with full flow in the sodium system.

The previous estimate provided by LMEC was for reduced flow in the sodium system but full delta $T$. I agreed to provide this information on Wednesday or Thursday of this week.

\section{$1 / 23 / 74-4: 00 \mathrm{PM}$}

I provided the following cost information to Mr. Amos on a full flow $\left(4.18 \times 10^{6}\right.$ $\mathrm{lb} / \mathrm{hr}$ ) in the sodium system. This cost estimate is based on the use of an FFTF thermal sodium pump and a pipe size of $14^{\prime \prime}$.

\section{COST ESTIMATE}

Engineering, Design, and Inspection

Construction

Na Heat Transfer System

Steam and Feedwater System

Plant Control System

Other Components and Systems

Contingency @ 20\% and Fee @ 5.5\%

$$
\begin{aligned}
& \$ 3,069,000 \\
& \$ 8,678,000
\end{aligned}
$$

$\$ 4,843,000$

$\$ 1,237,000$

$\$ 1,390,000$

$\$ 1,208,000$

$$
\frac{\$ 3,124,000}{\$ 14,871,000}
$$

$\mathrm{HBD}: 1 \mathrm{~h}$

\section{Distribution:}

K. L. Adler, J. O. Bates, J. C. Cochran, W. S. DeBear, R. J. Gimera, L. R. Iwanicki, S. D. Whitten AEC - H. Feinroth, J. Montgomery - RRD-HQ, A. Kelley-RRD-SO, $\overline{\mathrm{SAN}}$ - J. L. Spencer-CP $\overline{\mathrm{GE}}$ - Jack Amos 
RECOMMENDED CODES AND STANDARDS APPROACH

The steam generator test alternatives under consideration involve nodifications and additions to existing facilities utilizing, where applicable, available components to provide a suitable test bed for prototype steam generator units. Design and construction of the facility modifications to the highest level of present day nuclear standards is neither consistent with the utilization of existing facilities which were designed and constructed to the level of standards existing at the time of their construction or necessary to assure an appropriate level of quality to meet the requirements of a test facility for tine intended application.

GE recommends that the design, fabrication and test of the facility modifications, and additions be based on the current edition of the codes and standards to which the facility or component was originally designed and built, (i.e., hSliE Boiler and Pressure Vessel Code and ANSI B31.1 Power Piping Code)upgraded where applicable by additional material requirements, inspection procedures, welding requirerients, cleaning and handling requirements, etc. based on applicable RDT standards.

Requalification of existing components would be based on the edition of the code to which the unit was originally constructed. Hovever, use of a component built to a lower level of codes and standards than the system to wich it with be added will not be permitted.

WCL $D$

Specific codes and standards to be applied to individual components and system modifications will be identified in the preliminary SDD prepared during the con-

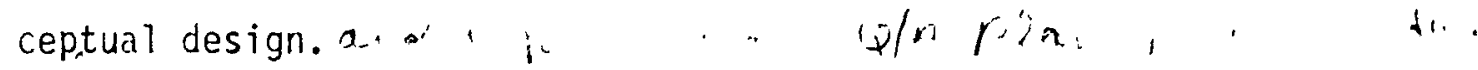

$\mathrm{C}^{-} . . . \%$ \%

Recommended general guidelines for codes and standards for facility modifications are as follows:

1. Al1 new components for sodium systems shall meet the requiroments of the latest addition and addendi of Section VIII vivision 1 - ASilEBEPVC. In addition, when considered appropriate, design analys is methods in accordance with INB-3000 of Section III ASHL-ECAPV will be employed. For high temperature corditions this allalysis shall be performed using the applicable design rules and stress limils of ASiE B\&PVC Case 1331-8. 
2. All sodium system material shall meet the requirements of Section II ASIME B\&PVC and where applicable, shall be upgraded by additional quality assurance requirements based on-" the appropriate faI material standazd.

3. A11 new sodium piping shall meet the requirements of the latest addition of ANSI B31.1 Power Piping Code-In-addicion, where applicable -requirements of ASME B\&PVC Section III, Class 2 piping sub- assemblies shall be applied.. . u. ' , 1

4. All steam system piping and components shall meet the requirements of AINSI B31.1 Power Piping Code or Section VIII - Division 1 ASME B\&PVC.

5. Requalification of existing components shall meet the requirements of the code edition to which the component was originally designed and constructed. No component which was originally built to a lower level of codes and standards than that applied to theisystem in which it is to be used, will be accepted.

6. SDD's will be prepared in accordance with RDT Standard F1-2T.

7. All quality assurance requirements" shall be based on the provisions of RDT Standard F2-2. 


\section{JUSTIFICATION - RATINGS VS MODEL SIZE}

(Refers to Table $V$ and Figure 1 of Text Section 3.0)

OBJECTIVE NO. 1 - Exercise and Perfect Manufacturing and Q.A. Techniques Ahead of First Demo Unit Fabrication

Important items here in decreasing order of importance are: tube-sheets with heater tube weld preps., tube to tube-sheet welds (and/or end cap welds), tube support (and/or protector tube arrangement), tubing, tube-sheet to vessel welds, pressure vessel, sodium nozzles, sodium inlet and outlet plenum regions, water inlet and outlet regions, and miscellaneous mechanical details. Obviously, only the $100 \%$ size test model will provide a prototypic exercise in all of these areas and, therefore, rates $100 \%$. A single tube model provides little more than a one heater tube exercise with a far from prototypic tube-sheet or tube-sheet weld and only rates 15\%. The 3-7 tube model does require a small tube-sheet forging with enough tube-sheet welds to test repeatability and a full scale limited number representation of the tube support structure. The rest of the manufacturing elements are present in miniature scale, thus a rating of $50 \%$ is awarded. The $33 \%$ and $65 \%$ sizes rate progressively higher with ratings of $75 \%$ and $80 \%$, respectively.

OBJECTIVE NO. 2 - Give Designer Necessary Confidence to Remove Over-Conservatism from First-of-Kind Design

The principal area of concern here is in the area of required heat transfer surface. A single tube design, although capable of giving better local heat transfer data than the larger models, can only be rated $30 \%$ since there would remain major unanswered questions regarding sodium side flow maldistributions, water side flow maldistributions, thermal maldistributions in the sodium inlet region, effect of plugged tubes, effect of by-pass flows, etc. The full size model would give the designer the complete situation with all prototypic effects present. The 3-7 tube model will also have all the effects present, but it is necessary to extrapolate the results to the larger size; thus a rating of $50 \%$ was assigned. The other sizes were rated progressively higher as they approached the prototype since the required extrapolations are smaller. 
OBJECTIVE NO. 3 - Proof-Test of Completeness of Design and Operating Assumptions Provide Remedies for Deficiencies

This objective deals with those surprises that often occur in testing which were not anticipated in the design. The single tube model has a low probability of turning up this type of deficiency in the design because most of the prototypic hardware is missing in the test model and because the test loop is scaled down so severely, it was assigned a 15\% rating. The 3-7 tube model also rates a low $40 \%$ because the multi-tube model, although it stands a better chance of turning up deficiencies, is still an extreme scale for both model and loop. The larger models were rated between 85 and $100 \%$.

OBJECTIVE NO. 4 - Proof-Test of $\mathrm{Na}_{-} \mathrm{H}_{2} \mathrm{O}$ Boundary Elements Under Effects of Thermal Transients, Friction, Pressure, Thermal Expansions, Flow, Vibration, Wear, Etc.

This objective deals with the probability of producing a water to sodium leak in one of the tubes or tube-sheet. Normally the probability would be proportional to the number of tubes present in the test model but a tube does not have to fail in the test to identify a problem area. For example, evidence of severe tube wear, vibration, or thermal oscillations in the test would be valuable information. Therefore, the ratings of $5 \%$ and $30 \%$ for the 1 tube and 3-7 tube models, respectively, are higher than the proportional number of tubes. To get statistically meaningful data on faulty welds or tubes, however, more tubes are needed. The larger models are, therefore, progressively rated $85-100 \%$.

OBJECTIVE NO. 5 - Proof-Test of Water Side Components Under Prototypic Uperating Conditions - Thermal Transients, Thermal Expansions, Seals, Corrosion, Pressure Loads, Etc.

The concern here is mainly in the steam plenum area where the heavy forgings, heads, bolted flanges, and tube-sheets are exposed to severe pressures, temperatures, and thermal expansions particularly when exposed to the therilal transients. In this, the small models are very inadequate (especially the 1-tube model) and only rate $15 \%$ and $30 \%$. The rating would have been lower except tinat the information on corrosion should be valid. The larger models rate progressively higner between $50 \%$ for the $33 \%$ size to $100 \%$ for the full size model. 
OBJECTIVE N0. 6 - Proof-Test of Sodium Side Components Under Prototypic Operating Conditions - Thermal Transients, Thermal Expansions, Seals, Wear, Corrosion, Etc.

This objective deals with all the components that are bathed in sodium. Examples are pressure vessel, pressure vessel nozzles, flow shrouds, inlet plenums, outlet plenums, tube support structure, heater tubes (and/or protector tubes), sodium seals, by-pass flow arrangements. The 1 -tube model was rated at $10 \%$ becuase $90 \%$ of the critical components mentioned above are missing and the operating conditions with respect to tube wear, sealing, and by-pass flows are either missing altogether or are far from prototypic. The 3-7 tube model provides a highly scaled down version of all the sodium side components which means that heavy reliance on scaling the results will be required. Because of this a rating of $50 \%$ was assigned. The larger test models were rated $80 \%-90 \%-100 \%$ since the hardware becomes progressively more prototypic and far less scaling of the test results is required.

OBJECTIVE NO. 7 - Provide For Improved Modification of Design Prediction, Overall Thermal Performance and Heat Transfer Coefficient Data

The best heat transfer data measurements can be obtained from a single tube test except that the sodium shell side flow channel may be non-prototypical. An example would be an annular flow region to simulate a triangular pitch array of tubes. Even if the flow channel is outfitted with dummy tules, these surfaces would be non-heat transfer surfaces. The single tube test is easiest and best for applying heat transfer instrumentation. Therefore, a rating of $80 \%$ was assigned to the single tube tests. The 3-7 tube models, altinough more difficult to instrument, do provide a more prototypic sodium flow channel with adjacent heated tubes. The data obtained wil1, therefore, be more prototypic. But as more tubes are added, it becomes more difficult to single out the local performance of one tube. Heat balances must be made on a gross basis for all tuives. The 3-7 tube model is probably near the optimum size for heat transfer evaluations and is rated at $90 \%$. As the model size becomes larger approaching $100 \%$ the ability to single out and measure the performance of any one tube in the tube bundle becomes more difficult. Thus, the ratings are reduced in the larger sizes to the $40 \%$ to $50 \%$ level. 
OBJECTIVE NO. 8 - Provide Data On Shell Side Flow Distribution and Pressure Losses

There is no sodium flow distribution problem in a single tube model since there is only one tube. Because the sodium channel is so non-prototypical, the pressure loss data measured is of little practical value either. This accounts for the low rating of $5 \%$ for the single tube test in muting objective ilo. 8 . The 3-7 tube test was rated at $20 \%$ because the sodium flow channel is becoming somewhat more prototypical, but the inlet and outlet plenum regions are not correctly modelled. In addition, measurements of local velocity vectors (magnitude and direction) are next to impossible in a sodium heated steam generator. Such measurements are best obtained from water flow tests. But the sodium heated models can be instrumented with thermocouples which combined with a knowledge of the velocity vectors from the water flow tests can give a fairly accurate picture of the flow and thermal maldistributions on the sodium side. Because of the need for supplemental water flow tests, the ratings for the larger model sizes range from $50 \%$ to $70 \%$.

OBJECTIVE NO. 9 - Determine Potential For Sodium Flow Oscillations Due To Pump and/or Cover Gas Actions

With a single cover gas space in the pump tank the potential for sodium flow oscillations probably eliminated. Nevertheless, this characteristic must be checked since it has been a problem in past tests. It is important in these tests that every part of the system and test model be as prototypic as possible. For this reason, the single tube test was rated $10 \%$, the 3-7 tube model was rated $40 \%$, and the larger models were rated between $80 \%$ and $100 \%$ as they approached full size.

OBJECTIVE NO. 10 - Determine Potential For Sodium Temperature Oscillations and Maldistributions

Temperature oscillations can occur either through flow oscillations or through intermittent mixing of two sodium streams at different temperatures. Temperature maldistributions in the sodium result from: 1) cooling of sodium in inlet region and outlet regions in traversing the outer tubes to gain ingress or egress to the center tubes, 2) flow starvation due to a higher resistance through one portion of the bundle than another, 3 ) hot streamers of sodium caused by plugging leaking tubes, and by-pass flows which transfer heat into the bundle at local regions. 
It is obvious from the above that a single tube test will produce very little information in these problem areas. This justifies a rating of $10 \%$. The $3-7$ tube model does have all the above mechanisms present but in a very small scale which may be difficult to extrapolate from; thus a rating of $40 \%$ was assigned. The larger models provide progressively more confidence and are rated $80-100 \%$.

OBJECTIVE NO. 11 - Measure By-Pass Flows on Sodium Side at Seals, Plenums, Support Plates, Etc.

There is no way to directly measure the by-pass flow in a steam generator test model. Use must be made of thermal analysis matched up with thermocouple readings to obtain an indirect evaluation of the by-pass flow. This procedure can be strengthened by running water flow tests and measuring the by-pass flow velocity. The single tube test model would have no by-pass flow and must be rated $0 \%$. The 3-7 tube model will exhibit the required characteristics but because of the very small scale, is rated at $30 \%$. The larger models are progressively more effective and are rated from $60 \%$ to $70 \%$. A rating of less than $100 \%$ was assigned because the by-pass flow measurements obtained are indirect as explained earlier.

OBJECTIVE NO. 12 - Provide Data on Water-Side Flow and Temperature Distribution Between Tubes

With only one tube it is impossible to evaluate flow and temperature maldistributions in the steam generator with a single tube model. Thus, a rating of zero was assigned. The 3-7 tube model does provide measurements which can be interpreted analytically with respect to the prototype unit and is rated $40 \%$ effective in muting this objective. The larger test models are rated between $80 \%$ and $100 \%$.

OBJECTIVE N0. 13 - Evaluate the Pressure Losses on the Water Side of the Steam Generator

Since most of the water side pressure loss occurs in the heater tubes all of the models are fairiy effective in providing answers which meet this objective. The smaller models suffer from deficiencies in inlet/outlet plenum effects and the effect of water-side flow maldistributions. Accordingly, the ratings range from 70-80\% for the smal1 models to $90-100 \%$ for the larger models. 
OBJECTIVE N0. 14 - Evaluate the Recirc System Characteristics (Flow, Pressure Drnp, and Power Requirements) Including the Performance of the Steam Separator and Dryer

The extrapolations required for the small model tests are fairly extreme with respect to the recirc system and in particular the performance of the steam separator and dryer. Ratings of $20 \%$ and $50 \%$ were assigned to the 1-tube and 3-7 tube models. The test results from the larger models can be more directly related and are rated from $80 \%$ to $100 \%$ as the size is increased

OBJECTIVE NO. 15 - Determine Operating Limits With Respect to DNB and Consequences of Operating with DNB

The one-tube model will give the best (most accurate and reliable) data for DNB correlations and deserves the highest rating $(70 \%)$. This rating is less than $100 \%$ because the objective of determining the consequences of operating with DNB may fall short. If the wall oscillations measured are small such that the stress analysts can state unequivocally that no damage will occur in 30 years of operation, then the full test objective will have been met. However, it's expected that the oscillations will be in a troublesome grey area where the only answer can be obtained through long term (approaching 30 years) operation.

As more tubes are tested, the problem of separating out the performance of a single tube for DNB evaluation becomes preogressively more difficult. The 3-7 tube model was rated at $60 \%$ and the larger models were rated $50 \%, 45 \%$, and $40 \%$ for the $33 \%$, $65 \%$, and $100 \%$ size mode $1 s$.

OBJECTIVE NO. 16 - Determine Operating Limits With Respect to Hydraulic Stability

When using a recirc system with a constant speed pump and operating without DNB, the chances of encountering a hydraulic stability problem on CRBRP are infinitesmal. However, to ease the designers mind, any model tests should include test runs where the unit is pushed to the point of unstable flow conditions. In this manner the degree of conservatism with respect to instability and an understanding of the causes of instability can be evaluated. A single tube test is a poor model 
for running hydraulic stability tests since there is an instability mode which is associated with multiple tubes where the flow pulses in rotation between tubes. The single tube test was rated at $50 \%$ since it cannot evaluate this effect. The 3-7 tube model is rated at $95 \%$ and the larger models at $100 \%$.

\section{OBJECTIVE NO. 17 - Measure Heat Losses Through Vessel Insulation}

Since the pressure vessel on the model must be trace heated, it is difficult to get a good fit (zero gap) between the vessel and the insulation. With a long vertical hot gap there is a strong tendency to develop vertical convection currents that effect the performance of the vessel insulation. This can be troublesome in the filling cycle where the lower end of the vessel tends to run cold.

Measuring the insulation performance under these conditions requires near prototypic models. Thus, the ratings of $5 \%, 20 \%, 50 \%, 75 \%$, and $100 \%$ seem appropriate in progressing from the 1 -tube model to the $100 \%$ model size.

\section{OBJECTIVE NO. 18 - Exercise and Evaluate Leak Detection Techniques}

A11 of the model sizes can be used to exercise the leak detection equipment and ga in valuable experience but the lower sodium inventories in the small models makes the leak detection task much easier than in the large models. If meaningful leak detection tests are run where hydrogen or water are injected into the system, the larger the model the better. The 1-tube and 3-7 tube models will produce data of very 7 imited value and only rate $50 \%$ and $60 \%$ scores with respect to meeting this objective. The larger models range from $80 \%$ to $100 \%$ in their ratings.

OBJECTIVE N0. 19 - Practice Leak Location, Tube Plugging and In-Service Surveillance of Tubing Integrity

There is no way to practice leak locating procedures in a one-tube test model and the practice of in-service surveillance of tube integrity is limited to a single tube. The tube could be plugged, but the tube-sheet conditions would be far from prototypical and there is no way to operate the model with a plugged tube. 
Thus, the single tube model was rated at 30\%. The 3-7 tube model can meet the objective rather well except that it must be rated down to $80 \%$ since the number of available tubes and the difficulty of locating a leak and running in-service inspections of the tubes is greatly reduced over a full size prototype. The larger models are rated $90-100 \%$ depending on the number of tubes available.

OBJECTIVE NO. 20 - Measure the Effect of Plugged Tubes on Thermal Hydraulic and Mechanical Performance of the Unit

When a tube is plugged in a steam generator, the heat load from the tube remains in the sodium around the tube. The result is hotter than average sodium around the adjacent tubes. Besides the thermal maldistribution, the extra heat load causes early occurance of DNB in the adjacent tubes. In addition, the differential thermal expansions of the plugged tube and adjacent tubes relative to the support structure is abnormal. If the plugged tube is adjacent to a tie rod, there will be thermal expansion distortions in the tube bundle suppor structure.

None of these effects are present in a single tube test model, therefore, it must be rated $0 \%$ as far as meeting this objective. The 3-7 tube model is subject to the above affects except for magnifications of the plugged tube responses due to the small number of tubes. A rating of $60 \%$ was assigned because of the required test extrapolations. The larger models were rated $90-100 \%$.

OBJECTIVE NO. 21 - Obtain Operating Experience With Sodium Fil1, Startup, Shutdown, Power Maneuvers, Power Split (EV/SH), Instrumentation, Etc.

The value of the test operating experience with regard to plant opration problems depends strongly on the scale of the model. Ratings of $20 \%, 70 \%, 90 \%, 95 \%$, and $100 \%$ were assigned to the various model sizes under consideration.

OBJECTIVE NO. 22 - Coupon-Tests In Sodium and Water Sides - Evaluate Alternate Materials, Corrosion, Mass Transport, Water Treatment Methods, Etc.

Coupon tests are of limited value unless the tests are of fairly long endurance (>20,000 hrs.). Placing coupons in small test models particularly a one-tube model is difficult without disturbing the flow. Also, the corrosion and mass 
transport effects may be different for very small scale experiments, particularly with respect to maintaining prototypic sodium purity levels. Thus, the single tube test model is rated $10 \%$ with the 3-7 tube test model receiving a $60 \%$ rating. The larger models are rated between $90 \%$ and $100 \%$.

OBJECTIVE NO. 23 - Practice and Perfect Maintenance Techniques Including Unit Cleaning and Disassembly

The single tube model has little to offer in the practice of maintenance and cleaning techniques. Accordingly, it was rated at 10\%. The 3-7 tube model has most of the component parts of the full size model and except for the problem of handling the heavy weights of the larger models, it is instructive in the maintenance, cleaning and disassembly processes. It was rated at $70 \%$. The larger models were rated higher in the $90-100 \%$ range depending on the model size.

OBJECTIVE NO. 24 - Perform Post-Test Distructive Examinations - Evaluate Effects of Stresses, Corrosion, Erosion Wear, Decarburization, Etc.

A single tube model is so radically different in its response to the test environment from a larger multi-tubed steam generator, that little will be learned from a destructive examination that can be applied to the prototype. Therefore, a rating of $20 \%$ was assigned. The 3-7 tube model is also deficient, but to a much lesser extent. It was rated at $60 \%$. The 1arger models were rated $90-100 \%$ depending on the model size.

OBJECTIVE NO. 25 - Confirm High Temperature Stress Criteria In Critical Components

Meeting this objective in steam generator model tests consists of submitting the model to as nearly the same accumulated strain cycle damage as would occur in the prototype unit. Unfortunately, it will be impossible to duplicate thermal transients exactly since a testing rig will respond differently than a reactor system, particularly if the test rig is scaled down in size. Additionally, the response of individual components to a given thermal transient will be different when scaled down in size. It's necessary to use the high temperature stress analytical tools for the model design and available test rig transients and arrange 
the component design to produce near prototypic responses. Then, by applying test rig thermal transient in sufficient variety and numbers to exceed by some percentage the prototype strain cycle damage, some confidence can be gained that the prototype design will be satisfactory when those same analytical tools are applied. The more prototypic the model size and test rig transients become, the better the results will be.

A single tube test would be of $0 \%$ value in meeting this objective due to the major deviations in model geometry and small rig size. The 3-7 tube model is of 1 imited value ( $30 \%$ rating) because of the very small scale sizes for model and test rig. The $100 \%$ model size was rated $90 \%$. This rating was 1 owered from $100 \%$ because it will not be possible to exactly duplicate all the thermal transients of the prototype even in a full size test rig. The intermediate size $(33 \%, 65 \%)$ models were rated at $60 \%$ and $70 \%$ due to the addition of component scaling. 
STEAM GENERATOR THERMAL TRANSIENTS -

CASES PRESENTLY ASSUMED TO HAVE LIMITING SEVERITY

The thermal transients identified to date for the CRBRP and considered to provide limiting rates or magnitudes of temperature changes are listed below. Either verbal descriptions or digital computer simulation results are provided for each case. Digital computer simulation results were generated by the Westinghouse "DEMO" code Revision 001 for a two superheater module-four evaporator module per loop configuration (AI modules).

The transient results are to be updated for the CRBRP PSAR by June 1974. The limiting transients which have preliminary simulation results attached are as follows:

1. Intermediate Pump Mechanical Failure $(E-1) *$

2. Main Steam Line Rupture (E-4)

3. Inadvertent Isolation and Blowdown of One Steam Generator Loop (E-9)

4. Steam Line Rupture ( 8 " Line Between Drum and Superheater) (E-15A). This transient is similar to, but not necessarily as severe as Recirculation Line Break: Between Evaporator Outlet and Drum Inlet $(\mathrm{E}-20 \mathrm{~B})$.

In addition, simulation results for the normal scram case included:

5. Reactor Trip From Full Power (U-1A).

Severe thermal transient cases which have not been analyzed are:

6. Failures Which Cause Steam Drum Overflow and Superheater Flooding (E-17). This transient characterizes the cases where a feedwater to steam flow unbalance occurs and is not corrected until water overflows into the superheater modules. A failed open feedwater control valve or a faulty level signal causing high feedwater flow to be demanded could initiate this event.

* Classifications of transients are as in ASME Boiler and Pressure Vessel Code, Section III. The duty cycle numbering used corresponds to that in letter, K. Hikido to W. M. Jacobi, "Updating of Demonstration Plant Design Duty Cycle List", DP598-74-1, dated January 3,1974. This reference includes current values for the number of transient cycles considered. 
A rapid reduction in superlieater water side temperature to $\sim 600^{\circ} \mathrm{F}$ will occur. Reactor scram with IHTS sodium flow coastdown will increase the rate of temperature reduction. The superheater outlet sodium temperature will decrease to $\sim 600^{\circ} \mathrm{F}$ and this sodium will be transnported to the evaporator causing the evaporator to become isothermal at $\sim 600^{\circ} \mathrm{F}$.

7. Inadvertent Evaporator Inlet Dump Valve Opening (U-24). A sufficient reduction of evaporator module water flows will occur in the affected loop resulting in a reactor trip on evaporator outlet temperature increase. Steam pressure in the affected loop will continue to fall until the isolation valve on the affected module is manually closed (assuring the water dump valve cannot be closed). The module will blow down to a dry condition. The severity of this transient can bc greatly increased if intermittent failure of the dump valve occurs or if conditions occur such that one or more evaporator module reflooding cycles occur.

A worst case approximation would be one or more cycles of affected nodule terminal temperature oscillations between $\sim 600^{\circ} \mathrm{F}$ and $\sim 850^{\circ} \mathrm{F}$.

8. Design Basis Steam Generator Sodium-Water Reaction (E-6). This event consists of an instantaneous rupture of TBD evaporator or superheater tubes which results in rupture disk action and activation of the steam generator blowdown and relief systems and the sodium rapid dump system along with a trip of the reactor and sodium pumps. The intermediate sodium system experiences a pressure transient resulting from the reaction. This event is classified as a fault for the affected steam generator module. For the rest of the loop, the occurrence is classified as an Emergency Event. The results of the transient are very dependent on the systeri and relief geometry choser. Analysis of an earlier two superheater four evaporator per loop system indicated sodium flow reversal in the unfailed modules. Analys is of a three superheater three evaporator per loop system predicted no flow reversal for a relief system at the module terminals or on the main headers.

On possible worst case assumption that migit be made for the sodium-water reaction thermal transient would be: 1) initial reversal of module sodium flow resulting in cold leg sodium $\left(\sim 625^{\circ} \mathrm{F}\right.$ ) entering the unit, 2 ) steam side blowdown, also cooling the module, followed by, 3) longer term sodium flow from the IHTS hot leg entering the unit with temperature increase to $\sim 900^{\circ} \mathrm{F}$. 
MAIN STEAM LINE RUPTURE 
MAIN STEAM LIINE RUPTURE

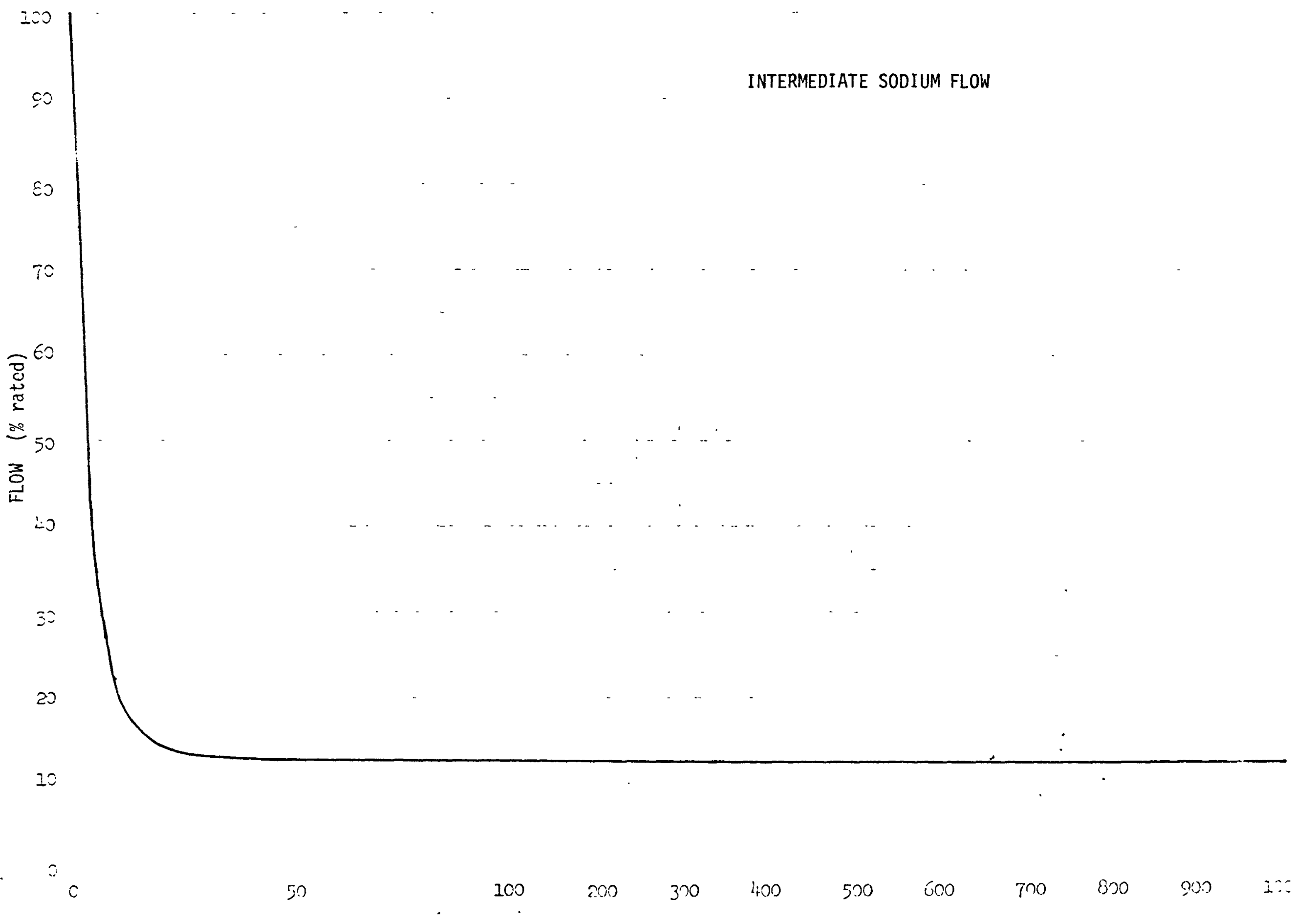




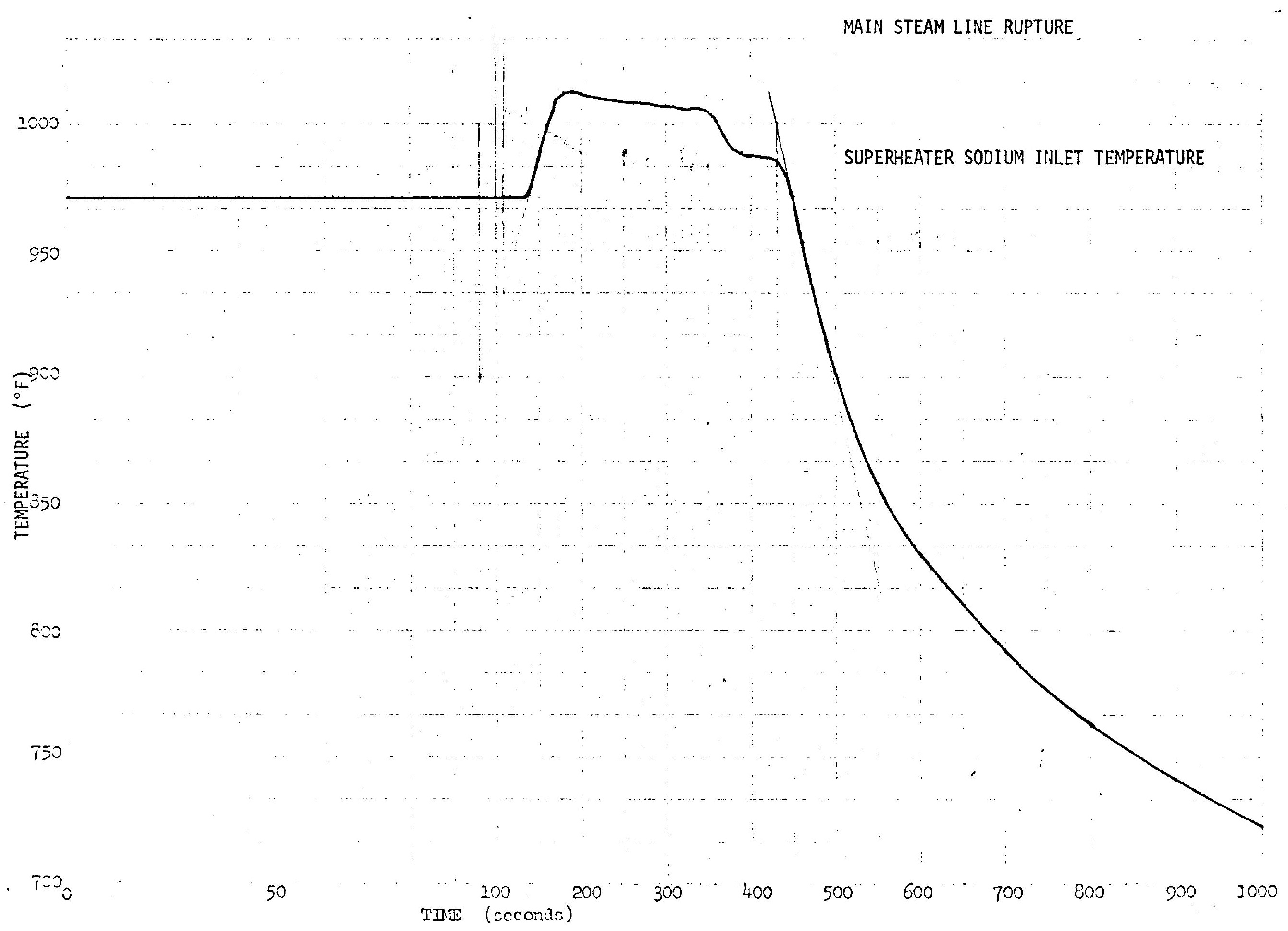




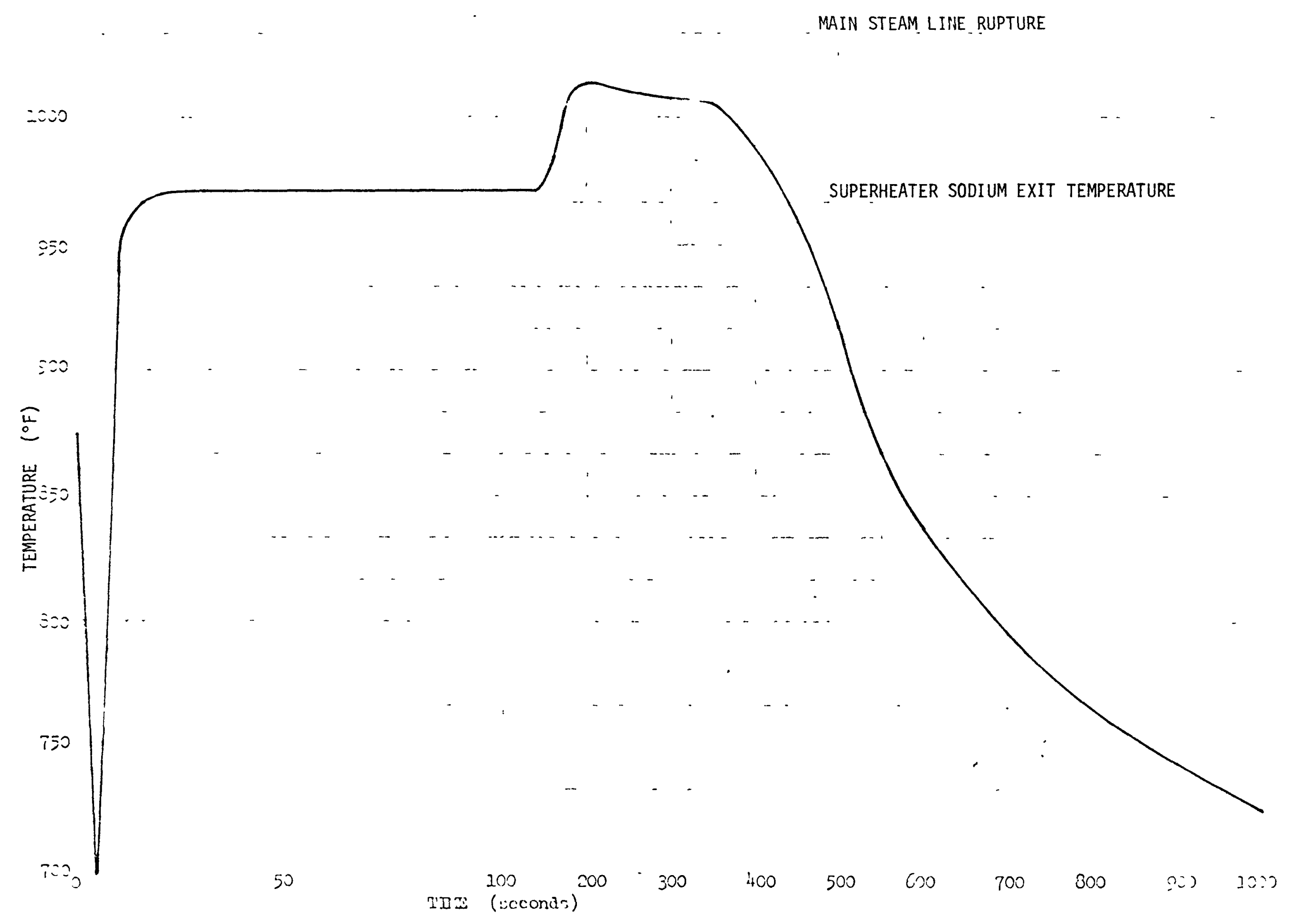




\section{-}

T0O

SUPERHEATER STEAM INLET TEMPERATURE

MAINSTEAM LINE RUPTURE

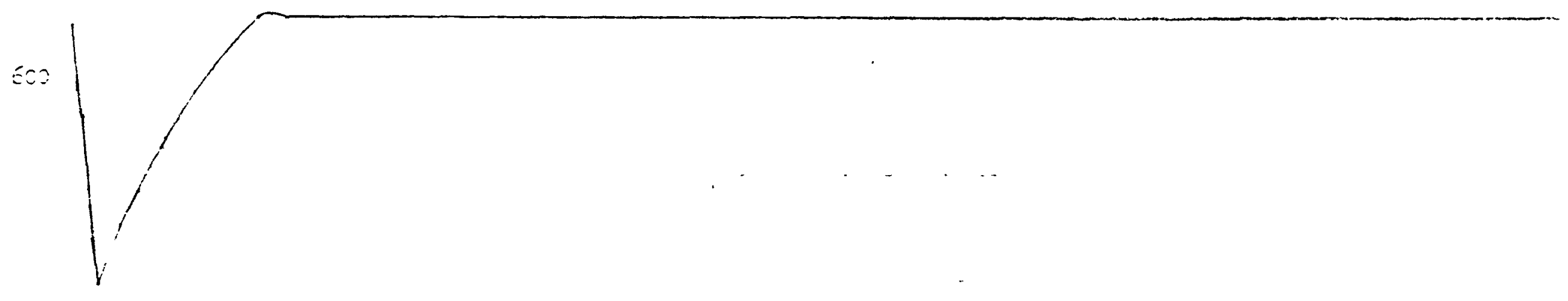

552 
MAIN STEAM LINE RUPTURE

SUPERHEATER STEAM FLOI.

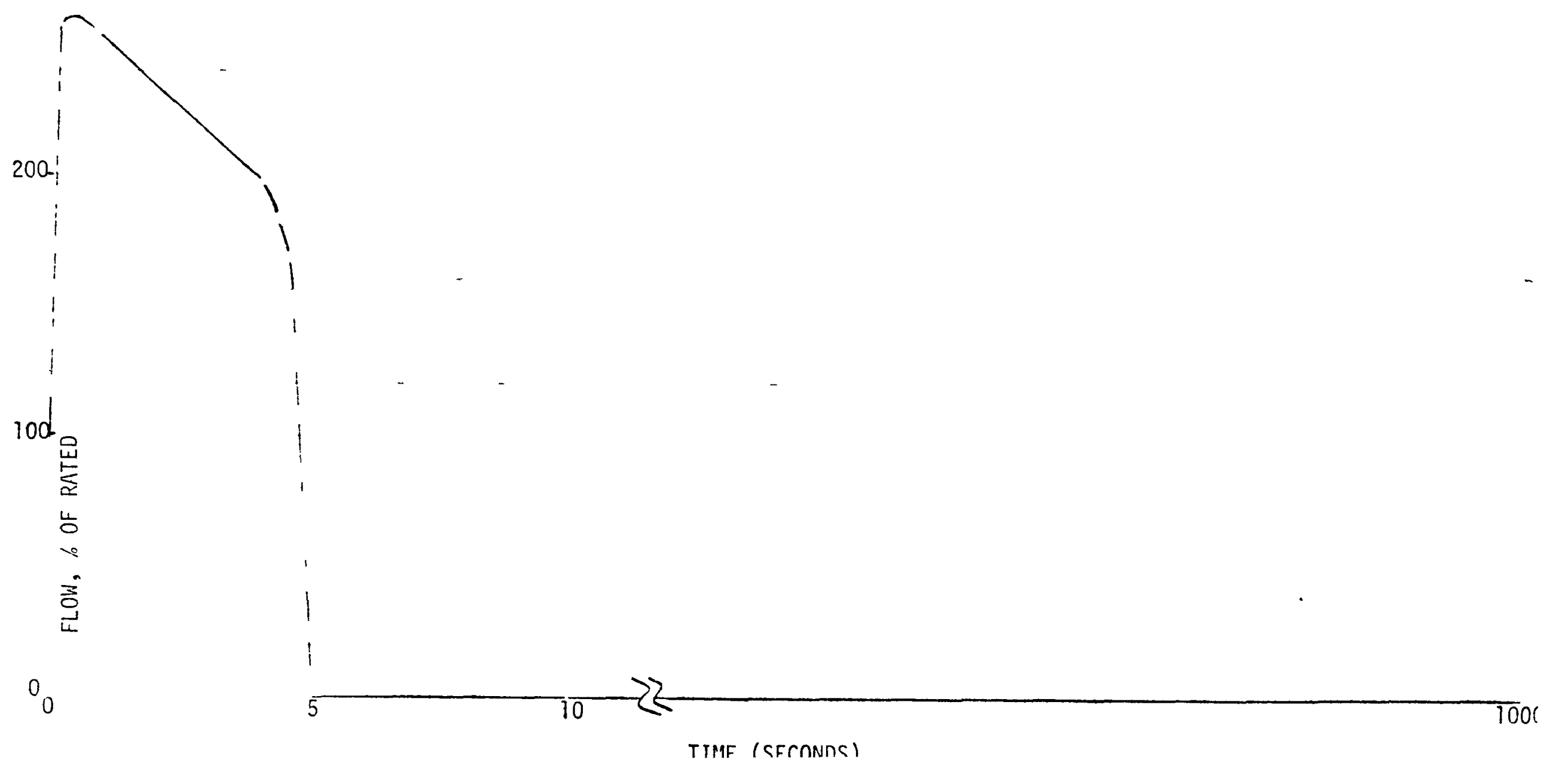


MAIN STEAM LINE RUPTURE

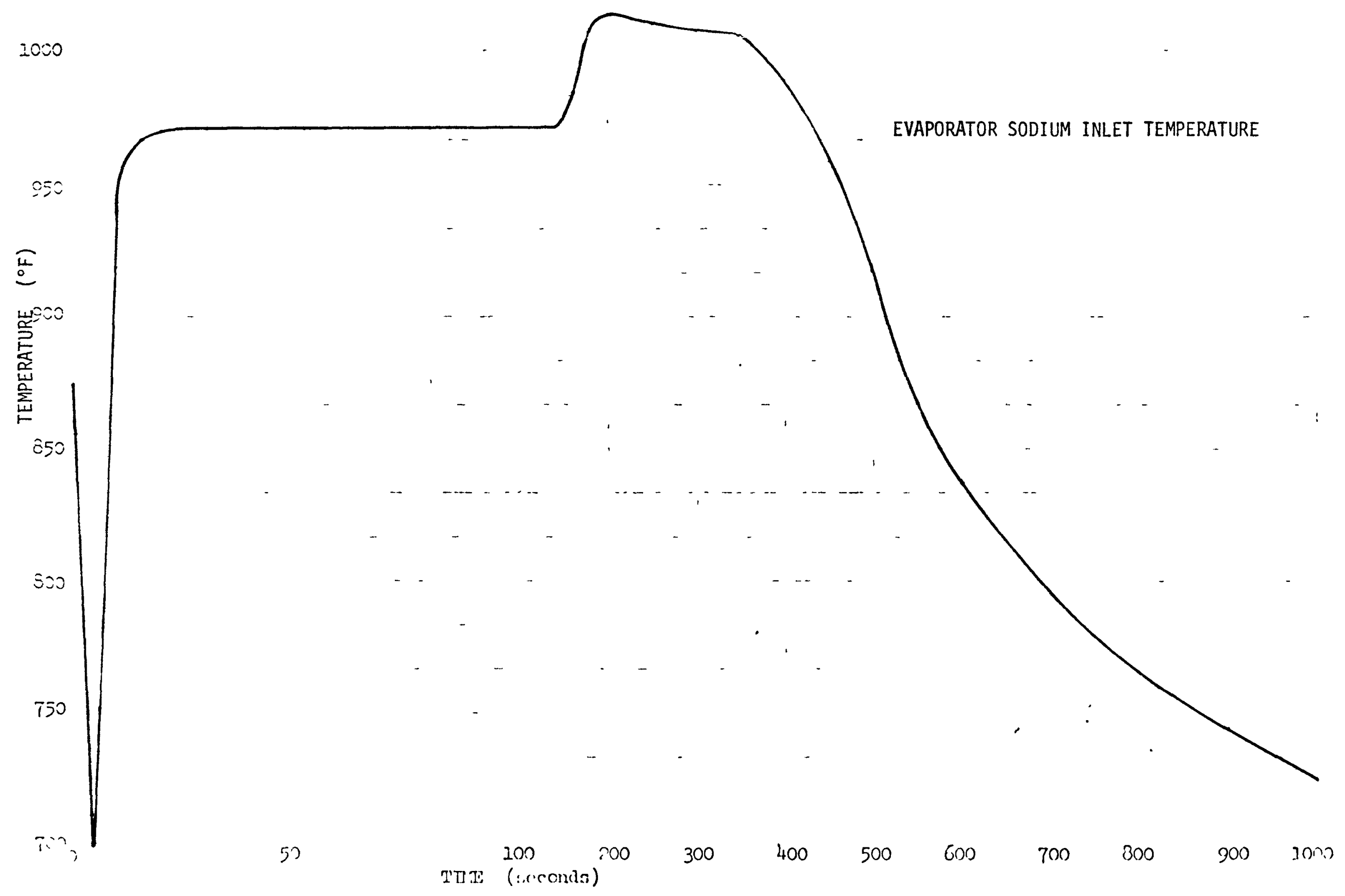




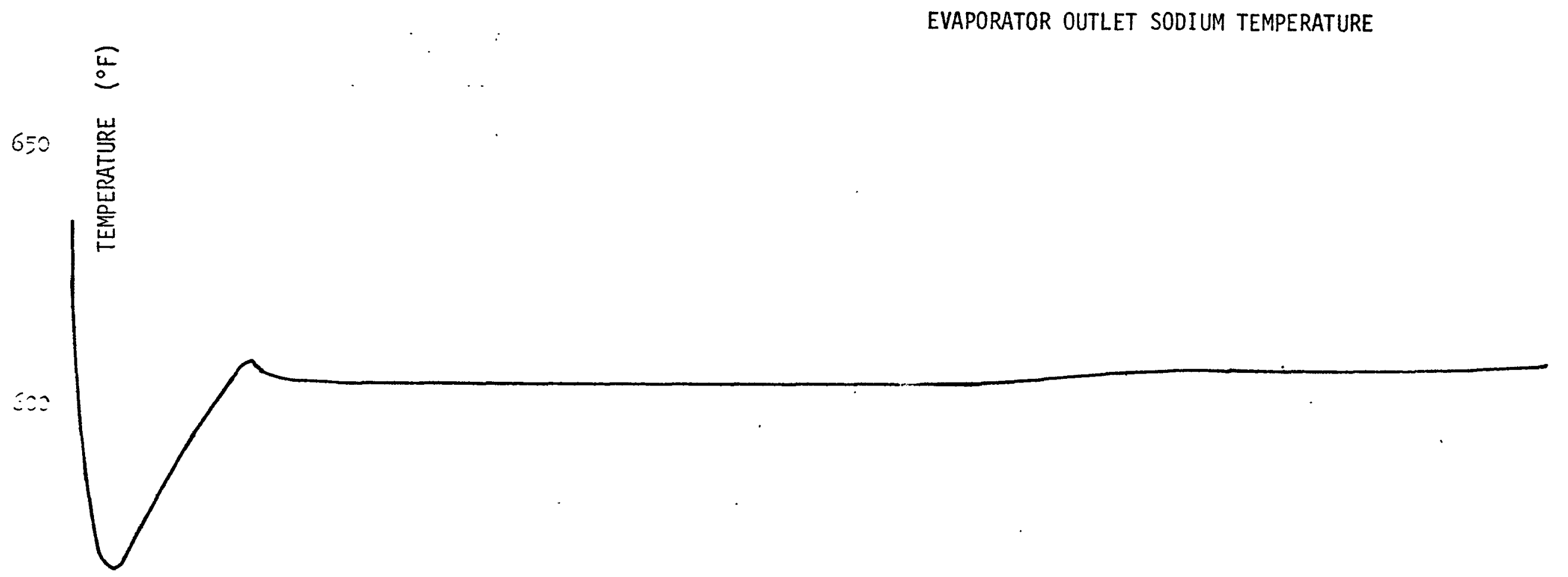

ミミン 
곻

iso 


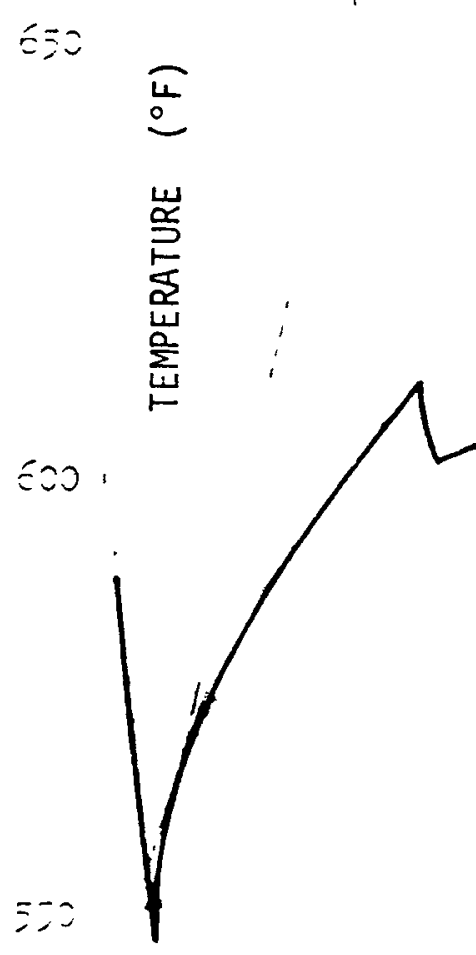


MAIN STEAM LINE RUPTURE

EVAPORATOR OUTLET WATER TEMPERATURE

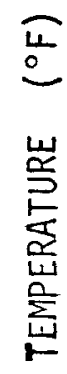

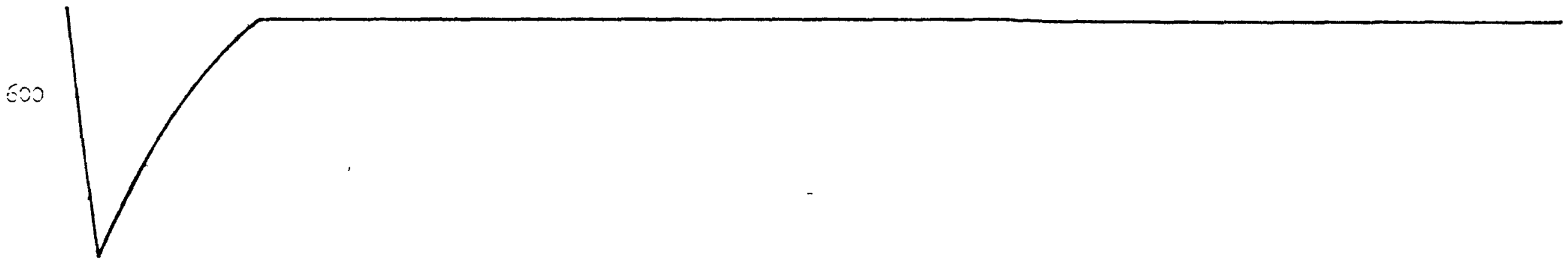

550 
INADVERTENT ISOLATION AND BLOWDOWN OF ONE STEAM GENERATOR LOOP 


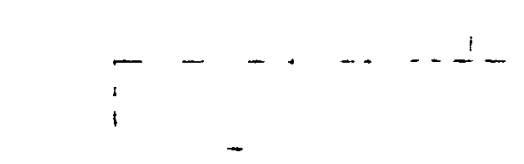

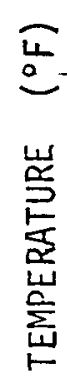

$\hat{c}=0$ 


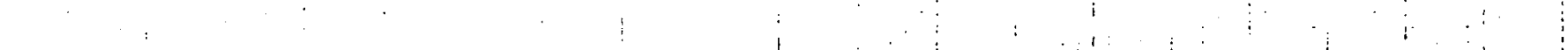

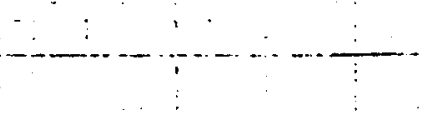

(1)

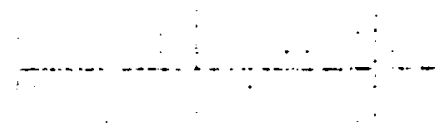

는

容

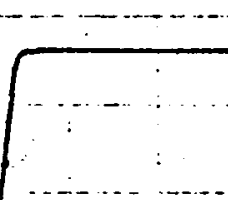

.

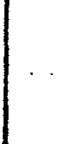

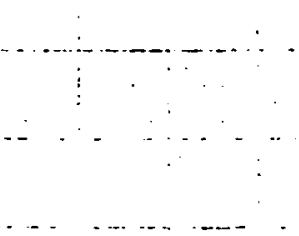

$-\cdots$

$-$ 


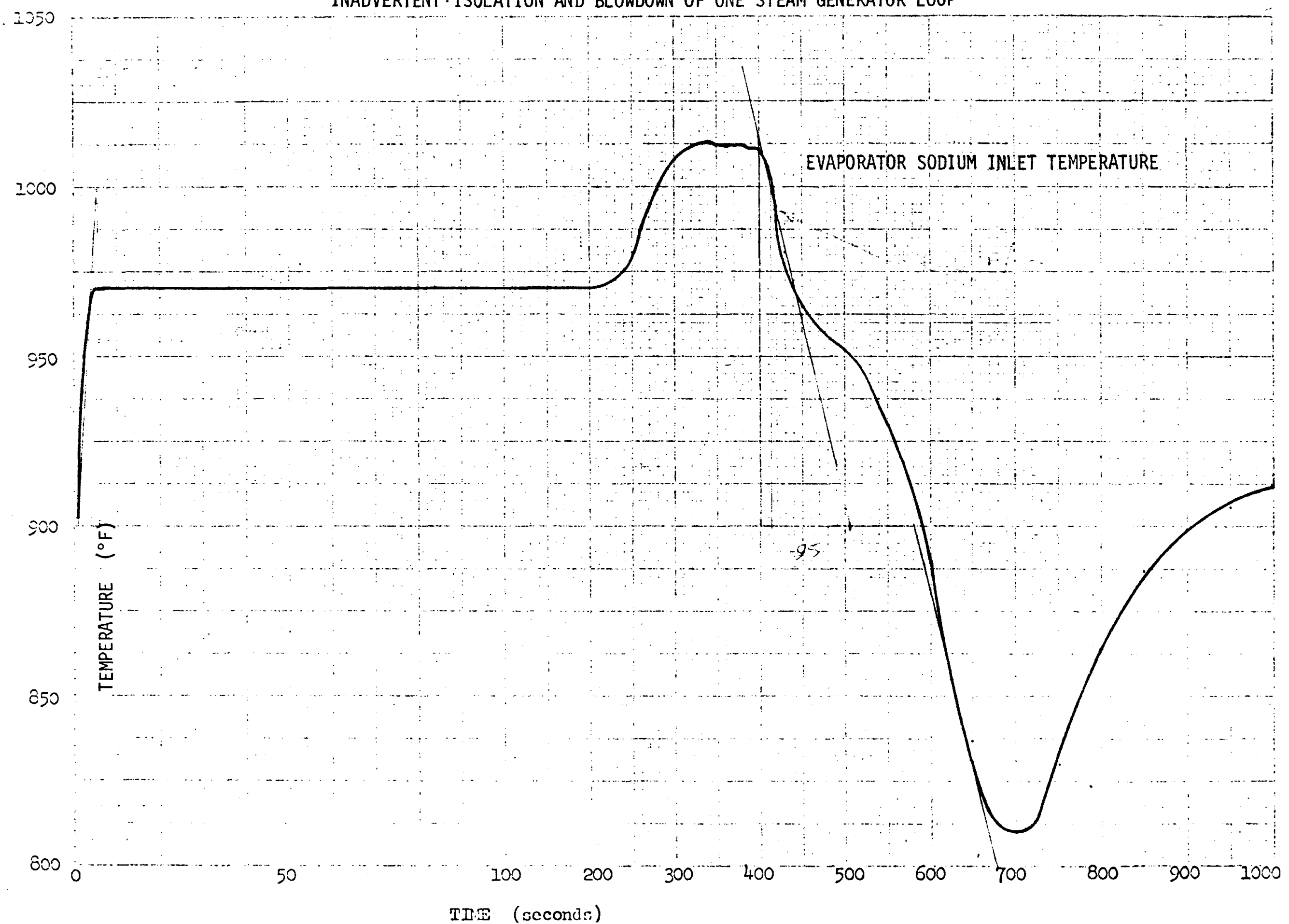


INADVERTENT ISOLATION AND BLOWDOWN OF ONE STLAM GENERATOR LOOP

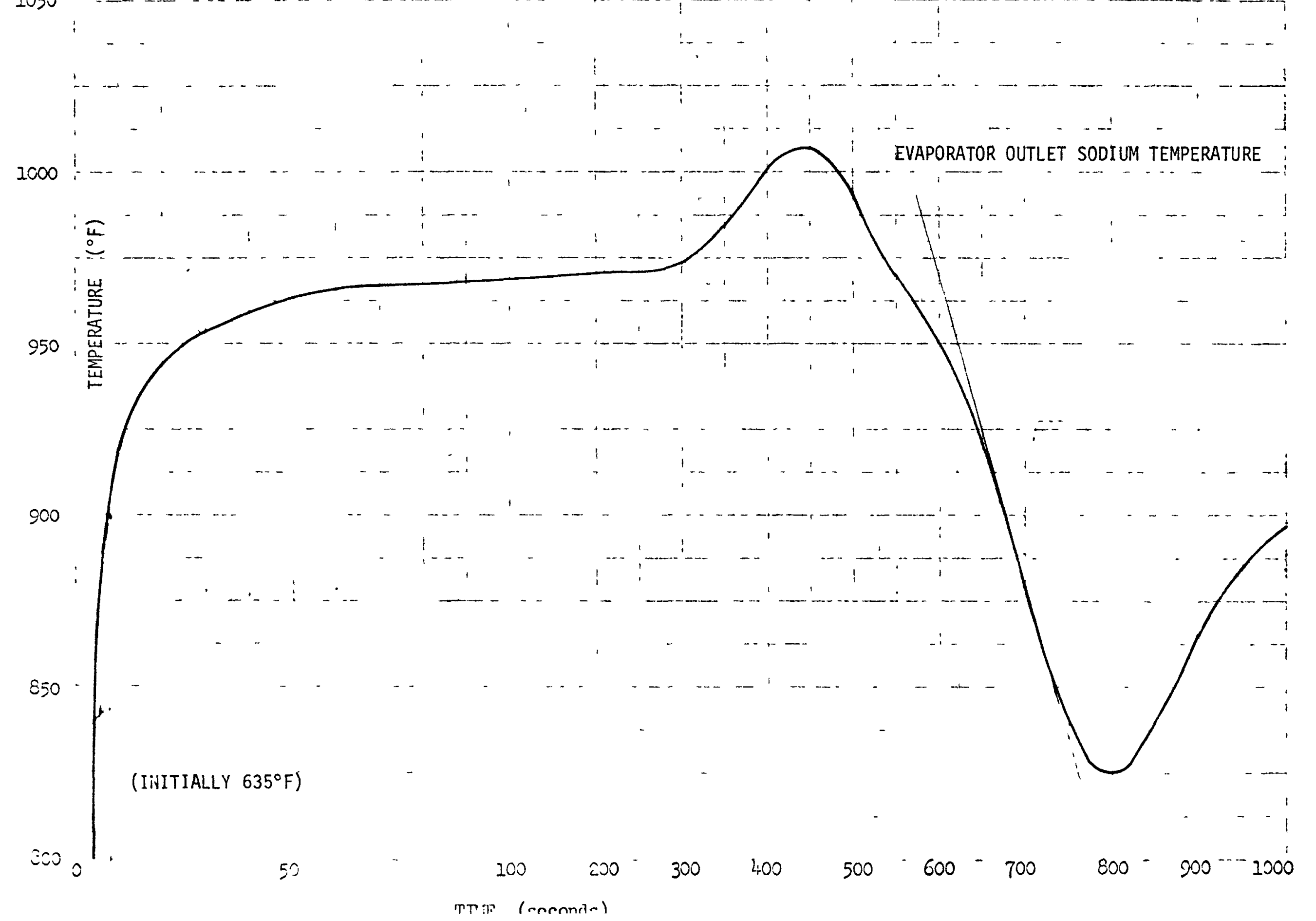


STEAM LINE RUPTURE

(8" LIME BETWEEN DRUM AND SUPERHEATER) 
EVAPORATOR INLET NA TEMPERATURE VS TIME

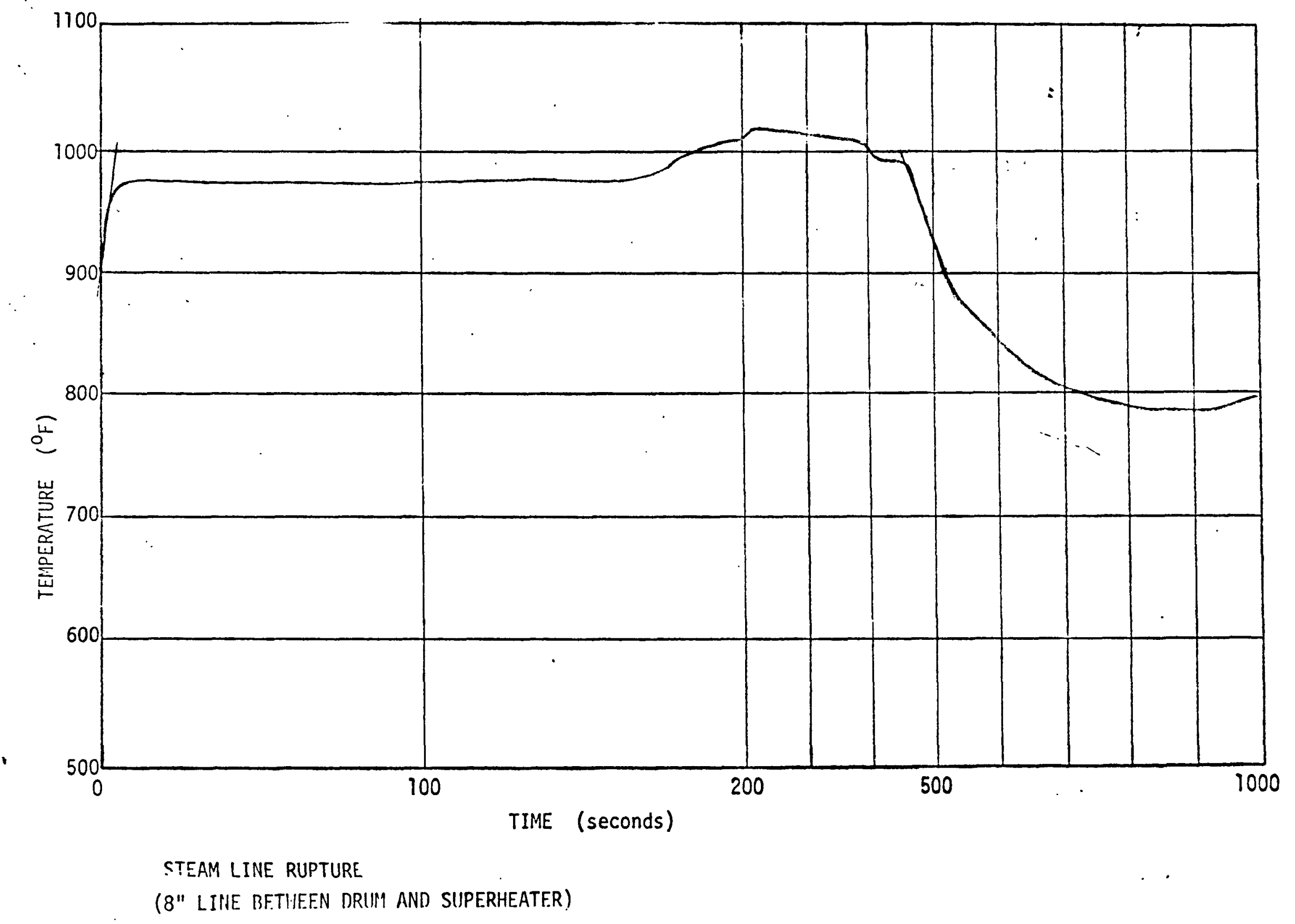


EVAPORATOR OUTLET NA TEMPERATURE VS TIME

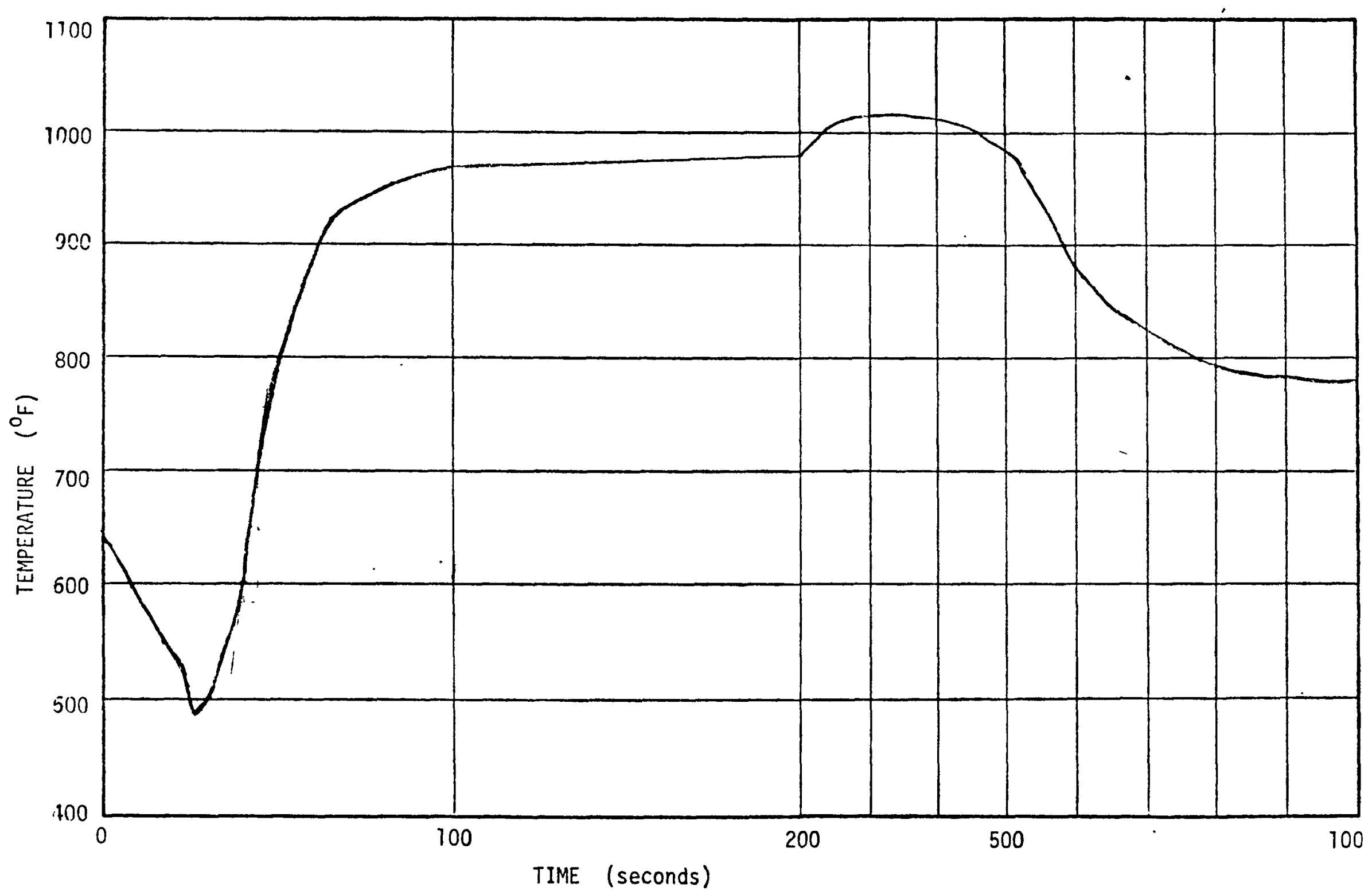

STEAM LINE RUPTURE

(8" LINE BETHEEN DRUM AND SUPERHEATER) 
FEEDWATER TEMPERATURE VS TIME

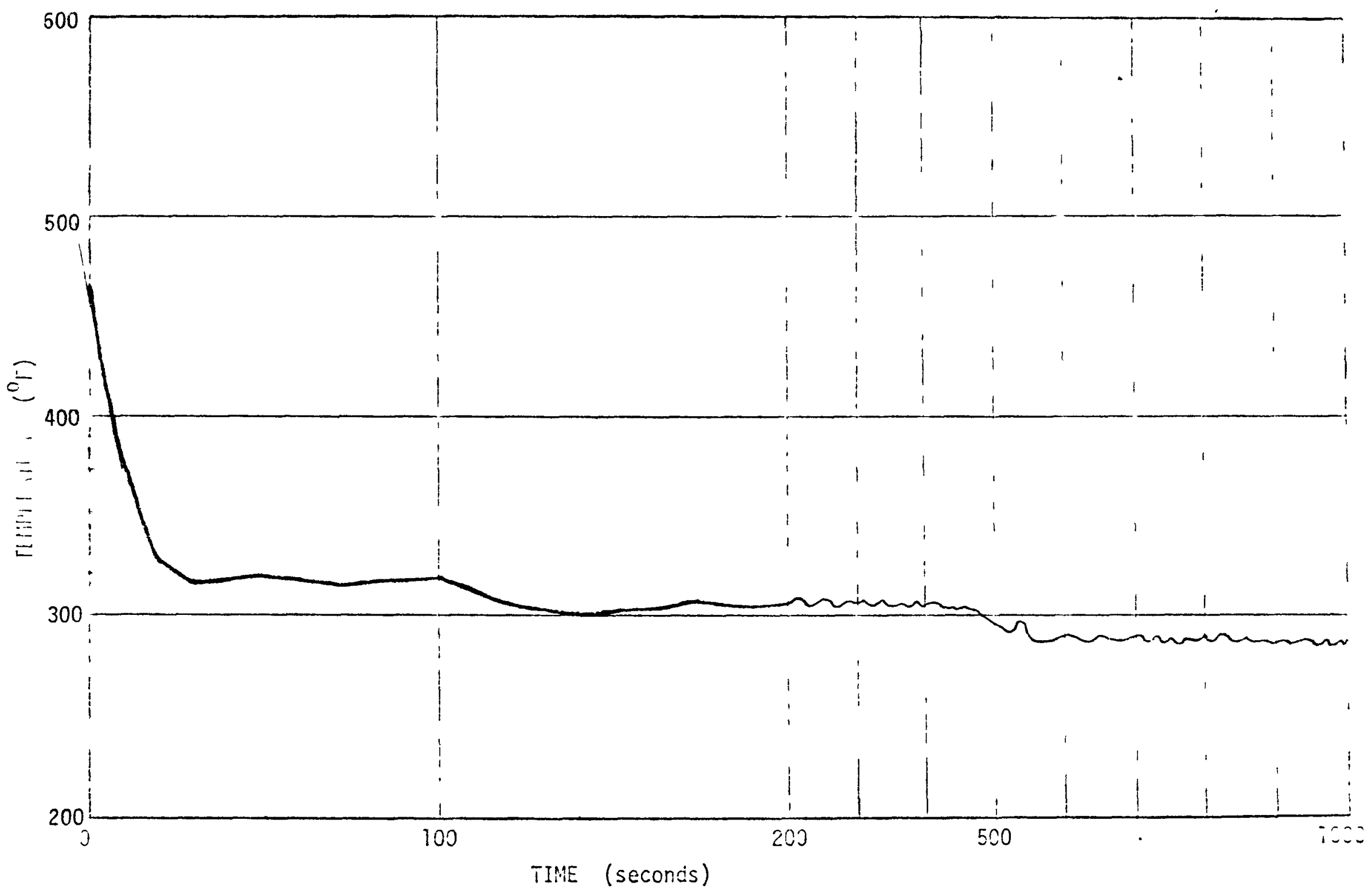

STEAM LINE RUPTURE

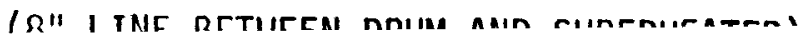




\section{REACTOR TRIP FROM FULL POWER}


INTERMEDIATE LOOP SODIUM FLOW VS TIME

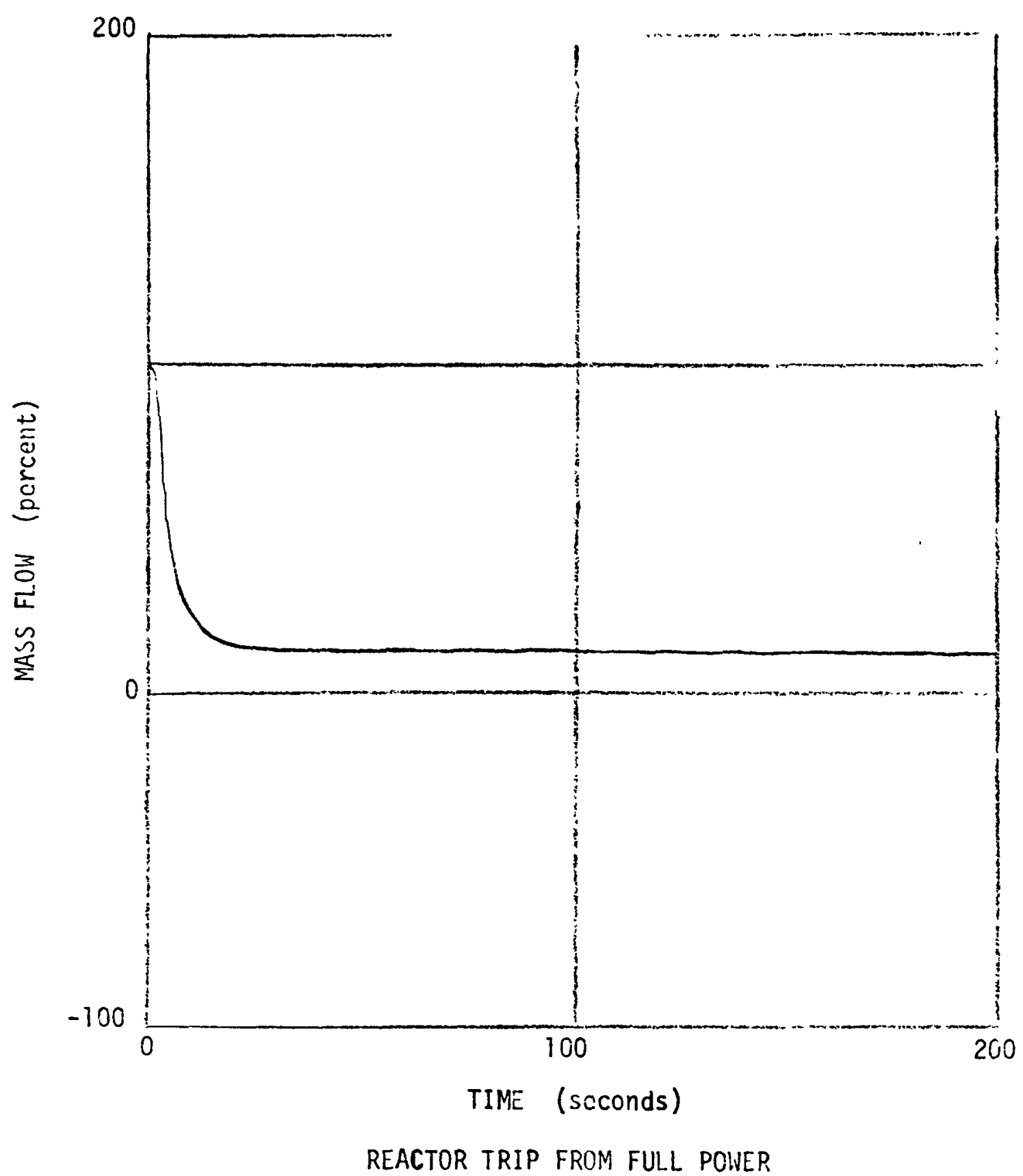




\section{SUPERHEATER INLET SODIUM TEMPERATURE VS TIME}

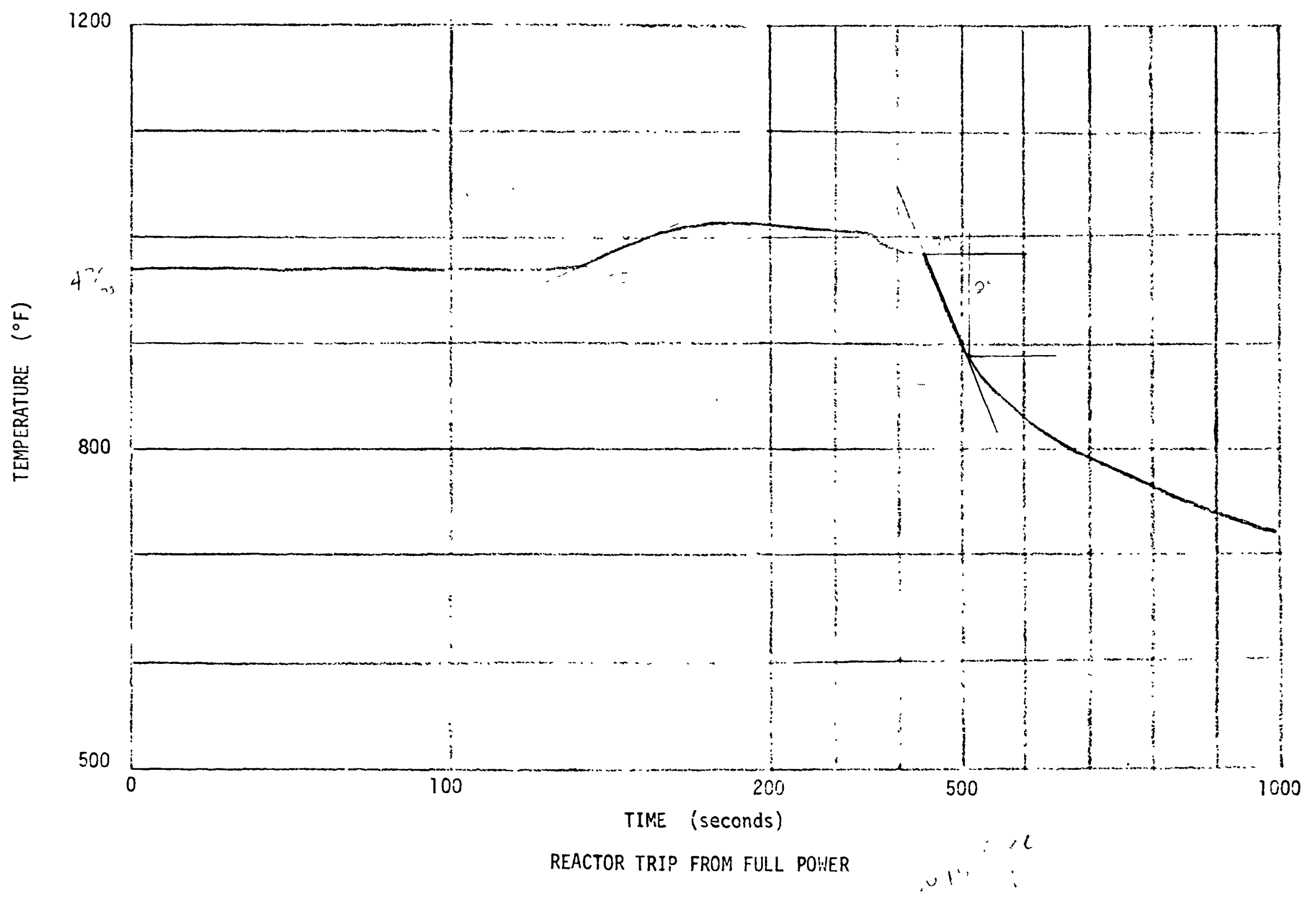


SUPERHEATER INLET STEAM TEMPERATURE

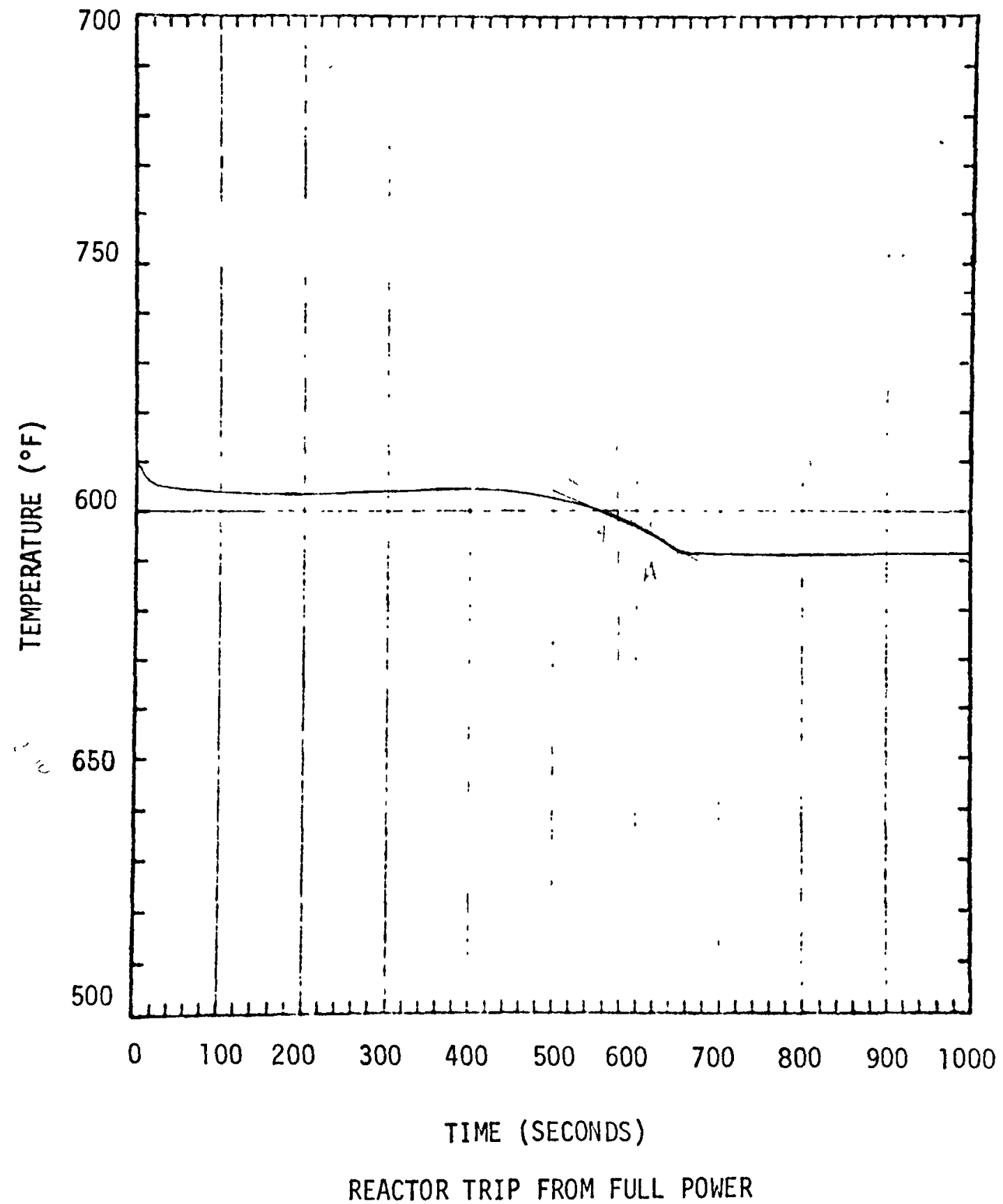


SUPERHEATER OUTLET STEAM TEMPERATURE VS. TIME

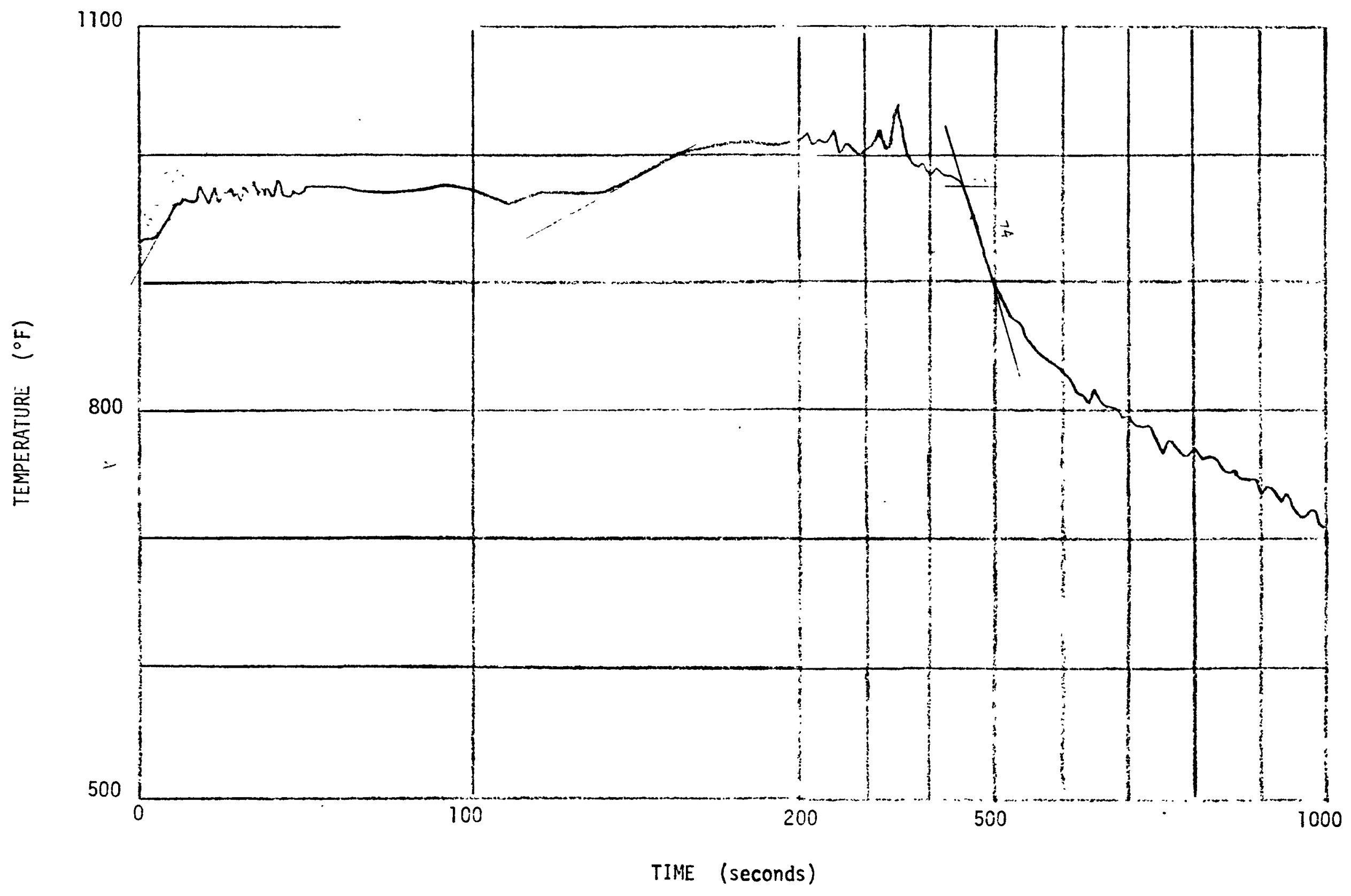

REACTOR TRIP FROM FULL POWER 
SUPERHEATER OUTLET STEAM MASS FLOW

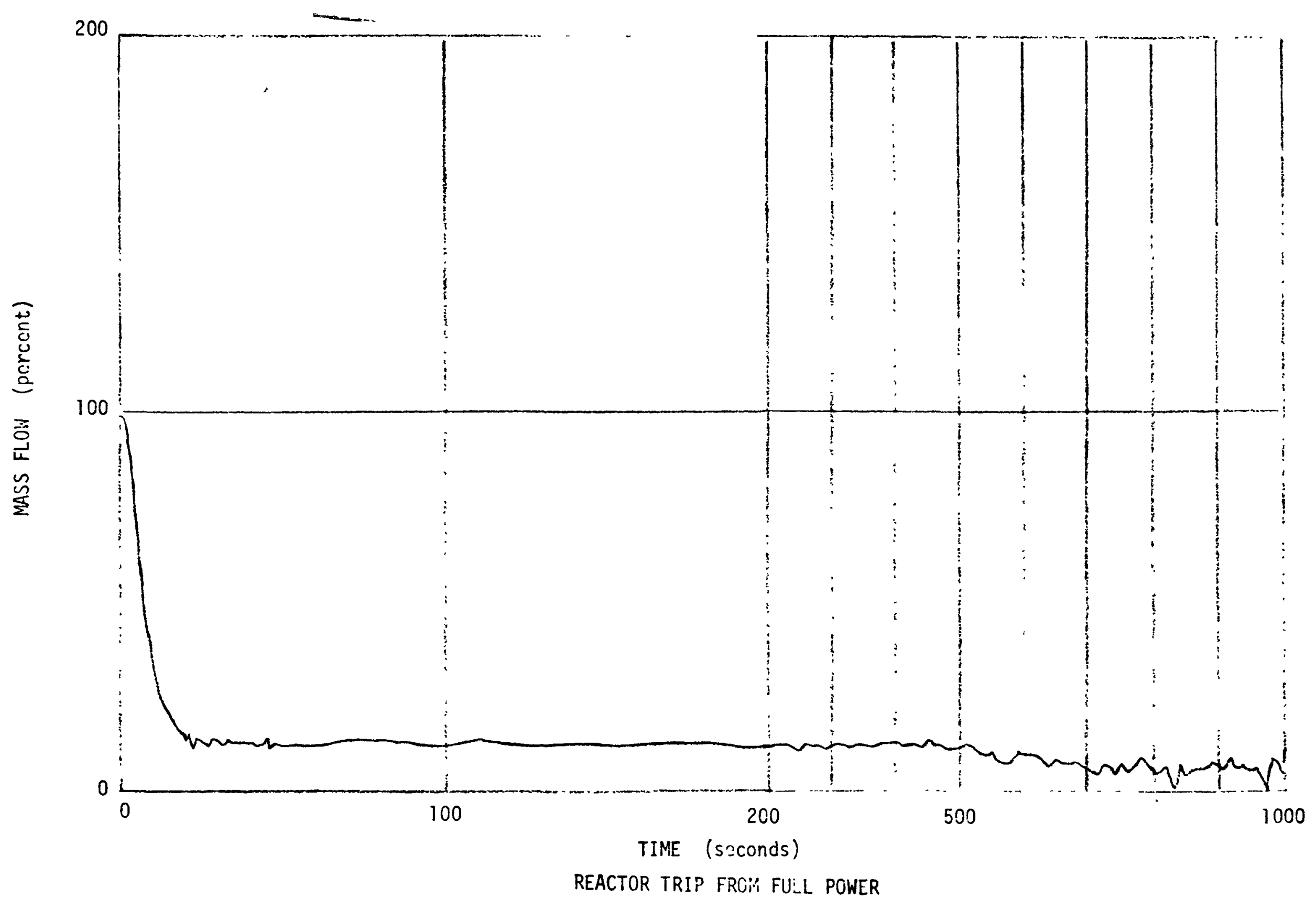


STEAM HEADER PRESJURE

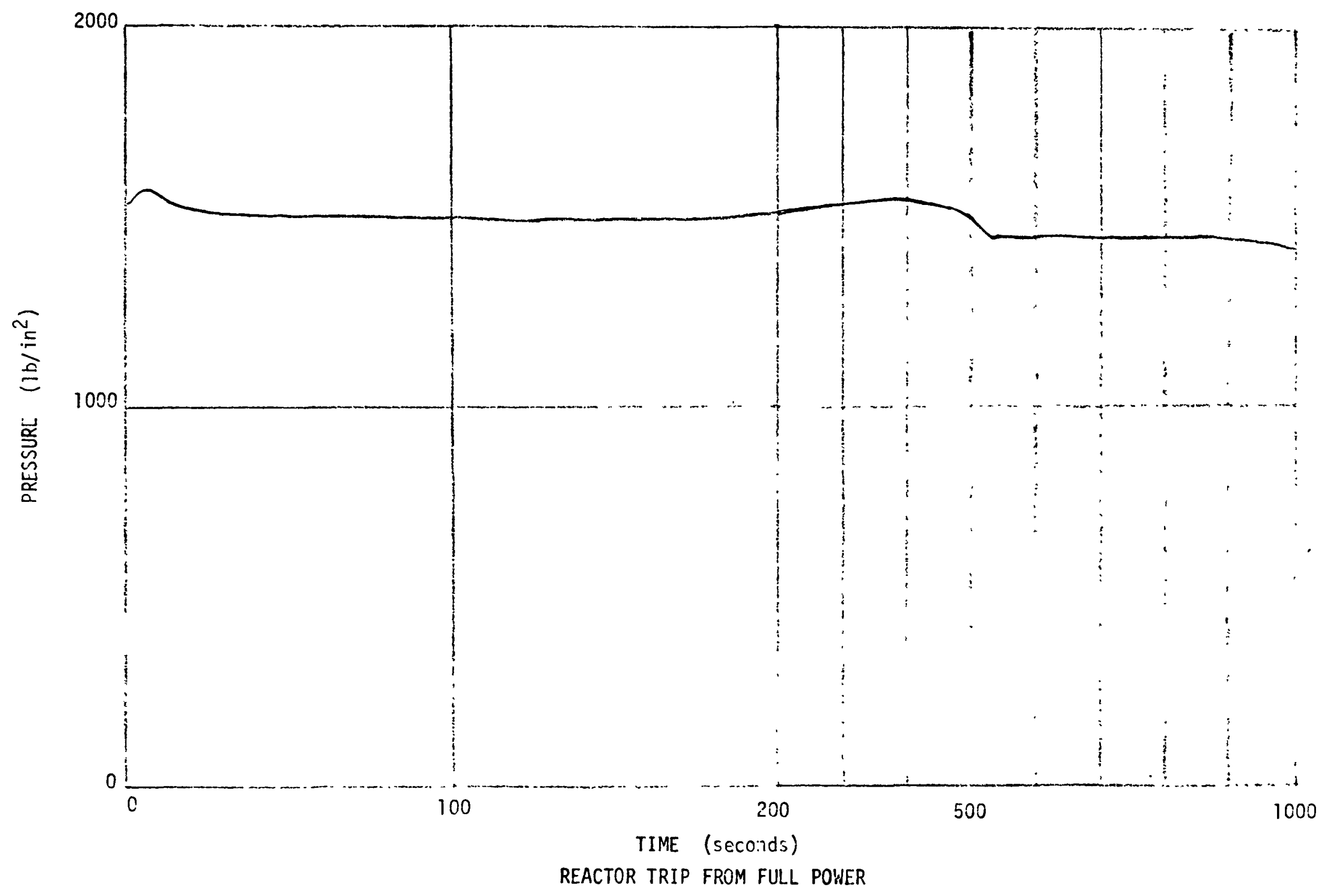


EVAPORATOR IHLET SODIUM TEMPLRATURE VS TIME

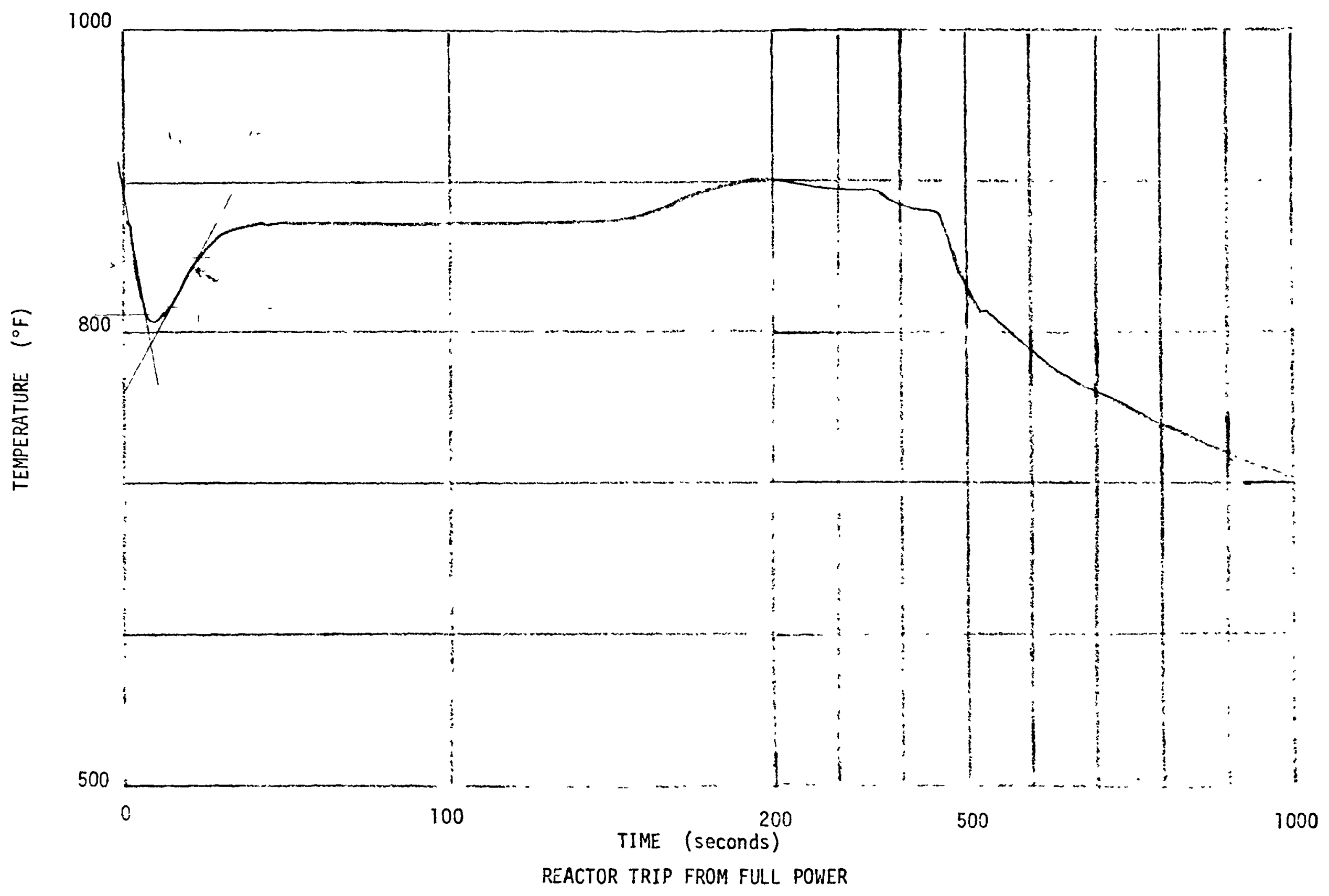




\section{EVAPORATOR OUTLET SODIUM TEMPERATURE VS TIME}

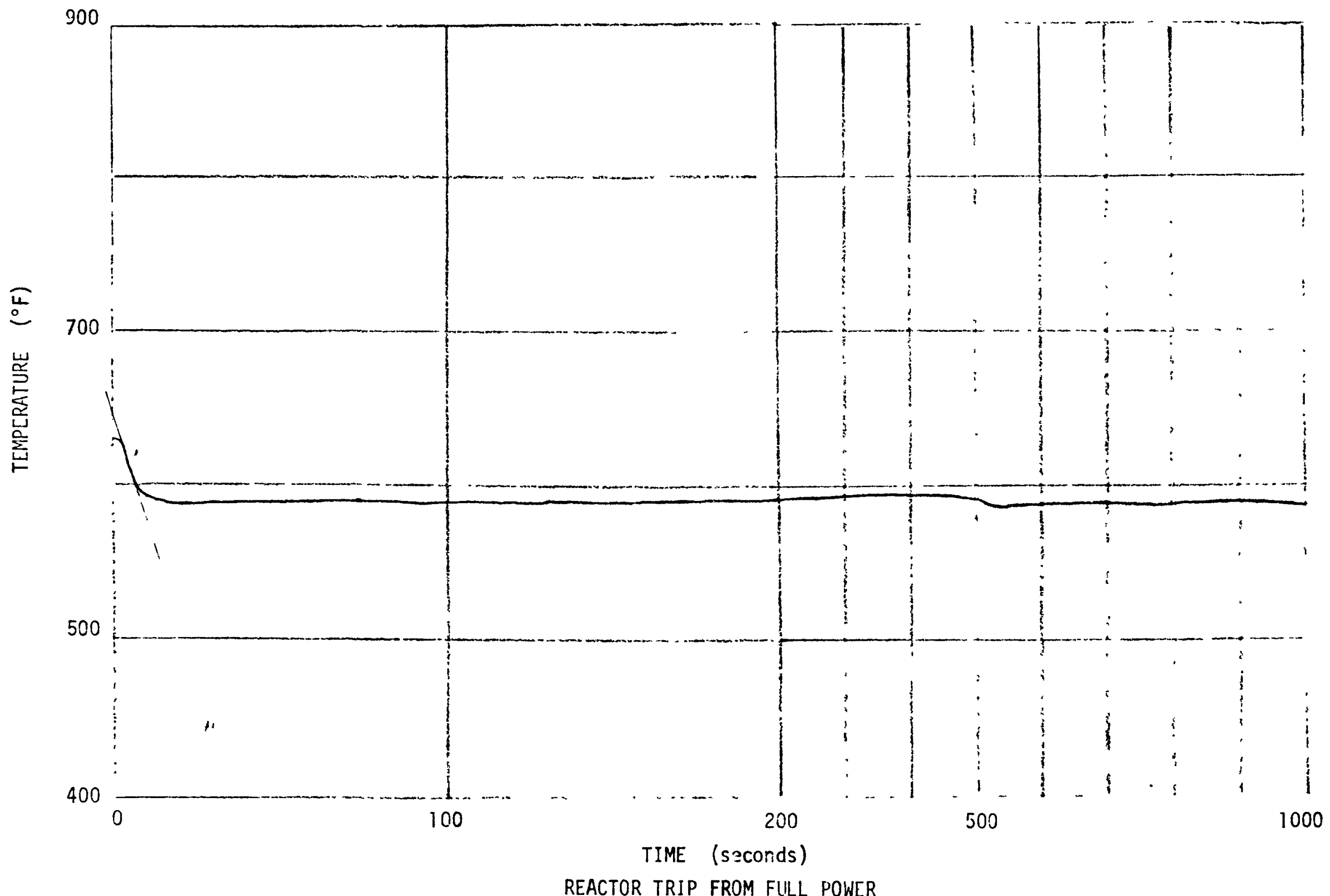


EVAPORATOR IIILET WATER TEMPERATURE VS TIME

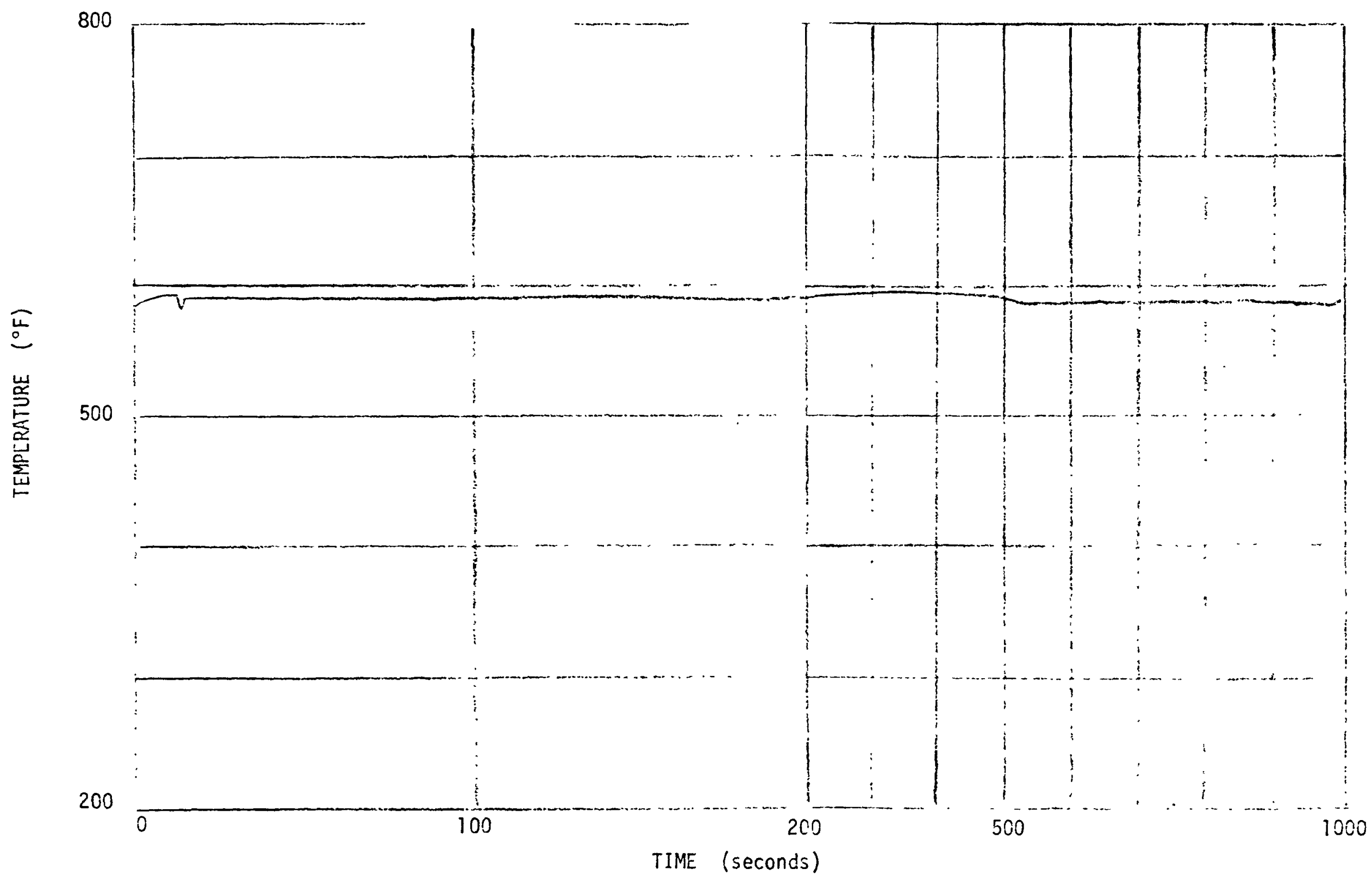

REACTOR TRIP FROM FULL POHER 
EVAPORATOR OUTLET STEAM TEMPERATURE

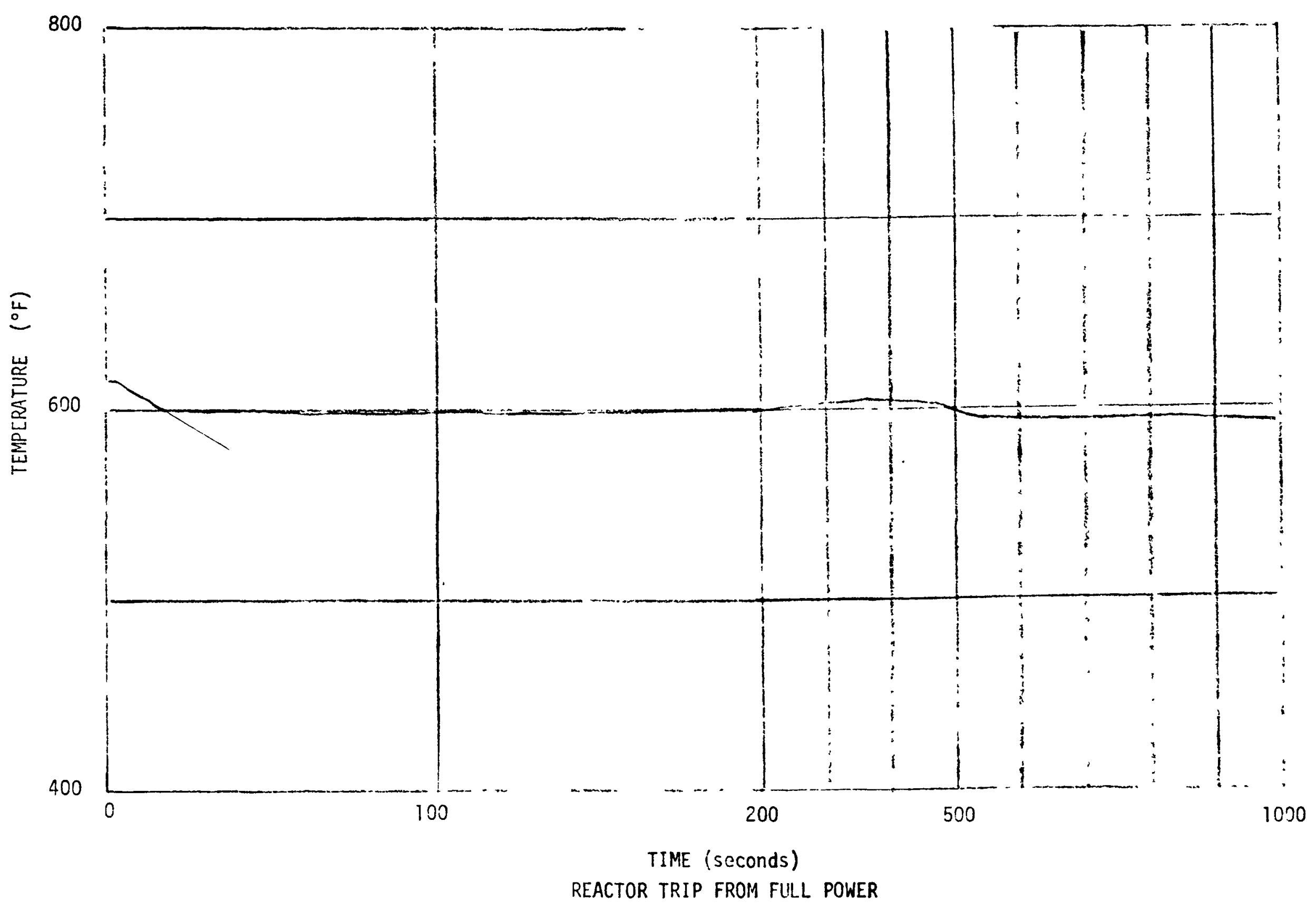




\section{EVAPORATOR INLET WATER MASS FLOW}

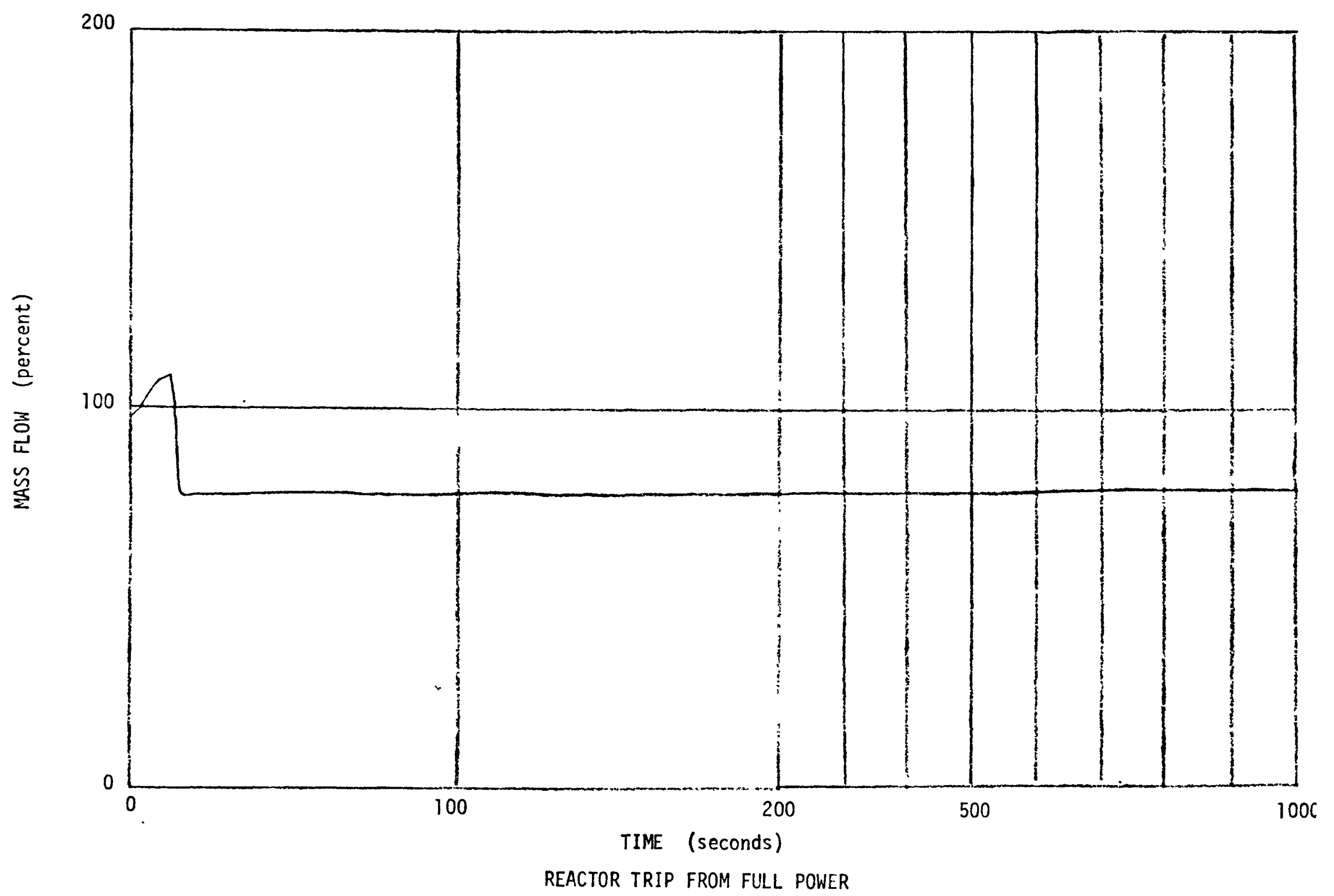


FEEDWATER TEMPERATURE

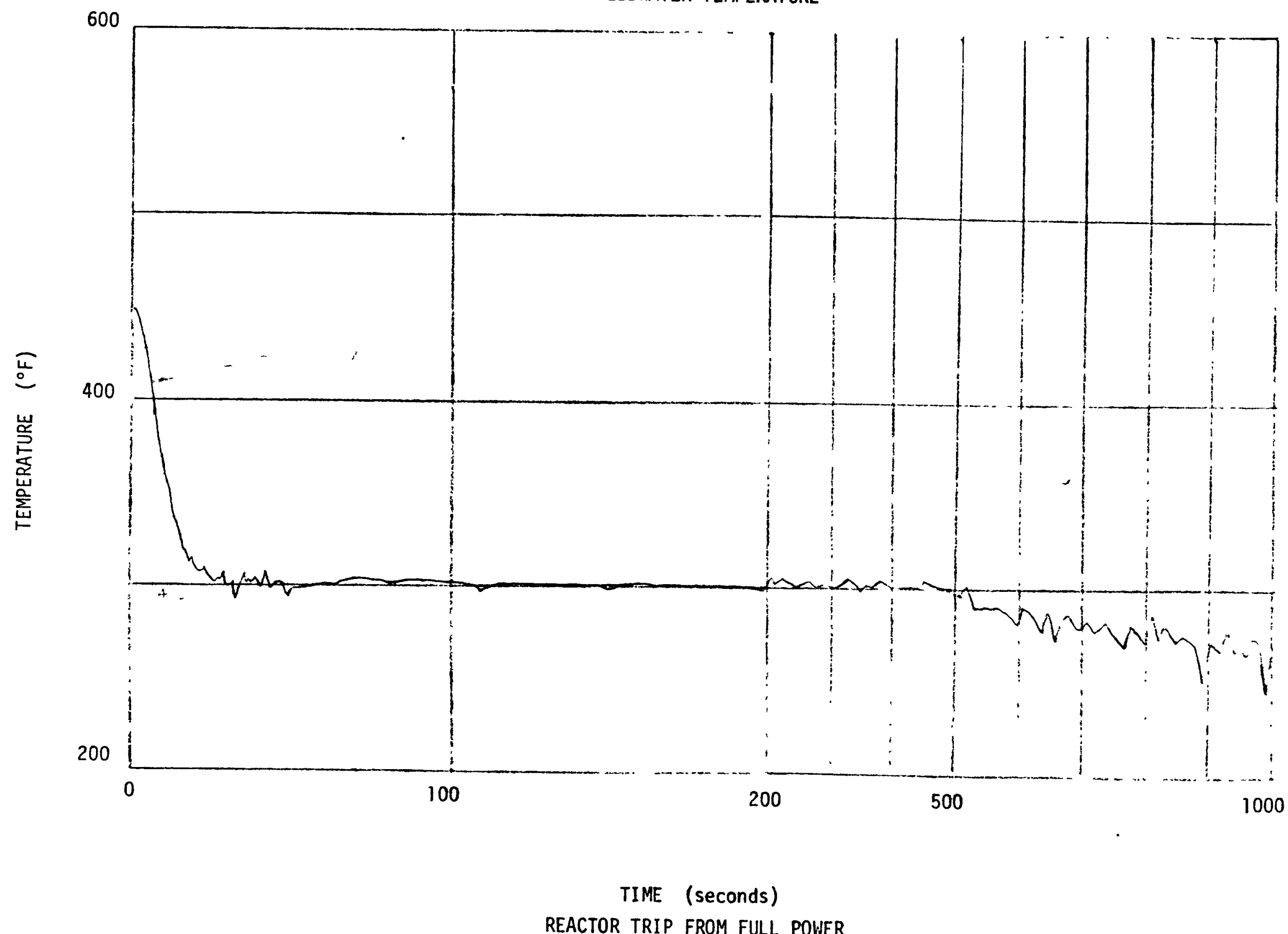




\author{
APPENDIX C \\ GE/RRD/W-ARD MEETING CONCERIIING \\ LMFBR STEAM GEINERATOR TEST ALTERNATIVES \\ DECEMBER 14 AND 15, 1974 AT AEC-GERMANTONN
}

A. BASIC GROUNDRULES EMPLOYED IN GE STUDY OF STEAM GENERATOR TESTING ALTERNATIVES

GE stated that the following groundrules were employed for their assessment and recommendations of steam generator testing alternatives submitted to this meeting.

1. Testing of $30 \mathrm{MW}$ Model

Testing of additional (beyond the AI/MSG unit) 30 MW steam generator modules is not assumed. A purpose of $30 \mathrm{MW}$ model testing is to support the design/fabrication of subsequent plant units, but the current Clinch River Breeder Reactor Plant (CRBRP) scnedule is such that additional 30 MW models cannot be tested in time to support the design/fabrication of plant units. In addition, design/fabrication of $30 \mathrm{MW}$ models in parallel with plant units will drain resources from the latter.

2. Relationship of Prototype Testing To Delivery Of Plant Units

Regarding testing of plant prototype steam generators, $\mathrm{GE}$ assumed that the lead unit would be tested; whether this unit is the first plant unit, a spare plant unit, etc., has not been addressed.

3. Funding and Schedular Restraints

GE did not impose a funding constraint upon its recommendations, but did constrain its recommendations consistent with an october, 1976 date for shipment of the first steam generator to the Clinch River Breeder Power Plant.

4. Testing Needs

GE advised that the need for testing of prototype superheater and evaporator units has been addressed considering the significance of the National LMFBR program and the importance to that program of successful steam generators. GE believes that testing of full size prototype units is necessary to assure that fully qualified steam generators are installed in the CRBRP and future LMFBR plants. (A\&C "C").

GE further advised that testing of few tube evaporators and superheater. modules on an early schedule such as to provide test results which could confirm/modify the prototype design is also considered necessary. (A\&C "E"). 


\section{B. TEST OBJECTIVES}

1. Scope

The scope of the test objectives is limited to the steam generator, defined as a single evaporator module and superheater module but not with associated drum recirculation system, and associated large leak protection system. The tests considered are essentially steam generator component tests, e.g., a single evaporator or single superheater or combination of both. W-ARD raised the question of whether testing of the recirculation system is included. It is recognized the test objectives do not require recirculation system component testing. The LMFBR steam generator base program has not currently identified any need for recirculation system testing; should systems oriented needs be identified these may be addressed by the LMFBR SG base program.

2. Plant Prototype Verification Testing Objectives

RRD asked whether demonstration of SG cleaning is an objective and if the objectives include demonstration of in-service surveillance, inspection and maintenance (e.g., leak location, tube plugging, tube thinning, tube pitting, unit removal/requalification and sodium removal associated with the above). It was agreed that such cleaning and maintenance actions consistent with the testing needs would be accomplished (e.g., leak location, tube inspection and tube plugging in the event of a leak). No deliberately destructive tests are anticipated. Demonstration of $S G$ inspectability is included. It was agreed that the sub-objective "Demonstration of Inspectability and Maintainability" should be added under "Verification of Integrity" in the Attachment 1 (Table I) list of test objectives.

3. Full scale, Fractional Size Testing

The question of validation of high-temperature design methods was ráised, and it was agreed that this is a proper objective for few tube or model tests, and will be added as a sub-objective under "Long Term Testing" on tha Attachment 1 (Table I) list of objectives. It was further agreed that evaluation of instrumentation other than leak detectors is a useful objective for few tube or model tests, and will be added to the list of objectives under this heading.

4. Single Tube Testing

It was agreed that single tube tests addressed to specific design features (for example, thermal expansion of a double wall tube) may be valuable, and it is agreed that the objective "Specific Design Feature Tests" will be added to the Attachment 1 list of objectives under this heading. The question of long term single tube endurance testing is addressed in Item $D$. 
5. Specific Design Development Testing

It was agreed that specific design development tests may include materials and fabrication technique qualification, and it is agreed this objective will be added under the subject heading in the Attachment 1 list of objectives.

6. Materials Testing

RRD observed that the objectives listed under this heading in the Attachment 7 list are not specific. GE observed that discussions are currently underway with ORIIL concerning the selection of ORNL and GE materials programs to requirements of the representative LMFBRs. RRD observed, in addition, that GE has been requested to review program assumption briefs for their relation to prototype units. GE agrees to focus the objectives under the category "Materials Testing" of Attachment 1 more clearly to LMFBR plant requirements based upon the results of these two activities.

7. Sodium/Water Reaction and Leak Detection Testing

RRD observed that the objectives listed under this category in Attachment 1 are oriented towards specific tests underway rather than design needs. GE agrees with this observation and further agrees to modify the objectives accordingly. 
PLANT STEAM GENERATOR*

TESTING APPROACHES AND OBJECTIVES

1. Plant Prototype Verification Testing

- Verification of Integrity

--Demonstrate Inspectability.\& Maintainability

--Lack of Infant Mortality Defects and Leaks

--Validation of Thermal Transient/Shock Design

- Verification of Overall Therma1/Hydraulic and Stability Performance

- Verification of Leak Detection System Response

2. Full Scale, Fractional Size Testing (Few Tube or Model Tests)

- Long Term Testing

--Validation of High Temperature Design Methods

--Validation of Acceptable Tube Spacer and Baffle Wear

- Validation of Absence of Thermal Fatigue Cracking

--Validation of Acceptable Corrosion, Mass Transfer and Fouling

- Validation/Qualification of Fabrication and Assembly Procedures

- Confirmation of Thermal/Hydraulic \& Stability Performance Predictions

- Leak Detector Drift \& Reliability Testing, Steam Side Effects Upon Hydrogen Background

Instrumentation Testing

3. Single-Tube Testing

- DNB Data

- Effect of Operation witn DNB

- Specific Design Fec.ture Tests

4. Specific Design Development Testing

- Proof-of-Principle (Protector-Tube, Double-Wall)

- Mechanical Key Feature (Tubesheets, Tubesheet Joints, etc.) 
- Full-Scale Hydraulic Mcdels (Vibration, Flow Distribution)

- Material and Fabrication Technique Qualification

5. Materials Testing

- Basic Corrosion and Mass Transfer Data

- High Temperature Mechanical Properties Data

7 to be made specific to CRBRP Needs

6. Sodium/Water Reaction and Leak Detection Testing

- Large-Leak Proof Tests (LLTR)

- SWR Analysis Support Tests (Planned)

- Small-Leak Behavior and Wastage Tests

change to Design Data Needs with ongoing as examples

- Leak Detector Endurance and Response Tests (SCTI,CCTL) 
Attisint -2

ines 1

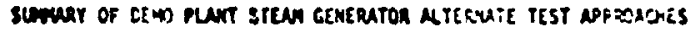

\begin{tabular}{|c|c|c|c|c|c|c|c|c|c|c|}
\hline \multirow[t]{2}{*}{ artomete } & \multirow[t]{2}{*}{ FACILITY } & \multirow{2}{*}{$\begin{array}{l}\text { X E sicy } \\
\text { powir (1) } \\
\text { S R. }\end{array}$} & \multirow{2}{*}{$\begin{array}{l}x: \text { sish } \\
\text { f = R (i) } \\
\text { cras. }\end{array}$} & \multirow{2}{*}{$\begin{array}{l}\text { S CESIGY } \\
\text { rLCH (I) } \\
\text { S.H. }\end{array}$} & \multirow{2}{*}{$\begin{array}{l}\text { Desicy } \\
\text { FLOU (i) } \\
\text { EVAP. }\end{array}$} & \multicolumn{2}{|c|}{ M cepNeIT } & \multirow{2}{*}{ 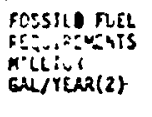 } & \multirow{2}{*}{ 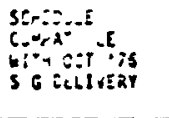 } & \multirow{2}{*}{ 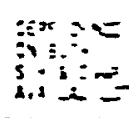 } \\
\hline & & & & & & RUCLEA & FossiLt & & & \\
\hline $\boldsymbol{A}$ & SCII & 100 & $\cdots$ & 100 & $\cdots$ & $-\infty$ & 35 & 4 & res & Ireserezr \\
\hline & & $\cdots$ & 100 & - & 100 & 60 & 20 & 3 & $\begin{array}{l}\text { rts } \\
\text { (nDM neATEN) }\end{array}$ & Ixparar \\
\hline 1 & cen-I & $n$ & 75 & 75 & $\pi$ & $\omega$ & 20 & 3 & Tis & aros \\
\hline 6 & Sक्̧ו1 & es & Gs(8s tVN. & 100 & 100 & & 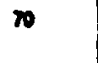 & 10 & $\begin{array}{l}\text { TSS (cxistins } \\
\text { MT.NEATte) }\end{array}$ & $x \sqrt{2}=2$ \\
\hline - & sका & $\mathbf{x}$ & $\boldsymbol{x}$ & 100 & in. & & 3 & 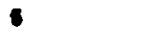 & ins & $=$ \\
\hline 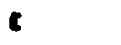 & $\operatorname{sen}$ & $\boldsymbol{0}$ & $\boldsymbol{p}$ & $\boldsymbol{x}$ & & & 2 & 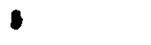 & $m$ & $w^{3}=$ \\
\hline 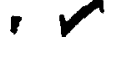 & tephas & 100 & 100 & 100 & $\omega$ & $\boldsymbol{0}$ & $\boldsymbol{c o}$ & 7 & $\begin{array}{l}\text { niss of oriar } \\
\text { (usi weates) }\end{array}$ & aracer \\
\hline 6 & ractury & 100 & 100 & 190 & $\omega$ & & 110 & 10 & $\begin{array}{l}\text { misx ef ocur } \\
\text { (nxy neatess) }\end{array}$ & Donez \\
\hline
\end{tabular}

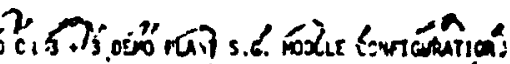

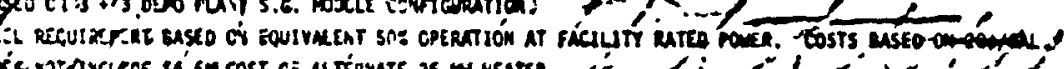

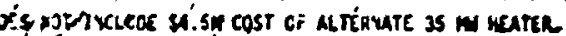

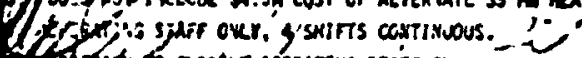

.

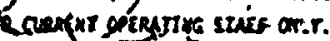


C. RESOLUTION OF PROTOTYPE TESTIHG ALTERINATIVES

GE presented a tabular summary of the facility alternatives studied for testing of steam generator protatypes along with a schedule and text including P\&I Diagrams and describing the required SCTI and/or EBR-II modifications required for each al ternative. The tabular summary is included as Attachment 2, not including the. GE rough scoping capital and operating cost estimates.

GE recommended Alternative $A$ of Attachment 2 in accordance with the groundrules of A\&C "A", and provided a cost estimate for near-term implementation to include conceptual designs for the selected alternative including a preliminary SDD and supporting updated facility modification and operating cost estimates. GE recormended alternative " $A$ " of Attachment 2 on the basis of the following technical considerations:

(1) Full Power Superheater Testing

(2) Full Power Evaporator Testing

(3) Maximum use of nuclear heat source with minimum fossil fuel requirements

(4) Ability to test evaporator or superheater independent of availability of companion unit.

RRD observed that the GE evaluation was complete and responsive in relation to the groundrules specified, but further observed that more detail was necessary as listed following before the evaluation of al ternative can be completed.

It was agreed that the number of al ternatives to be studied in more detail will consist of the following:

(1) Alternative "A" of Attachment 2

(2) Alternative " $C$ " of Attachment 2

(3) Alternative "F" of Attachment 2

GE will establish the scope of the more detailed evaluation of the fewer al ternatives listed and establish with LMEC and ANL their respective work Scopes... GE will transmit the more detailed evaluation by February 1, 1974. By December 19, 1973 any problems encountered by GE in arranging to accomplish the work will be discussed by telecon with RRD.

of particular concern is the need for improved definition of the facility design base with respect to codes and standards to be used, and the design base transients to be used. With respect to EER-II, the evaluation should determine the interaction between EBR-II and the SGHI's insofar as similar systems interaction and transients are concerned. The SCTI-SGHIX interaction and associated testing limitations should be discussed. RRD also believes it vital that the transient design envelope for both the Test Facility and CRBRP should be provided as a priority effort. Transient test plan objectives should also be identified and evaluated. 
GE should quantify the inpact, e.g., the for.i of identifiaule increases in risk to the CRBRP of testing prototype Silik's at less than full power. To minimize effort, it is suggested that the increased risk associated vitn Alternate $C$ be quantized, although GE should go beyond this to the extent required to fully understand the test power - risk trade-off, e.g., specific changes in the test programs and objectives.

GE should proceed to further evaluate and refine cost estimate on design Alternates $A, C$, and $F$. To minimize effort, it is suggested that Alternate $F$ and $G$ be coupled, if feasible; i.e., consider building $G$ at EBR-II with provision for using EBR-II heat to minimize fossile fuel energy requirements.

GE will identify the general level of codes and standards associated with cost and schedular estimates provided. GE will also identify the general level of transient capability expected relative to comparable facilities.

With respect to EBR-II the evaluation should determine the interaction between EBR-II and the SGHX's insofar as general systems information and transients are concerned. Similarly the SCTI-SGHX interaction and associated test limitation should be identified.

GE should evaluate availability and use of existing equipment and other design changes with the objective of reducing the Alternate $F$ cost by 15 million dollars. Significant cost reductions could be achieved by a stretchout of the facility availability date of up to one year, should be identified. GE should also evaluate the provision that should be made for initial capability as opposed to ultimate capability of power and flow.

\section{OVERALL STEAM GENERATOR SYSTEM PLANNING DIAGRAMS}

To allow an understanding of the total Steam Generator effort in perspective, GE will prepare and provide to RRD by January 23, 1974, an integrated linked activities network of the total SG effort, including prototype component design and fabrication, CRBRP Systems Engineering, and component design and procurement supporting development activities and testing. GE may use the format they believe best. GE may establish the proper level of detail, but the first six months should recognize the immediate needs and efforts associated with recent changes in emphasis and spacing, such as near-term CRBRP needs. Where possible, GE should include best effort initia: estimates of activities cost, identifying the uncertainty felt to exist in the estimate.

\section{E. RESOLUTION OF "FEW-TUBE" TESTING ALTERNATIVES}

GE presented tabular summaries of (1) facility flow and power requirements for testing of single evaporator and superheater tubes of the current $A I$, FW and W plant steam generator designs, (2) a comparison of the capabilities of the GE-SGTR, the $W$ GPL-1/SWL-1 and the ANL planned $500 \mathrm{~kW}$ facilities. Cost estimates and schedules for modification of the $W$ and GE facilities for few-tube tests corresponding to the item-2 objectives of Attachment 1 
were also presented along with associated texts. GE recommended tine SGTR facility to be preferable over the W GPL-1/S!:-1 facility on the basis of higher thermal power (2.0 ilW vs. $1.0 \mathrm{ilW})$ and on the basis that the $W$ facility has no recirculation system and is, therefore, currently limited to evaporator testing. GE observed that addition of a drum and recirculation system to the $W$ facility was quite practical, but $G E$ has obtained no cost estimate or schedule for this modification.

On the basis of need for item-2, Attachment 1 test information (including endurance testing) GE recommended initiation of preparations for testing of a few-tube steam generator module in SGTR (based upon selected plant evaporator and superheater approaches). GE observed that about 15 montiss were estimated as required for test section procurement, and observed (based upon an assumed June, 1975 start-of-testing date that greater than 10,000 hours of testing could be accumulated by the 10/76 delivery date of the first plant unit and greater than 30,000 hours by the early 1979 date for completion of plant :fuel loading.

RRD questioned the long time required before tests could be initiated, and suggested that single tube tests could be initiated sooner. A greater number of single-tube tests, in addition, could be operated (as opposed to few-tube tests) within the same facility limitations and the single tube tests might be operated at different parameter valves (e.g., water chemistry, geometry, etc.).

GE observed that single tube tests would not address the Attachment 2 item 2 objectives regarding tube spacer and baffle wear and that few tube tests would provide considerably more information regarding fabrication/assembly procedures and thermal/hydraulic and stability performance than would singletube tests. GE observed that materials testing was generally oriented towards effects such as water chemistry, etc., whereas the proposed tests wer $=$ design-oriented (prototype tubes).

RRD questioned the extent of additional information which could be obtained from few-tube tests as opposed to single-tube tests. GE agreed to provide an assessment (quantative if possible) describing in more detail that additional information wilch can be obtained from few-tube as opposed to singletube steam generator tests. GE will transmit this assessment by February 1 , 1974. 